\title{
Production and use of biochar from lignin and lignin-rich residues (such as digestate
} and olive stones) for wastewater treatment

Eid Gula , Khalideh Al Bkoor Alrawashdeh ${ }^{\mathrm{b}}$, Ondrej Masek ${ }^{\mathrm{c}}$, Øyvind Skreiberg ${ }^{\mathrm{d}}$, Andrea Corona ${ }^{\mathrm{e}}$,

Mauro Zampillie, Liang Wang c, Petros Samaras ${ }^{\mathrm{f}}$, Qing Yang ${ }^{\mathrm{g}}$, Hewen Zhoug, Pietro Bartoccie,

\section{Francesco Fantozzi}


Perugia, Italy

'Mechanical Engineering Department, Al-Huson University College, Al- Balqa' Applied University, Al-Huson- Irbid, P. O. Box 50, 21510, Jordan

'UK Biochar Research Centre, School of GeoSciences, University of Edinburgh, Edinburgh, EH9

$$
\text { 3FF, United Kingdom }
$$

${ }^{\mathrm{d} S I N T E F}$ Energy Research, Postboks 4761 Torgarden, Trondheim, Norway

'Department of Engineering, University of Perugia, Via G. Duranti 67, Perugia, 06125, Italy

${ }^{\mathrm{f}}$ Laboratory of Technologies of Environmental Protection and Utilization of Food By-Products,

Department of Food Science and Technology, International Hellenic University, Thessaloniki, GR-

$$
\text { 57400, Greece }
$$

gState Key Laboratory of Coal Combustion, Huazhong University of Science and Technology,

$$
\text { Wuhan 430074, PR China }
$$

${ }^{\mathrm{h} C h i n a-E U ~ I n s t i t u t e ~ f o r ~ C l e a n ~ a n d ~ R e n e w a b l e ~ E n e r g y, ~ H u a z h o n g ~ U n i v e r s i t y ~ o f ~ S c i e n c e ~ a n d ~}$ Technology, Wuhan 430074, PR China

'Department of New Energy Science and Technology, School of Energy and Power Engineering, ${ }^{j}$ Huazhong University of Science and Technology, Wuhan 430074, PR China John A. Paulson School of Engineering and Applied Sciences, Harvard University, 
Abstract: Clean water is an essential source of life, and its demand is continuously increasing with the rapid growth in population, while the freshwater reserves are also depleting. A large amount of wastewater is released by different industries, which is affecting the environment as well as polluting the freshwater reserves. Recycling and treatment of wastewater are highly essential to meet the demand for clean water and to protect the environment. Activated carbon can be used in primary, secondary and tertiary wastewater treatment steps. It can be used to capture pollutants which stop microbial activity or to produce clean water with high purity. About 3 million tons of activated carbon are produced per year and it is mainly used for fluid purification. The objective of this review is to investigate the preparation and production of biochar from lignin which is an important resource available in great quantities (about 100 Million tons per year) and the practical application of it for wastewater treatment. Biochar can be produced through pyrolysis (at temperatures of $600-700^{\circ} \mathrm{C}$ ) and Hydrothermal carbonization (at temperature between $180-300^{\circ} \mathrm{C}$ ). Subsequent activation can be performed in two ways (physical and chemical) usually at temperatures between $600-800^{\circ} \mathrm{C}$. Chemical activation has the advantage to lower the temperature and also to slightly increase the final yields. The quality of biochar and activated carbon produced from lignin-rich residues can be very high, even though the costs also are higher respect to other fossil derived materials (carbon black, lignite and pet coke).

Keywords, Biochar technologies; Wastewater treatment, Heavy metals; Dyes; Pyrolysis; HTC

\section{INTRODUCTION}

\subsection{Lignin as a subproduct}

Lignin is becoming a more and more abundant resource, as this is a subproduct of many important industrial sectors. It can for example be produced from the paper industry, by recovering it from the black liquor fraction. The total lignin amount produced by the pulping industry is estimated to be around 40 million tons per year [1]. This lignin accounts for about $55 \%$ of the total lignin production [2]. The remaining production is represented mainly by lignosulfonate lignin (a byproduct from the production 
of wood pulp), while a small part is represented by organosolv lignin (mainly coming from $2^{\text {nd }}$ generation bioethanol production). The total lignin production in 2015 was estimated to be about 100 tons per year, and it is forecasted to increase of about $20 \%$ in 2025 [2]. Lignin is the second most abundant compound after cellulose in the plant-world ecosystem.

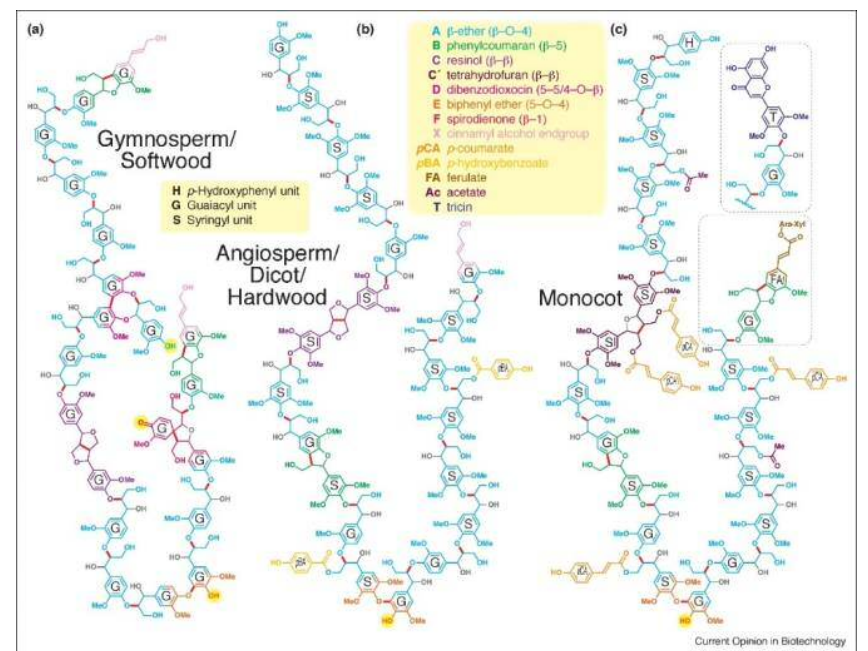

Figure 1. Lignin model structures. Model lignin oligomers are shown for: (a) A gymnosperm/softwood, (b) An angiosperm/dicot/hardwood, and (c) A (commelinid) monocot [3].

Lignin is a branched polymer, where the different units can be classified in $\mathrm{H}, \mathrm{G}$ and $\mathrm{S}$ monolignols [3]. The composition of lignin varies between different vegetal phyla. The detailed biological synthesis of the monolignols is shown in [4].

Lignin can be used to produce many chemicals and materials, among which: adhesives, carbon fibers, thermoplastics, emulsifiers, concrete mixtures etc. These routes are under analysis in many projects-at European level and-especially underin the LIGNOCOST action,: which is chaired by Wageningen University (Netherland) and co-chaired by VTT (Finland), see: https:/lignocost.eul.

Together with lignin also lignin rich residues have to be considered, such as digestate (at least the solid separated part)-and olive pits. Digestate has two fractions: one is liquid and one is solid. The solid can be separated by the liquid and contains a relevant concentration of lignin, because it cannot be 
digested by the microorganisms which populate the digester. We can calculate the European availability of digestate based on these assumptions:

- If we assume that for an average a biogas plant of the power capacity of $500 \mathrm{kWe}-$,produces, about 10,000 t of digestate, according to are produced [5],

- given athe total installed capacity of biogas plants in Europe is equal to $12,000 \mathrm{MWe}$, according to in the EU[6]

- From the above mentioned data the resulting production of we can assume a production of digestate can be calculated and it is equal to 0 about $240 \mathrm{Mt}$, which is a relevant amount.

Assuming that the digestate has a remaining solid content of $10 \%$ (which can be also much higher), wehave a production of solid digestate of about $24 \mathrm{Mt}$ per year. If we consider olive stones, we have to take into account that the average global production of olives is about $3 \mathrm{Mt}$ per year, they contain about $18 \mathrm{wt} \%[7]$ of stones and so about $0.54 \mathrm{Mt}$ of olive stones are produced per year globally.

\subsection{Charcoal and activated charcoal production}

Charcoal (also indicated as char) is the solid product of the pyrolysis of biomass, this can be used in many ways, if it is used as soil amendment it is often addressed as "biochar", while if it is used as a fuel it is addressed as "biocarbon". Charcoal can be used in many cases as a precursor of activated carbon.

$\underline{\text { In this paper we consider a particular kind of biomass, which is represented by lignin rich biomass. }}$ This is very favorable to be used to produce charcoal and activated carbon because the yields of solid products obtained from the pyrolysis of lignin is surely greater than that obtained from cellulose and hemicellulose. All these above mentioned lignin rich bio-based compounds can be used to produce activated charcoal, see for example [8]. In this contribution we see that agricultural residues, which are rich in lignin are e.g. coconut shell and palm shell. In this study, lignin-rich agricultural wastes (e.g. coconut shell and palm shell) have been activated through chemical and physical methods. So, what is activated charcoal and how can we produce it? Activated charcoal can be considered as a highly porous material, which can be produced from erganic-carbon containing substrates through chemical and physical activation and it is used for many applications, among them for the sorption of contaminants

\begin{tabular}{|l|}
\hline Formatted: Font: (Default) Times New Roman \\
\hline Formatted: Font: (Default) Times New Roman \\
\hline Formatted: Font: (Default) Times New Roman \\
\hline Formatted: Font: (Default) Times New Roman \\
\hline Formatted: Font: (Default) Times New Roman \\
\hline Formatted: Font: (Default) Times New Roman \\
\hline Formatted: Font: (Default) Times New Roman \\
\hline Formatted: Font: (Default) Times New Roman \\
\hline Formatted: Font: (Default) Times New Roman \\
\hline Formatted: Font: (Default) Times New Roman \\
\hline Formatted: Font: (Default) Times New Roman \\
\hline Formatted: Font: (Default) Times New Roman \\
\hline Formatted: Font: (Default) Times New Roman \\
\hline Formatted: Font: (Default) Times New Roman \\
\hline Formatted: Indent: First line: $0 "$ \\
\hline Formatted: Font: (Default) Times New Roman \\
\hline Formatted: Font: (Default) Times New Roman \\
\hline
\end{tabular}

Field Code Changed 
from fluids [9]. The production of activated carbon is usually more complex than that of biochar. Assuming that activated carbon is produced from biomass, biochar can be a precursor in its supply chain. So, if biochar can be produced through pyrolysis and hydrothermal carbonization (HTC), as a second step activation is then required to produce the final activated carbon from it. We don't consider gasification as a thermal treatment to produce biochar because in the case of activated carbons the biochar obtained from gasification would have a high ash content and this can limit the activation phase and the formation of a high porosity material.

As we will see in this review, activation can be performed by using chemical and physical methods, the final aim of this step is to increase the porosity of the biochar, which can be measured with the Brunauer-Emmett-Teller (BET) analysis. Dealing with pyrolysis, this is a thermal treatment, which happens in the absence of oxygen and produces three phases: a liquid (pyrolysis oil) a solid (char) and a gas (pyrogas). The process begins at temperature around $300^{\circ} \mathrm{C}$ and can continue till very high temperatures are reached (usually not more than $900^{\circ} \mathrm{C}$ ) [10]. Like the pyrolysis process, also hydrothermal carbonization is a biochar production process, which happens at temperatures of about $180-300^{\circ} \mathrm{C}$ in a suspension containing biomass and water, with a pressure high enough to prevent water evaporation, for several hours [11]. Main reaction mechanisms happening in the HTC process are hydrolysis, dehydration, decarboxylation, aromatization, and condensation polymerization.

Physical activation can be performed using gaseous reagents (air or $\mathrm{CO}_{2}$ ), steam, or both [12]. The temperature usually is about $700^{\circ} \mathrm{C}$ [13]. In chemical activation the temperature is lower, compared to the physical one (about $500^{\circ} \mathrm{C}$ ). In both types of activation, the chemical reactions happening are mainly based on oxidation. In the first case oxidation is performed by gases or steam (in a similar way in which the gasification process is performed) and in the second case oxidation is performed by chemical agents which are adsorbed on the charcoal powder to be activated. Chemical agents can be $\mathrm{ZnCl}_{2}$ and $\mathrm{H}_{3} \mathrm{PO}_{4}$ [14-16]; $\mathrm{H}_{2} \mathrm{SO}_{4}, \mathrm{~K}_{2} \mathrm{~S}$ and KCNS [17]; $\mathrm{HNO}_{3}, \mathrm{H}_{2} \mathrm{O}_{2}, \mathrm{KMnO}_{4}$ and $\left(\mathrm{NH}_{4}\right)_{2} \mathrm{~S}_{2} \mathrm{O}_{8}$ [13]; $\mathrm{NaOH}$ and $\mathrm{KOH}$ $[18] ; \mathrm{K}_{2} \mathrm{CO}_{3}[19,20]$. The surface area yields are a key aspect for both chemical and physical activation.

The versatile characteristics of charcoal and its capacity to adsorb many pollutants are due to two mechanisms: chemisorption and physisorption. The chemisorption mechanism is due to the presence of functional groups in the porous internal surface of the activated charcoal [21]. 
Theose functional groups in activated carbons derive from the elements which are present in the activated chareallraw material composition, some of those can be: $\mathrm{O}, \mathrm{S}, \mathrm{H}, \mathrm{N}, \mathrm{Cl}, \mathrm{K}, \mathrm{Na}, \mathrm{Mg}, \mathrm{Ca}$ [2224]. Oxygen for example can form many functional groups, such as carboxyl, carbonyl, phenols, lactone and others [25-27]. The groups which are available on the surface can be classified as protonated (C$\left.\mathrm{OH}_{2}^{+}\right)$, neutral $(\mathrm{COH})$ or ionized $\left(\mathrm{CO}^{-}\right)$. The groups are shown in Figure 2, as measured with IR.

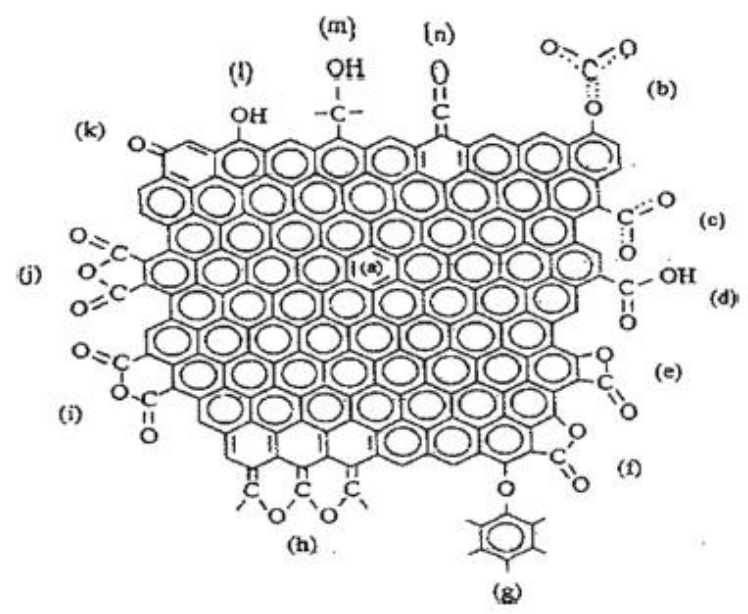

Figure 2. IR-active functional groups on carbon surface: (a) aromatic $\mathrm{C}^{1 / 4} \mathrm{C}$ stretching; (b) and (c) carboxyl-carbonates; (d) carboxylic acid; (e) lactone(4-memberedring); (f) lactone(5-memberedring); (g) ether bridge; (h) cyclic ether; (i) cyclican hydride (5-membered ring); (j) cyclican hydride (6membered-ring); (k) quinine; (l) phenol; (m) alcohol; and (n) ketene [8]

\subsection{Wastewater treatment}

The physisorption and chemisorption mechanisms can be used for water purification, which is the subject of this work. Clean water is the most essential source for all living species and the clean water reserves are now decreasing [28]. If we consider the UN SDG 6 (sustainable management of water and sanitation for all), this is linked with many other SDGs (particularly SDG 1 (No poverty), 2 (Zero hunger), 3 (Good health and well-being), 14 (Life below water) and 15 (Life on land)) [29]. This importance is highly felt in African territories. Another way to consider the importance of water is the 
so-called Food-Energy-Water NEXUS which has already been shown to involve a great part of the 17 UN SDGs [30]. The use of charcoal in water treatment is done with the aim of reducing three types of contaminants [31]:

- Natural organic matter (NOM, mainly consisting of residues of the metabolism of living things);

- Synthetic organic matter (e.g. oil, benzene and toluene, phenols and chlorophenols, trichloromethane and carbon tetrachloride, detergents, pesticides, dyes, surfactants etc.);

- by-products of chemical water treatment (for example the byproducts of the drinking water disinfection step, which is usually done with chlorine compounds and it is followed by the treatment with activated charcoal to adsorb the formed trihalomethanes).

Dealing with the AC market in the US, $50 \%$ of it is used in drinking water sanitation, $40 \%$ is used in wastewater treatment and the remaining is used in ground water treatment, as it is reported in the book of Harry Marsh and Francisco Rodríguez-Reinoso, which takes into account carbon porosity modelling, activation, use and applications of activated carbons [31]. The total market of activated charcoal was about 2.7 Mt in 2015 and it is projected to reach about $5.4 \mathrm{Mt}$ in 2021 for a total market value of 8.1 billion dollars with a unit price of $1.5 € / \mathrm{kg}$ [32]. Higher values are reported by [33], so this can be evaluated as a very interesting market and as mentioned before, the total production of lignin worldwide can easily cover the current demand of activated charcoal, with interesting economic benefits.

Wastewater treatment can be divided into the following phases:

1. the first (or pre-treatment) stage happens when the effluent contains toxic substances, which can influence the activity of the biological treatment. In this phase we can apply redox reactions, followed by precipitation to separate metals; ozonation followed by filters based on granular AC, to eliminate big organic molecules; air stripping to eliminate light organics and ammonia;

2. secondary treatment is based on the use of lime and other chemicals, followed by nitration and neutralization using acids or bases; this will remove suspended solids, oils and floating materials; then follows the removal of proteins, starches and sugars and phenols by biological treatment in aerobic conditions; 
3. the tertiary phase consists of the removal of inorganic and organic compounds by adsorption, obtaining an extremely pure effluent with $99 \%$ BOD reduction.

The use of activated charcoal in the above-mentioned cleaning processes can be done in many ways: it can be inserted as an adsorbent after the primary and after the secondary biological processes directly in the reactors; or it can be used in a separate reactor (especially during the tertiary treatment). An example of $20 \mathrm{~m}^{3}$ reactor used with powdered activated carbon (PAC) is shown in Figure 3. This reactor is capable to address the micropollutants problem which is of paramount importance in the tertiary wastewater treatment. Among micropollutants we find: pesticides, pharmaceuticals, cosmetics, flame retardants, perfumes, waterproofing agents, plasticizers and insulating foams [34]. The reactor is 5 meters high and has a surface area of $4 \mathrm{~m}^{2}$. The water flows upstream through a packed bed of pulverized activated carbon (PAC). New PAC is continuously injected into the reactor, while the same quantity of exhausted PAC is removed. The overall solid retention time of the PAC is about 5-7 days, while the total concentration of the PAC inside the reactor is $5-10 \mathrm{~g} / \mathrm{L}$.

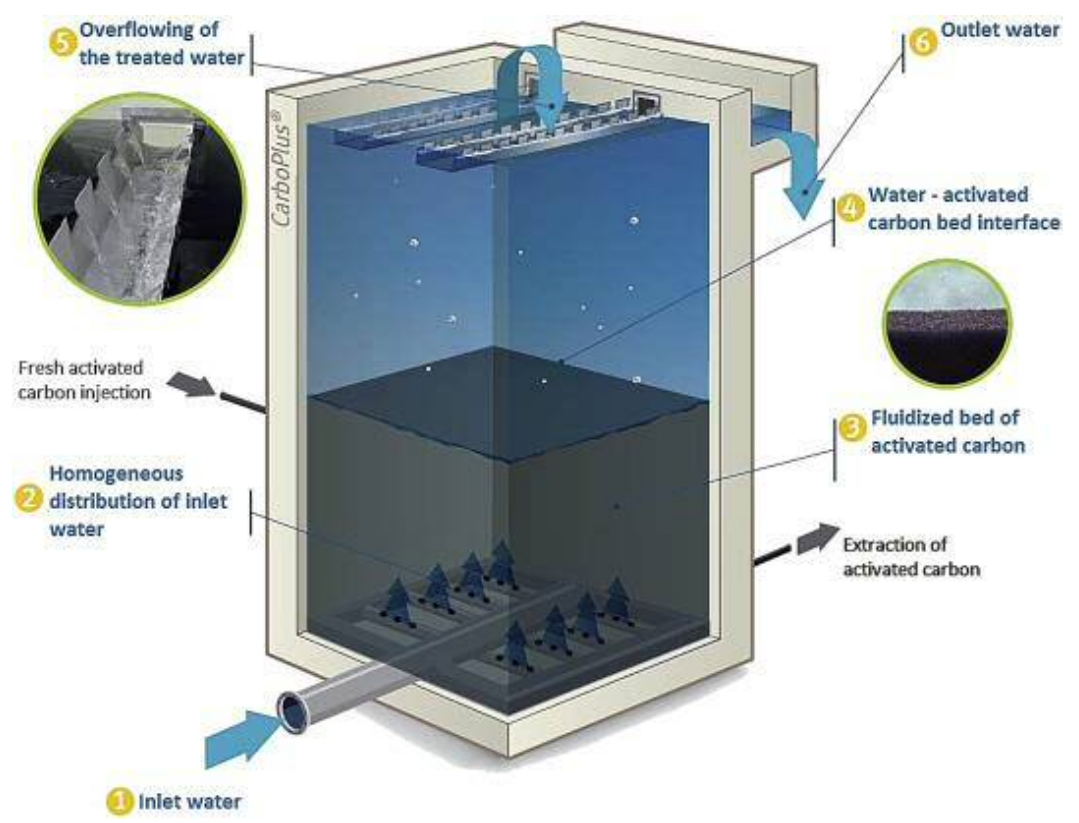

Figure 3: Layout of the $20 \mathrm{~m}^{3}\left(5 \mathrm{~m} \times 4 \mathrm{~m}^{2}\right)$ CarboPlus ${ }^{\circledR}$ pilot (SAUR source), adapted from [35] 


\section{AIM OF THE WORK AND METHODS}

Few reviews are available on the topic of activated charcoal production from lignin (or lignin rich residues) and its use in wastewater treatment. One is that presented by [36], but in that work it is missing a detailed part on adsorption performance, which is only treated shortly. Besides this, economic considerations on the feasibility of the whole supply chain are missing and also the comparison with other possible uses of lignin. The works [37-40] take into consideration the production and the use of biochar in wastewater treatment, but the quality and properties of biochar are much different from those of activated charcoal. According to [41], if digestate sludge has a porosity of $1.92 \mathrm{~m}^{2} / \mathrm{g}$, the porosity of biochar is about $20.86 \mathrm{~m}^{2} / \mathrm{g}$. This is very low, if we consider that the porosity of activated charcoal can reach more than $2000 \mathrm{~m}^{2} / \mathrm{g}$ [36]. Other works [42, 43] take into consideration the modification of biochar through the use of chemicals, oxidation, carboxylation and amination, treatment with organic solvents and use of Fe to produce magnetic biochar, and the use of biochar in the adsorption of heavy metals is also considered. Still modified biochar is different from activated charcoal.

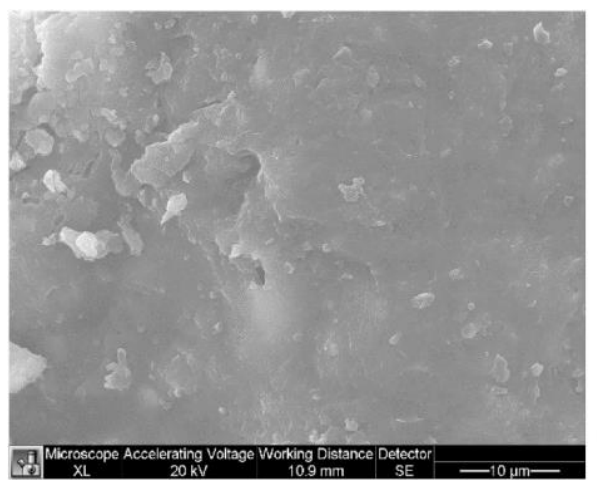

(a)



(b)

Figure 4: SEM image of (a) digested sludge and (b) biochar sample BC450 [41].

Dealing with the use of activated carbon and more broadly with the application of adsorption in WWTP, some relevant books have been written, such as: [44-47]. To these important publications it has to be added also the book of Harry Marsh on activated carbon production [31]. We also have to remember 
the review of lignin materials adsorption capacities [48], this is an important work showing all the sorbents which can be derived from lignin and their sorption capacity, nevertheless the work is not sufficiently focused on activated carbons. The work [49] is focused on lignin activated carbon production and modeling of the adsorption process, but little information is available on the actual adsorption capacity. Also the work [50] is very general, adsorption application are not dealt with in detail and lignin-rich residues are not taken into account.

So, none of the above-mentioned works gets a sufficiently detailed insight on lignin activated charcoal production and use in wastewater treatment and to the best of the authors' knowledge, there is no work considering the economic aspects of activated carbon production from lignin and comparing the economic performance with other possible uses.

For these reasons this works aims at:

- describing biochar production technologies from lignin and examine lignin pyrolysis and HTC, focusing on yields, solid products characterization (through BET, ashes, total porous volume analysis etc.) and chemical and kinetic aspects;

- describing the activation step, taking into consideration the chemical activation process and also the physical activation process;

- describing the pollutants adsorption process, focusing on process parameters, efficiency adsorption capacity, activated charcoal dose, process kinetics;

- describing the pollutants adsorption performance of activated charcoal derived from lignin compared to other activated charcoals;

- compare the economic feasibility of producing activated charcoal from lignin with other possible uses.

To do this, detailed searches have been performed in google scholar using the keywords shown in table S1 of the supplementary material. About 348 papers in the literature have been consulted. Their distribution among the main topics of research is shown in Figure 5. 
As it can be seen from Figure 5, about 8 hothe following topics have been identified for the production of activated charcoal from lignin: pyrolysis; hydrothermal carbonization (HTC); physical activation; chemical activation; modification.$;$ Besides these topics the review will provide also information on adsorption process modelling (Ad modelling); wastewater treatment and technical economic performance. This last aspect is considered only for lignin, while for digestate and olive stone it is neglected. This is due to the wider market which is now growing for lignin valorization, as also demonstrated by the EU cost action LIGNOCOST (https://lignocost.eu). It can be easily understood that in the case of lignin it is very important to discern the most economically attractive uses.Dealing with the pyrolysis conversion technology, which can be both conventional pyrolysis or microwave pyrolysis, much research has been done with digestate, while with olive stone more research is needed. For this last residue of the olive production the most interesting technologies are based on activation. Chemical and physical activation are performed for both olive stones and lignin; while for digestate no activation is performed. 


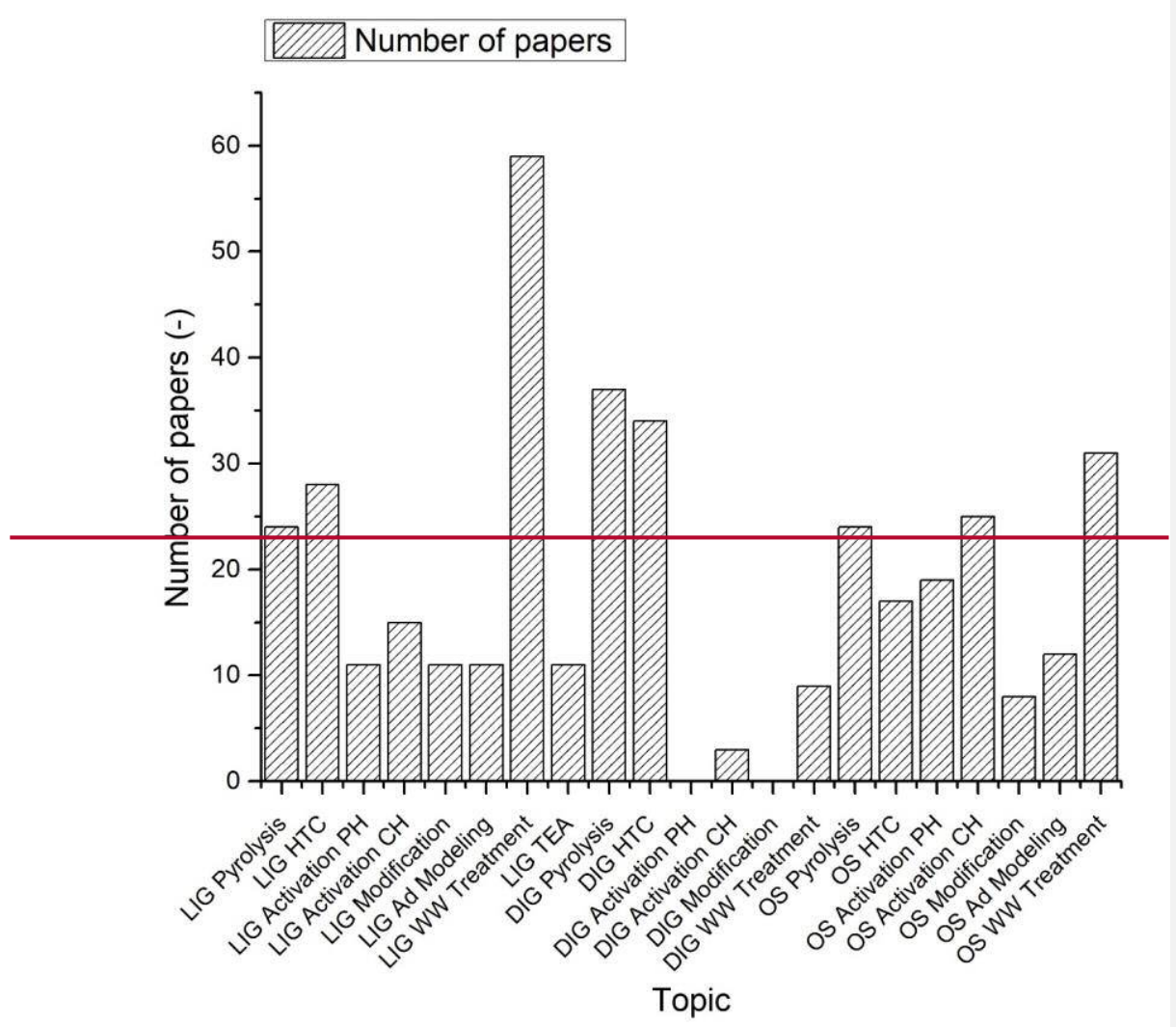




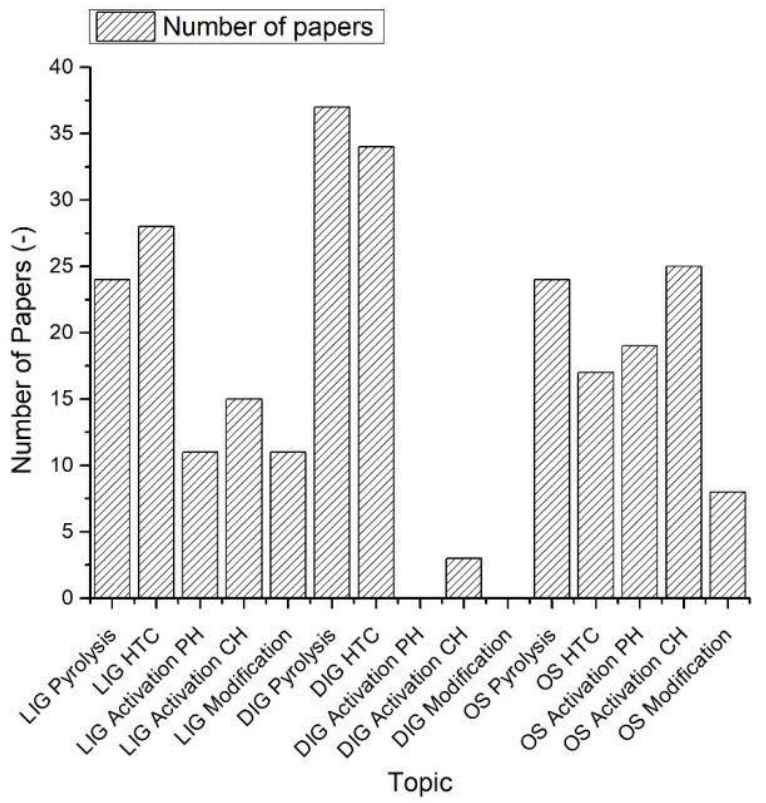

Figure 5: Literature review, $\mathrm{LIG}=$ lignin; $\mathrm{HTC}=$ Hydrothermal Carbonization; $\mathrm{PH}=$ Physical; $\mathrm{CH}=$ chemical; $\mathrm{Ad}=\mathrm{Ad}$ sorption; $\mathrm{WW}=$ Wastewater; $\mathrm{TEA}=$ Technoeconomic analysis; $\mathrm{DIG}=$ digestate; OS $=$ Olive Stones

We will deal in the following sections with: lignin, digestate and olive stones characterization and thermal treatment, charcoal modification and activation, wastewaters treatment and technical economic feasibility of producing activated carbons from lignin.

\section{LIGNIN, DIGESTATE AND OLIVE STONES CHARACTERIZATION}

\subsection{Lignin characterization}


The most important lignin characteristics are clearly presented in [51], these are reported also in Table 1. Different lignins are taken into consideration: organosolv eucalyptus lignin, kraft eucalyptus lignin, organosolv spruce lignin, kraft spruce lignin.

Table 1: Lignin characterization [51]

\begin{tabular}{|c|c|c|c|c|}
\hline Parameter & $\begin{array}{c}\text { Organosolv } \\
\text { eucalyptus lignin }\end{array}$ & $\begin{array}{l}\text { Kraft eucalyptus } \\
\text { lignin }\end{array}$ & $\begin{array}{c}\text { Organosolv } \\
\text { spruce lignin }\end{array}$ & $\begin{array}{c}\text { Kraft spruce } \\
\text { lignin }\end{array}$ \\
\hline Klason lignin (\%) & 83.7 & 58.6 & 94.3 & 88.5 \\
\hline $\begin{array}{l}\text { Acid soluble lignin } \\
(\%)\end{array}$ & 1.6 & 6.3 & 3.1 & 2.3 \\
\hline Ash (\%) & 3.6 & 22.4 & 3.2 & 2.5 \\
\hline Total sugars $(\%)$ & 2.9 & 2.2 & 0.5 & 1.0 \\
\hline $\mathrm{C}(\%)$ & 61.4 & 49.8 & 68.8 & 63.7 \\
\hline $\mathrm{H}(\%)$ & 6.0 & 5.0 & 6.3 & 6.1 \\
\hline $\mathrm{N}(\%)$ & 0.13 & 0.11 & 0.08 & 0.10 \\
\hline $\mathrm{S}(\%)$ & 0.06 & 0.78 & 0.20 & 1.45 \\
\hline $\begin{array}{l}\text { Number-average } \\
\text { molecular weight }\end{array}$ & 1567 & 1059 & 1065 & 1540 \\
\hline Molecular Weight & 5079 & 2653 & 3081 & 7195 \\
\hline PDI & 3.24 & 2.51 & 2.89 & 4.67 \\
\hline $\operatorname{Ash}(\%)$ & $3.6 \pm 1.9$ & $22.4 \pm 0.3$ & $3.2 \pm 0.3$ & $2.5 \pm 0.0$ \\
\hline Volatiles (\%) & $63.4 \pm 1.7$ & $49.1 \pm 0.0$ & $55.0 \pm 0.2$ & $63.9 \pm 2.0$ \\
\hline Fixed carbon (\%) & $32.9 \pm 0.0$ & $27.2 \pm 0.0$ & $41.7 \pm 0.0$ & $33.5 \pm 2.5$ \\
\hline Organic matter (\%) & $96.3 \pm 1.9$ & $76.3 \pm 0.1$ & $96.7 \pm 0.3$ & $97.4 \pm 0.0$ \\
\hline $\mathrm{HHV}(\mathrm{MJ} / \mathrm{kg})[52]$ & 22.7 & 18.3 & 24.0 & 23.0 \\
\hline HHV (MJ/kg) [53] & 22.5 & 18.0 & 24.2 & 22.8 \\
\hline
\end{tabular}


It can be seen from Table 1 that kraft lignins have usually higher content of nitrogen and sulfur compared to organosolv lignins. The presence of sulfur can be explained with the fact that some acids used for lignin isolation can remain in the compound when analyzed. Organosolv lignin has a high carbon content so it is the more suitable for active carbon production. Organosolv lignin is also purer than kraft lignin, having higher Klason lignin concentration. Lignin molecular weight average (Mw) can be different depending on the feedstock and the extraction process [54]. For this reason, the samples shown in Table 1 have values that differ in an important way and this is due probably to the fact that they have been extracted in two different ways. The polydispersivity (PDI) values are generally high for all the samples considered, which is confirmed also by [55]. From the proximate analysis we can see that the moisture content is very low, so lignin can be transformed easily with thermochemical processes. Also the ash content is quite limited (with the exception of eucalyptus kraft lignin), while fixed carbon content is important and this means that we expect interesting yields of charcoal after the thermal treatment. Lignins have also an interesting heating value.

\subsection{Digestate characterization}

In Table 2 we find the characterization analysis of a digestate obtained from a biogas plant realized in a farm in the Umbria region (Italy), which is mainly fed with energy crops (maize and sorghum silage). Compared with other digestates, which are obtained when the anaerobic digestion plant is fed with animal wastes, the ones obtained using energy crops have surely a higher content of lignin. In this case the lignin content is about $41 \mathrm{wt} \%$. The high content of lignin implies also an interesting heating value of the residue. Ash concentration is also important, if compared for example with that of pure lignin. The heating value is slightly lower than that of lignin, the same is also for the fixed carbon content. This means that pure lignin is potentially a better substrate for activated carbon production. Digestate produced from energy crops seems to have better characteristics, if compared with olive stones, for example. 
Table 2: Digestate characterization $[56,57]$

\begin{tabular}{|l|l|l|}
\hline Parameter & Value & Unit of measure \\
\hline Ash & 12.38 & wt $\%$ d.b. \\
\hline Volatile matter & 67.07 & wt $\%$ d.b. \\
\hline Fixed carbon & 20.55 & wt $\%$ d.b. \\
\hline VM/FC & 3.29 & wt $\%$ d.b. \\
\hline C & 42.52 & wt $\%$ d.b. \\
\hline H & 5.94 & wt $\%$ d.b. \\
\hline N & 1.79 & wt $\%$ d.b. \\
\hline O & 49.75 & wt $\%$ d.b. \\
\hline Cellulose & 21.64 & wt $\%$ d.b. \\
\hline Hemicellulose & 15.08 & wt $\%$ d.b. \\
\hline Lignin & 40.88 & wt $\%$ d.b. \\
\hline Extractives & 10.02 & wt $\%$ d.b. \\
\hline Higher Heating Value & 19.74 & MJ $/ \mathrm{kg}$ d.b. \\
\hline
\end{tabular}

\subsection{Olive stones characterization}

If we consider olive stones, they have a lignin content of about $26.5 \pm 0.42 \mathrm{wt} \%$, according to [58]. Other components are cellulose $(31.9 \pm 0.34 \mathrm{wt} \%)$ and hemicellulose $(21.9 \pm 1.62 \mathrm{wt} \%)$ [58]. Lignin content is lower than that of the digestate reported in Table 2; this explains also the reason why the fixed carbon content is lower than that of digestate. It seems that olive stones can give less yield of charcoal compared to the other two considered raw materials (lignin and digestate). The advantage for the olive stones is that they have a lower moisture content, compared to olive pomace and so they can be easily be converted through thermochemical processes. Cellulose and hemicellulose will produce some charcoal also even though with less efficiency, compared to lignin. 
Table 3: Olive stones and olive pomace characterization [59]

\begin{tabular}{|l|l|l|}
\hline Parameter & Olive Stone & Wet Pomace \\
\hline Moisture (wt\% d.b.) & 4.53 & 49.02 \\
\hline Ash (wt\% d.b.) & 0.49 & 0.84 \\
\hline Volatiles (wt\% d.b.) & 87.06 & 42.35 \\
\hline Fixed carbon (wt\% d.b.) & 12.45 & 7.79 \\
\hline C & 50.00 & 55.54 \\
\hline H & 6.17 & 7.98 \\
\hline N & 0.42 & 1.98 \\
\hline O & 43.41 & 34.5 \\
\hline HHV (wt\% w.b.) & 19.21 & 5.7 \\
\hline
\end{tabular}

\section{BIOCHAR PRODUCTION FROM LIGNIN RICH SUBSTRATES}

\subsection{Biochar production technologies from lignin-rich substrates}

Biochar production technologies are basically thermochemical processes. They can be pyrolysis, gasification and hydrothermal carbonization. Gasification is not considered in this work because it produces a charcoal which has a high concentration of ashes. This can generally limit the porosity of the charcoal and so limit its adsorption efficiency. Another important aspect to take into consideration is that if we want to obtain activated carbon as a final product, we have to consider that two ways are possible: direct activation (physical or chemical) or thermal treatment (pyrolysis or HTC), which is then followed by activation (physical or chemical). In this sense biochar can be an intermediate product for activated charcoal production [36]. Concerning physical activation, this can be defined as a gasification process, performed using $\mathrm{CO} 2$ or steam as gasifying agents. Chemical activation is usually a pyrolysis process using acids or basic catalysts. These catalysts can be loaded into the raw materials pores through imbibition or simply mixed with the raw material particles through ball milling.

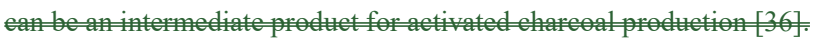




\subsection{Lignin and lignin-rich residues pyrolysis}

From a chemical point of view, during pyrolysis lignin decomposition starts with the breaking of the bonds which are weaker (e.g. hydrogen bonds and $\mathrm{C}-\mathrm{OH}$ bonds), and with the increase of temperature stronger bonds are broken, such as the $\beta-\mathrm{O}-4$ linkages. In the first low-temperature phase of the pyrolysis process aldehydes, toluols, styrenes, and guaiacyl hydroxyls are formed. In the second step of the pyrolysis, which happens at higher temperatures, p-hydroxy-phenols, catechols, and cresols are produced. When the $\beta-\mathrm{O}-4$ linkages are broken, free radicals are liberated and they start the depolymerization reaction of lignin [60-62]. The radicals can form compounds like vanillin and 2methoxy-4-methylphenol. The formation of important quantities of radicals starts the chain propagation reaction. At temperatures higher than $350^{\circ} \mathrm{C}$ through the random repolymerization of radicals, biochar is formed [60].

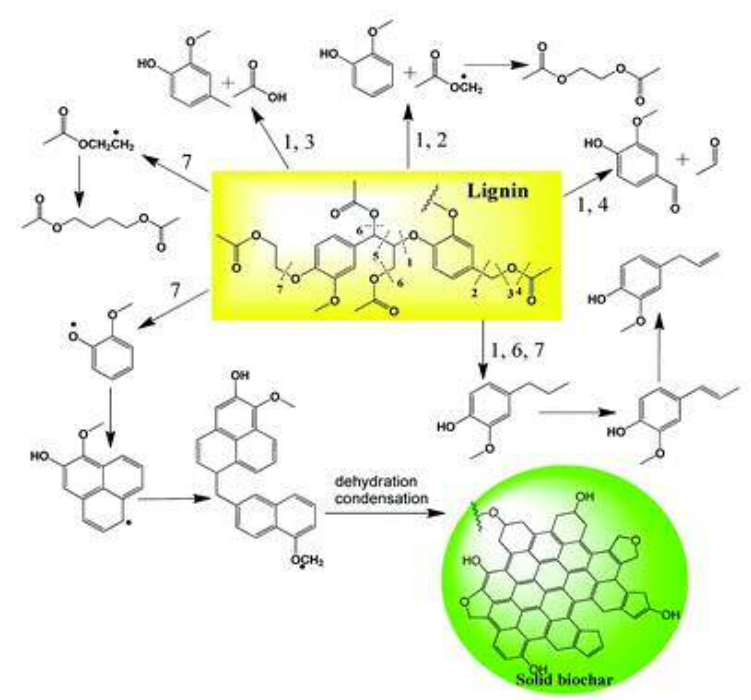


Figure 6: Pyrolysis of lignin, depolymerization mechanism [62]

A key parameter to take into consideration when performing lignin pyrolysis is the effect of temperature on biochar yield. This is reported for example in [63], but it can also be derived from TG diagrams, given that the residue that it is weighted by the thermal balance is the charcoal itself. So, if we consider the values presented in the TG diagram shown in [51] we can derive the values reported in Figure 7 on char yields obtained during lignin pyrolysis.

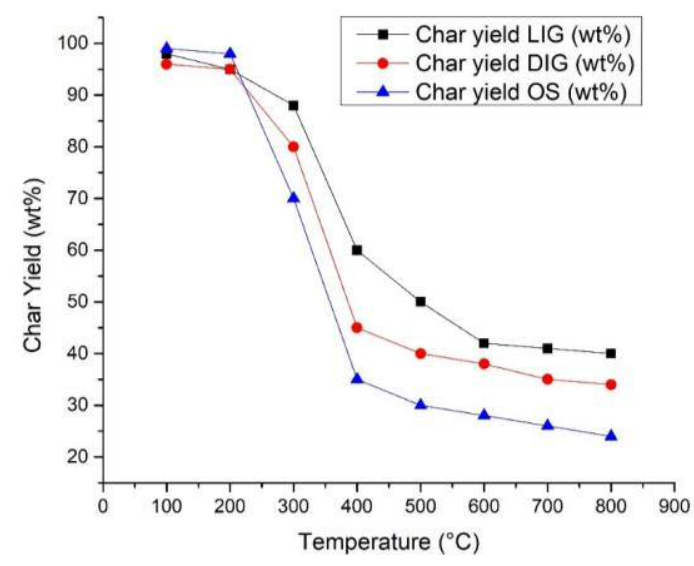

Figure 7: Comparison of TG curves between: lignin [51], digestate [56] and olive stones [64, 65]

Another important aspect is the effect of temperature on the porosity of the final material, as reported in [66]. 


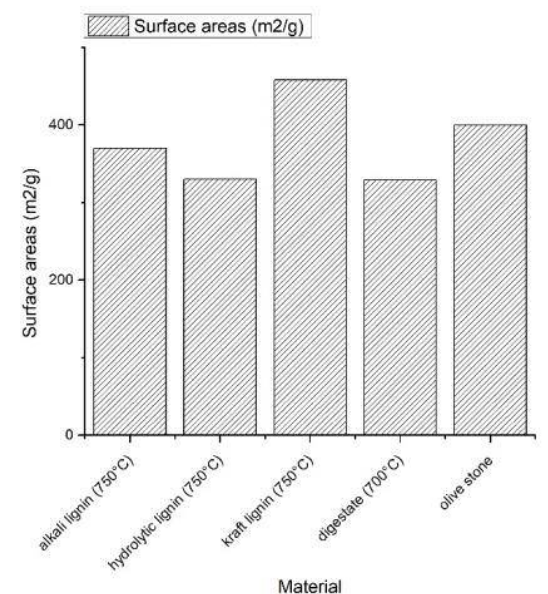

Figure 8: Surfaces areas of charcoals produced from different lignins and lignin-rich residues [66-68]

As it can be seen from Figure 8, different types of lignin and also the lignin-rich residues seem to have a similar surface area. It is important so, to understanding the role played by hemicellulose, cellulose and lignin on porosity development and main characteristics [69]. To consider the effect of the three components of biomass the TG and DTG diagrams shown in Figure 9 can be useful. 



Figure 9: Thermal behavior of lignin, cellulose and hemicellulose [69]

It can be seen from Figure 9 that the total mass losses (in \%) for hemicellulose, cellulose and lignin are $76.5 \%, 80.9 \%$ and $55.1 \%$. So, the final charcoal yields at $800^{\circ} \mathrm{C}$ are $23.5 \%$ (for hemicellulose), $19.1 \%$ (for cellulose) and $45.9 \%$ (for lignin). From this data it seems that lignin is the major contributor to charcoal formation, but it is not so simple as it seems. In the study of Boundzanga et al. [69], in fact, an interesting method to calculate the contribution of hemicellulose, cellulose and lignin to the final mass of the formed charcoal is proposed. The contribution is estimated using a predictive method based on Cagnon equations [70], such as:

$$
\mathrm{Y}=100-((1-\mathrm{x}) \cdot 100)
$$

with: 


$$
\mathrm{x}=\mathrm{H} \cdot \mathrm{y}_{\mathrm{c}, \mathrm{H}}+\mathrm{C} \cdot \mathrm{y}_{\mathrm{c}, \mathrm{C}}+\mathrm{L} \cdot \mathrm{y}_{\mathrm{c}, \mathrm{L}}
$$

being $\mathrm{Y}$ the charcoal yield expressed in percentage. $\mathrm{H}, \mathrm{C}$ and $\mathrm{L}$ are respectively the percentage of hemicellulose, cellulose and lignin in the precursor (in \%) and $\mathrm{y}_{\mathrm{c}, \mathrm{i}}$ are the heat treatment yields of each individual component (in \%).

Considering the initial mass of the raw material, the contribution of each component can be calculated based on the following equation, which takes into consideration, as an example, lignin:

$$
\mathrm{L}_{\mathrm{c}}=\left(1-\left(\mathrm{x}-\left(\mathrm{L} \cdot \mathrm{y}_{\mathrm{c}, \mathrm{L}}\right) / \mathrm{x}\right) \cdot 100\right.
$$

Where $\mathrm{L}_{\mathrm{c}}$ is the production of charcoal from the lignin in the sample after pyrolysis (expressed in $w t \%$ ), $\mathrm{x}$ is the calculated char mass after heat treatment, $\mathrm{y}_{\mathrm{c}, \mathrm{L}}$ is the yield of charcoal from the pyrolysis of pure lignin (expressed in \%). If we consider the values of the contributions of cellulose, hemicellulose and lignin to char formation, from olive pomace, reported in [69], these are the following: $36.9 \mathrm{wt} \%$ (hemicellulose), $18.5 \mathrm{wt} \%$ (cellulose) and $44.6 \mathrm{wt} \%$ (lignin). Based on these data lignin cannot be considered as the major component of charcoal, also cellulose and hemicellulose are playing an important role.

\subsection{Lignin and lignin-rich residues HTC}

Hydrothermal carbonization of biomass is a thermal treatment which happens in the liquid phase at moderate temperature and high pressure (above the saturation pressure of water) [71]. The most common reactions in hydrothermal treatment of biomass are: the cleavage of $\mathrm{C}-\mathrm{O}-\mathrm{C}$ and $\mathrm{C}-\mathrm{C}$ bonds; de-methoxylation; alkylation, and condensation. The cleavage of the $\beta-O-4$ linkages and ${ }^{\alpha} \mathrm{C}-{ }^{\beta} \mathrm{C}$ linkages happens first, while aromatic bonds are not broken during HTC. The changes in structure of char during 
HTC of lignin are presented in [1]. Usually, lignin decomposition increases with the increase of temperature. With higher temperature HTC char tends to have a more crystalline structure; besides above $350^{\circ} \mathrm{C}$ many functional groups tend to disappear and only $\mathrm{OH}$ groups are left.

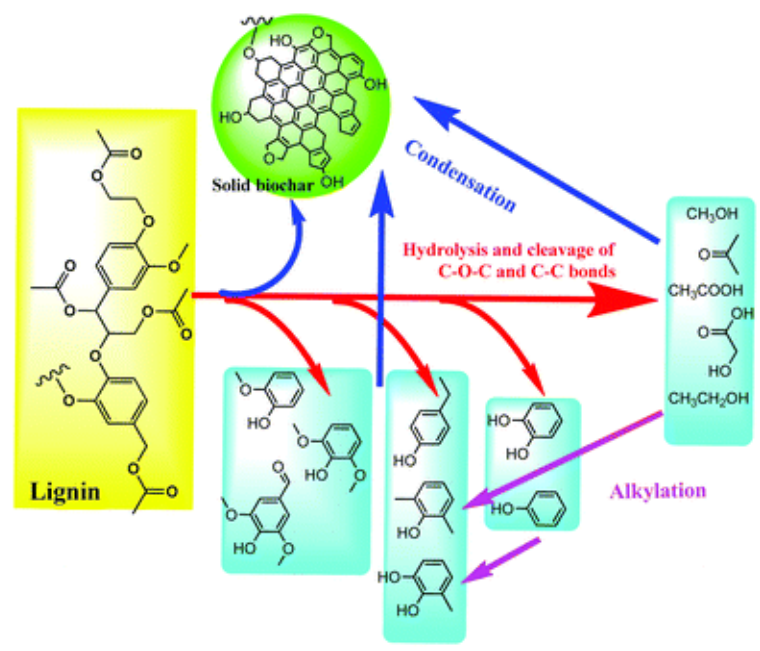

Figure 10: Mechanism of lignin HTC [62]

If compared with lignin pyrolysis, lignin HTC generally yields more charcoal, but this is a less stable product, so when activation is performed the final yield of activated product is in many cases less for HTC than for pyrolysis [72].

Dealing with the porosity of the obtained hydrochars, few data are available. This is mainly because a simple HTC treatment does not produce a sufficiently porous carbon and the hydrochar has to be activated in a second step, to have a final product to be used as an adsorbent. The porosity of lignin hydrochar, obtained with a thermal treatment lasting 4 hours at a temperature equal to $360^{\circ} \mathrm{C}$, is about $12.5 \mathrm{~m}^{2} / \mathrm{g}$ [73]. This value is much lower than that of pyrochar. 


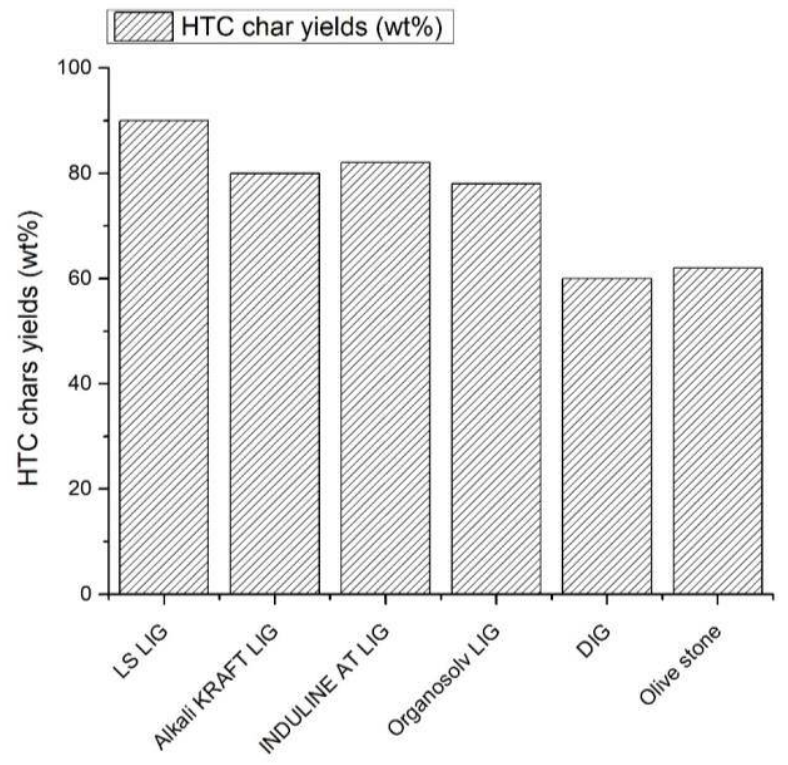

Figure 11: Hydrochar yields obtained at a temperature of $220^{\circ} \mathrm{C}[72,74,75]$, where $\mathrm{LS}=$ Low sulfonate; $\mathrm{LIG}=$ Lignin; $\mathrm{DIG}=$ digestate.

Where Indulin AT is a type of lignin derived from a purified form of kraft pine lignin. It has to be considered that the yields of hydrochar obtained with digestate and olive stones at the same temperature of $220^{\circ} \mathrm{C}$ (typical of wet torrefaction) are much lower than those obtained from lignin. This can be explained with the following facts:

-first the yields reported in Figure 11 with regard to lignins are maybe too high if we consider that [76] reports a yield of hydrochar at $225^{\circ} \mathrm{C}$ equal to $60 \%$;

- general hydrochar yields obtained with lignin are higher than those obtained with cellulose and hemicellulose;

- this is due to the fact that the phenolic structure of lignin is more thermally stable. 
It has also to be considered that HTC temperature has an important effect on lignin hydrochar yields, as it is reported in [75] and this is shown in Figure 12.

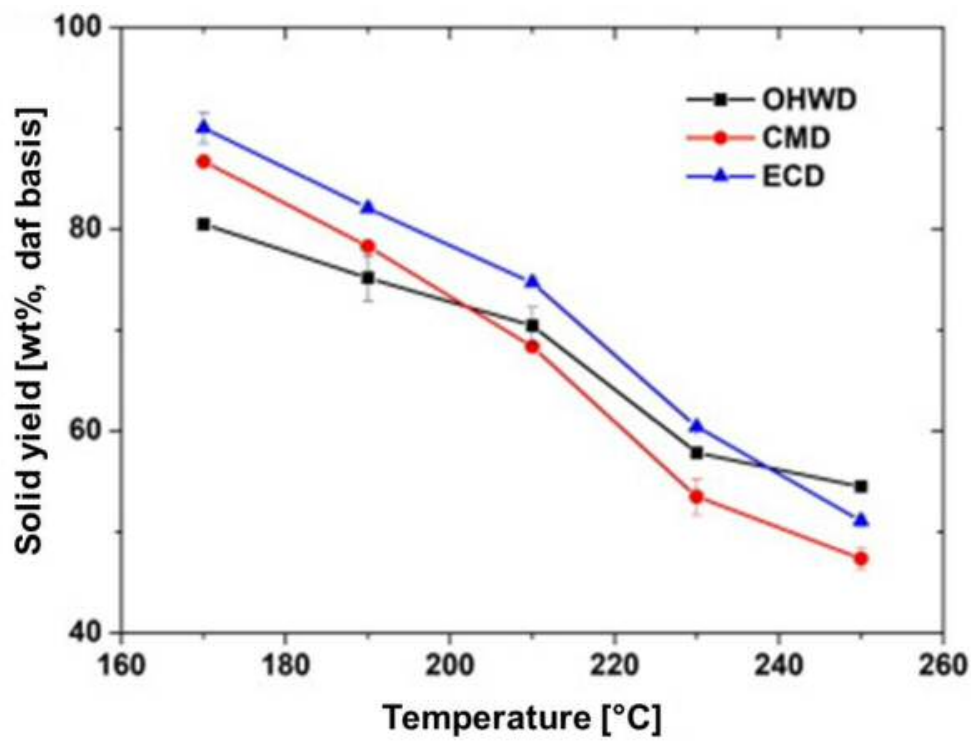

Figure 12: Effect of temperature on hydrochar yields [75], where OHWD = organic household waste digestate $\mathrm{CMD}=$ Cow Manure Digestate $\mathrm{ECD}=$ energy crops digestate.

From Figure 12 it can be seen that compared to biochar obtained from pyrolysis the yields of hydrochar are generally higher, this is due to the lower process temperature which makes hydrochar in general more reactive than pyrolysis biochar. 


\subsection{Biochar modification processes}

\subsubsection{Influence of process parameters on final porosity and activated carbon yields}

Given that lignin has a good sorption capacity, even without being modified, and also a high carbon content, it is an ideal raw material for the production of activated carbons [36, 77-79]. As reported by Mackay and Roberts $[80,81]$ the final porosity and textural characteristics of activated carbons strongly depend on both raw materials properties and the process parameters. Dealing with raw materials properties, the influence of their carbon content, lignin content and fixed carbon content have been clearly explained in the previous paragraphs. We have also to take into consideration that the contents of cellulose, hemicellulose and lignin have important effects on the final porosity of the material. In fact, in cellulose charcoal the volume occupied by mesopores is $82 \%$ of the total porosity volume; in the hemicellulose charcoal the volume occupied by the mesopores is about $45 \%$ of the total, while the micropores occupy about $54 \%$ of the total; in the lignin the volume occupied by the micropores is about $63 \%$ of the total [69]. Depending on the final application the average diameter of the obtained pores can be changed by changing the raw material. The important parameters that have to be taken into account when dealing with activation are shown in Table 4.

Table 4: Key Parameters during chemical and physical activation of lignin [36]

\begin{tabular}{|c|c|c|c|c|c|c|}
\hline \multicolumn{7}{|c|}{ ACTIVATION OF LIGNIN } \\
\hline Source & Precursor & Activation & Temperature & Time & $\begin{array}{l}\text { Surface } \\
\text { area } \\
\left(\mathrm{m}^{2} / \mathrm{g}\right)\end{array}$ & $\begin{array}{l}\text { Micropore } \\
\text { volume } \\
\left(\mathrm{cm}^{3} / \mathrm{g}\right)\end{array}$ \\
\hline$[82]$ & Indulin $\mathrm{C}^{\mathrm{a}}$ & $\begin{array}{l}(\mathrm{Ph}) \\
\text { Carbonization } \\
\text { with } \mathrm{N}_{2}\end{array}$ & $300^{\circ} \mathrm{C}$ & $1 \mathrm{~h}$ & $<10$ & $<0.01$ \\
\hline \multirow[t]{4}{*}[83]{} & \multirow[t]{4}{*}{ Kraft Lignin } & \multirow{2}{*}{$\begin{array}{l}(\mathrm{Ph}) \\
\text { Carbonization } \\
\text { with } \mathrm{N}_{2} \text { Activation } \\
\text { with } \mathrm{CO}_{2}\end{array}$} & $350^{\circ} \mathrm{C}$ & $2 \mathrm{~h}$ & \multirow[t]{2}{*}{1613} & \multirow[t]{2}{*}{0.47} \\
\hline & & & $800^{\circ} \mathrm{C}$ & $40 \mathrm{~h}$ & & \\
\hline & & \multirow{2}{*}{$\begin{array}{l}(\mathrm{Ph}) \\
\text { Carbonization } \\
\text { with } \mathrm{N}_{2} \text { Activation } \\
\text { with } \mathrm{CO}_{2}\end{array}$} & $350^{\circ} \mathrm{C}$ & $2 \mathrm{~h}$ & \multirow[t]{2}{*}{1853} & \multirow[t]{2}{*}{0.57} \\
\hline & & & $850^{\circ} \mathrm{C}$ & $20 \mathrm{~h}$ & & \\
\hline
\end{tabular}




\begin{tabular}{|c|c|c|c|c|c|c|}
\hline [84] & Lignin $^{\mathrm{b}}$ & $\begin{array}{l}(\mathrm{Ph}) \\
\text { Carbonization } \\
\text { with } \mathrm{N}_{2}\end{array}$ & $500-900^{\circ} \mathrm{C}$ & - & $10-50$ & - \\
\hline \multirow[t]{2}{*}{ [85] } & \multirow{2}{*}{$\begin{array}{l}\text { Hydrolytic } \\
\text { lignin }\end{array}$} & \multirow{2}{*}{$\begin{array}{l}(\mathrm{Ph}) \\
\text { Carbonization } \\
\text { with Ar Activation } \\
\text { with steam }\end{array}$} & $600^{\circ} \mathrm{C}$ & $2 \mathrm{~h}$ & \multirow[t]{2}{*}{865} & \multirow[t]{2}{*}{0.365} \\
\hline & & & $800^{\circ} \mathrm{C}$ & - & & \\
\hline \multirow[t]{2}{*}{ [86] } & \multirow{2}{*}{$\begin{array}{l}\text { Hydrolytic } \\
\text { lignin }\end{array}$} & \multirow{2}{*}{$\begin{array}{l}(\mathrm{Ph}) \text { carbonization } \\
\text { with Ar Activation } \\
\text { with steam }\end{array}$} & $700^{\circ} \mathrm{C}$ & - & \multirow[t]{2}{*}{769} & \multirow[t]{2}{*}{-} \\
\hline & & & $780^{\circ} \mathrm{C}$ & - & & \\
\hline [87] & $\begin{array}{l}\text { Hydrolytic } \\
\text { lignin }\end{array}$ & $\begin{array}{l}(\mathrm{Ph}) \quad \text { Activation } \\
\text { with steam }\end{array}$ & $700^{\circ} \mathrm{C}$ & $2 \mathrm{~h}$ & - & 0.33 \\
\hline [82] & Indulin $C^{a}$ & $\begin{array}{l}\text { (Ch) carbonization } \\
\text { and Activation } \\
\text { with } \mathrm{KOH} \\
\text { (Lignin:KOH = } \\
4: 1)\end{array}$ & $700^{\circ} \mathrm{C}$ & 1 & 514 & 0.214 \\
\hline [84] & Lignin $^{b}$ & $\begin{array}{lr}(\mathrm{Ch}) & \mathrm{ZnCl}_{2}, \\
\mathrm{H}_{2} \mathrm{PO}_{4}, & \mathrm{~K}_{2} \mathrm{CO}_{3}, \\
\mathrm{Na}_{2} \mathrm{CO}_{3}, & \mathrm{KOH}, \\
\mathrm{NaOH} . & \\
\text { Impregnation ratio } \\
\text { (1) }\end{array}$ & - & - & $\begin{array}{l}800- \\
2000\end{array}$ & - \\
\hline [88] & Kraft Lignin & $\begin{array}{l}(\mathrm{Ch}): \mathrm{ZnCl}_{2}, \\
\text { Lignin:1:2.3 }\end{array}$ & $500^{\circ} \mathrm{C}$ & $1 \mathrm{~h}$ & 1800 & 1.039 \\
\hline [89] & Kraft Lignin & $\begin{array}{l}\text { (Ch): } \quad \mathrm{H}_{3} \mathrm{PO} 4, \\
\text { Lignin: } \mathrm{H}_{3} \mathrm{PO}_{4}: 1: 2\end{array}$ & $427^{\circ} \mathrm{C}$ & $2 \mathrm{~h}$ & 1459 & 0.82 \\
\hline [90] & $\begin{array}{l}\text { Hydrolysis } \\
\text { lignin }\end{array}$ & $\begin{array}{l}(\mathrm{Ch}): \\
\text { Carbonization and } \\
\text { Activation with } \\
\text { KOH. } \\
\text { Lignin:KOH: } 1: 4\end{array}$ & $850^{\circ} \mathrm{C}$ & 15 & 2753 & 1.37 \\
\hline [91] & Kraft Lignin & $\begin{array}{l}(\mathrm{Ch}) \quad \mathrm{H}_{3} \mathrm{PO}_{4} . \\
\text { Lignin:H3PO4: } \\
\text { 1:1.4 }\end{array}$ & $600^{\circ} \mathrm{C}$ & $1 \mathrm{~h}$ & 1370 & 0.78 \\
\hline
\end{tabular}

As it can be seen from table 4 that an important parameter is the process temperature, this has influence on both yields and porosity. A clear view of the effects on porosity is shown in Figure 13 where SEM images of activated carbon produced from lignin at different temperatures are shown. 


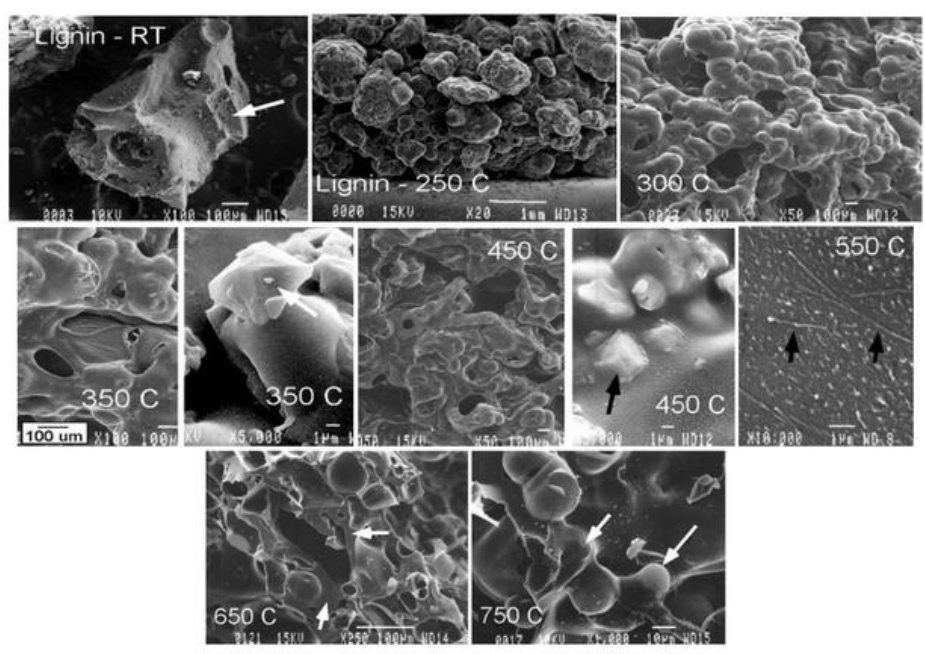

Figure 13: SEM images of lignin and lignin charcoals produced at different temperatures [62]

Table 5: Key Parameters during chemical and physical activation of digestate

\begin{tabular}{|c|c|c|c|c|c|c|}
\hline \multicolumn{7}{|c|}{ ACTIVATION OF DIGESTATE } \\
\hline Source & Precursor & Activation & Temperature & Time & $\begin{array}{l}\text { Surface } \\
\text { area } \\
\left(\mathrm{m}^{2} / \mathrm{g}\right)\end{array}$ & $\begin{array}{l}\text { Micropore } \\
\text { volume } \\
\left(\mathrm{cm}^{3} / \mathrm{g}\right)\end{array}$ \\
\hline \multirow[t]{2}{*}{ [92] } & \multirow[t]{2}{*}{ Digestate } & \multirow{2}{*}{$\begin{array}{l}\text { HTC and (Ch) } \\
\text { KOH:Char: } 4: 1\end{array}$} & $190^{\circ} \mathrm{C}$ & $3 \mathrm{~h}$ & \multirow[t]{2}{*}{854} & \multirow[t]{2}{*}{0.324} \\
\hline & & & $600^{\circ} \mathrm{C}$ & $2 \mathrm{~h}$ & & \\
\hline \multirow[t]{2}{*}{ [92] } & \multirow[t]{2}{*}{ Digestate } & \multirow{2}{*}{$\begin{array}{l}\text { HTC and (Ch) } \\
\text { KOH:Char: } 4: 1\end{array}$} & $220^{\circ} \mathrm{C}$ & $3 \mathrm{~h}$ & \multirow[t]{2}{*}{1178} & \multirow[t]{2}{*}{0.440} \\
\hline & & & $600^{\circ} \mathrm{C}$ & $2 \mathrm{~h}$ & & \\
\hline \multirow[t]{2}{*}{ [92] } & \multirow[t]{2}{*}{ Digestate } & \multirow{2}{*}{$\begin{array}{l}\text { HTC and (Ch) } \\
\text { KOH:Char: } 4: 1\end{array}$} & $250^{\circ} \mathrm{C}$ & $3 \mathrm{~h}$ & \multirow[t]{2}{*}{1609} & \multirow[t]{2}{*}{0.596} \\
\hline & & & $600^{\circ} \mathrm{C}$ & $2 \mathrm{~h}$ & & \\
\hline \multirow[t]{2}{*}{ [92] } & \multirow{2}{*}{$\begin{array}{l}\text { Leached } \\
\text { Digestate }\end{array}$} & \multirow{2}{*}{$\begin{array}{l}\text { HTC and (Ch) } \\
\text { KOH:Char: } 4: 1\end{array}$} & $190^{\circ} \mathrm{C}$ & $3 \mathrm{~h}$ & \multirow[t]{2}{*}{1180} & \multirow[t]{2}{*}{0.502} \\
\hline & & & $600^{\circ} \mathrm{C}$ & $2 \mathrm{~h}$ & & \\
\hline \multirow[t]{2}{*}{ [92] } & Leached & HTC and (Ch) & $220^{\circ} \mathrm{C}$ & $3 \mathrm{~h}$ & \multirow[t]{2}{*}{1317} & \multirow[t]{2}{*}{0.563} \\
\hline & Digestate & KOH:Char: 4:1 & $600^{\circ} \mathrm{C}$ & $2 \mathrm{~h}$ & & \\
\hline \multirow[t]{2}{*}{ [92] } & Leached & HTC and (Ch) & $250^{\circ} \mathrm{C}$ & $3 \mathrm{~h}$ & \multirow[t]{2}{*}{1762} & \multirow[t]{2}{*}{0.665} \\
\hline & Digestate & KOH:Char: 4:1 & $600^{\circ} \mathrm{C}$ & $2 \mathrm{~h}$ & & \\
\hline \multirow[t]{2}{*}{ [93] } & \multirow[t]{2}{*}{ Digestate } & HTC and (Ch) & $250^{\circ} \mathrm{C}$ & $1 \mathrm{~h}$ & \multirow[t]{2}{*}{1106} & \multirow[t]{2}{*}{0.54} \\
\hline & & KOH:Char: 3:1 & $600^{\circ} \mathrm{C}$ & $2 \mathrm{~h}$ & & \\
\hline \multirow[t]{2}{*}{ [93] } & \multirow[t]{2}{*}{ Digestate } & \multirow{2}{*}{$\begin{array}{l}\mathrm{HTC} \text { with } \mathrm{H}_{2} \mathrm{SO}_{4} \\
\text { and } \quad(\mathrm{Ch}) \\
\text { KOH:Char: } 3: 1\end{array}$} & $250^{\circ} \mathrm{C}$ & $1 \mathrm{~h}$ & \multirow[t]{2}{*}{503} & \multirow[t]{2}{*}{0.30} \\
\hline & & & $600^{\circ} \mathrm{C}$ & $2 \mathrm{~h}$ & & \\
\hline [94] & Digestate & $\begin{array}{l}\text { Carbonization and } \\
\text { (Ch) KOH:char: }\end{array}$ & $\begin{array}{l}400^{\circ} \mathrm{C} \\
850^{\circ} \mathrm{C}\end{array}$ & $\begin{array}{l}1 \mathrm{~h}+3.5 \\
\mathrm{~h}\end{array}$ & 1754 & - \\
\hline & & & $850^{\circ} \mathrm{C}$ & $1 \mathrm{~h}$ & & \\
\hline
\end{tabular}


Table 6: Key Parameters during chemical and physical activation of olive stone; $\mathrm{Ch}=\mathrm{Chemical}$ activation; $\mathrm{Ph}=$ physical activation; $\mathrm{BO}=\mathrm{Burn}$-off

\begin{tabular}{|c|c|c|c|c|c|c|}
\hline \multicolumn{7}{|c|}{ ACTIVATION OF OLIVE STONE } \\
\hline Source & Precursor & Activation & Temperature & Time & $\begin{array}{l}\text { Surface } \\
\text { area } \\
\left(\mathrm{m}^{2} / \mathrm{g}\right)\end{array}$ & $\begin{array}{l}\text { Micropore } \\
\text { volume } \\
\left(\mathrm{cm}^{3} / \mathrm{g}\right)\end{array}$ \\
\hline [95] & Olive stone & $\begin{array}{l}\text { (Ch) Impregnation } \\
\text { with H3PO4 (60 } \\
\text { wt } \%) \text { and } \\
\text { carbonization }\end{array}$ & $500^{\circ} \mathrm{C}$ & $2 \mathrm{~h}$ & 257 & 0.123 \\
\hline [95] & Olive stone & $\begin{array}{l}\text { (Ch) Impregnation } \\
\text { with H3PO4 ( } 70 \\
\text { wt } \%) \text { and } \\
\text { carbonization }\end{array}$ & $500^{\circ} \mathrm{C}$ & $2 \mathrm{~h}$ & 779 & 0.35 \\
\hline [95] & Olive Stone & $\begin{array}{l}\text { (Ch) Impregnation } \\
\text { with H3PO4 (80 } \\
\text { wt } \%) \text { and } \\
\text { carbonization }\end{array}$ & $500^{\circ} \mathrm{C}$ & $2 \mathrm{~h}$ & 1218 & 0.6 \\
\hline \multirow[t]{2}{*}{ [96] } & \multirow[t]{2}{*}{ Olive Stone } & \multirow{2}{*}{$\begin{array}{l}\text { Carbonization and } \\
(\mathrm{Ch}) \quad \mathrm{KOH} \\
(50 \mathrm{wt} \%) \text { :Char: } 1: 1\end{array}$} & $600^{\circ} \mathrm{C}$ & $1 \mathrm{~h}$ & \multirow[t]{2}{*}{-} & \multirow[t]{2}{*}{-} \\
\hline & & & $900^{\circ} \mathrm{C}$ & $3 \mathrm{~h}$ & & \\
\hline \multirow[t]{2}{*}{ [96] } & \multirow[t]{2}{*}{ Olive Stone } & \multirow{2}{*}{$\begin{array}{l}\text { Carbonization and } \\
(\mathrm{Ch}) \quad \mathrm{KOH} \\
(75 \mathrm{wt} \%): \text { Char: } 1: 1\end{array}$} & $600^{\circ} \mathrm{C}$ & $1 \mathrm{~h}$ & \multirow[t]{2}{*}{-} & \multirow[t]{2}{*}{-} \\
\hline & & & $900^{\circ} \mathrm{C}$ & $3 \mathrm{~h}$ & & \\
\hline$[97,98]$ & Olive stone & $\begin{array}{l}\text { (Ch) Impregnation } \\
\text { with } \mathrm{ZnCl}_{2} \\
(20 \mathrm{wt} \%)\end{array}$ & $650^{\circ} \mathrm{C}$ & $2 \mathrm{~h}$ & 790.25 & - \\
\hline \multirow[t]{2}{*}{ [99] } & \multirow[t]{2}{*}{ Olive stone } & \multirow{2}{*}{$\begin{array}{l}\text { Carbonization and } \\
(\mathrm{Ch}) \text { KOH:char: } \\
0.5: 1\end{array}$} & $350^{\circ} \mathrm{C}$ & $1 \mathrm{~h}$ & \multirow[t]{2}{*}{1500} & \multirow[t]{2}{*}{0.31} \\
\hline & & & $800^{\circ} \mathrm{C}$ & $2 \mathrm{~h}$ & & \\
\hline \multirow[t]{2}{*}{ [99] } & \multirow[t]{2}{*}{ Olive stone } & \multirow{2}{*}{$\begin{array}{l}\text { Carbonization and } \\
\text { (Ch) KOH:char: } \\
1: 1\end{array}$} & $350^{\circ} \mathrm{C}$ & $1 \mathrm{~h}$ & \multirow[t]{2}{*}{1635} & \multirow[t]{2}{*}{0.52} \\
\hline & & & $800^{\circ} \mathrm{C}$ & $2 \mathrm{~h}$ & & \\
\hline \multirow[t]{2}{*}{ [99] } & \multirow[t]{2}{*}{ Olive stone } & \multirow{2}{*}{$\begin{array}{l}\text { Carbonization and } \\
(\mathrm{Ch}) \quad \mathrm{KOH} \text { :char: } \\
2: 1\end{array}$} & $350^{\circ} \mathrm{C}$ & $1 \mathrm{~h}$ & \multirow[t]{2}{*}{1768} & \multirow[t]{2}{*}{0.80} \\
\hline & & & $800^{\circ} \mathrm{C}$ & $2 \mathrm{~h}$ & & \\
\hline \multirow[t]{2}{*}{ [99] } & \multirow[t]{2}{*}{ Olive stones } & \multirow{2}{*}{$\begin{array}{l}\text { Carbonization and } \\
(\mathrm{Ch}) \quad \mathrm{H}_{3} \mathrm{PO}_{4} \\
(75 \mathrm{wt} \%) \text { :char: } \\
2.4: 1 \text {; steam }\end{array}$} & $350^{\circ} \mathrm{C}$ & $1 \mathrm{~h}$ & \multirow[t]{2}{*}{393} & \multirow[t]{2}{*}{0.12} \\
\hline & & & $500^{\circ} \mathrm{C}$ & $1 \mathrm{~h}$ & & \\
\hline \multirow[t]{2}{*}{ [99] } & \multirow[t]{2}{*}{ Olive stones } & Carbonization and & $350^{\circ} \mathrm{C}$ & $1 \mathrm{~h}$ & 584 & 0.11 \\
\hline & & $(\mathrm{Ph}) \mathrm{CO}_{2}$ & $840^{\circ} \mathrm{C}$ & $11 \% \mathrm{BO}$ & & \\
\hline [99] & Olive stones & Carbonization and & $350^{\circ} \mathrm{C}$ & $1 \mathrm{~h}$ & 793 & 0.14 \\
\hline & & $(\mathrm{Ph}) \mathrm{CO}_{2}$ & $840^{\circ} \mathrm{C}$ & $27 \% \mathrm{BO}$ & & \\
\hline [99] & Olive stones & Carbonization and & $350^{\circ} \mathrm{C}$ & $1 \mathrm{~h}$ & 1038 & 0.17 \\
\hline & & $(\mathrm{Ph}) \mathrm{CO}_{2}$ & $840^{\circ} \mathrm{C}$ & $57 \% \mathrm{BO}$ & & \\
\hline$[100]$ & Olive stone & $\begin{array}{l}\text { (Ch) Impregnation } \\
\text { with H3PO4 } \\
(50 \mathrm{wt} \%): \mathrm{char}= \\
10 \mathrm{ml} / \mathrm{g}\end{array}$ & $400^{\circ} \mathrm{C}$ & $2 \mathrm{~h}$ & 1740 & 0.89 \\
\hline
\end{tabular}


Those shown in Table 6 are only some examples on the production of activated carbons from olive stones, they are interesting because they show the influence of different activating agents. It is shown in the literature also that chemical activation is more effective than physical activation in many cases [99]. Chemical activation is generally preferred for olive stones (and also other precursors). More activation examples performed with olive stones are presented in the review [101]. From this review we can see that about 25 chemical activation tests have been performed in the literature, while the performed physical activation tests are only 2. Generally chemical activation produces activated carbons with higher porosity, compared to physical activation.

Dealing with the final yields of activated carbons, some values are presented in Figure 14. Dealing with reactor conditions, in [72] we see that pyrolysis is performed with a flow of nitrogen equal to $10 \mathrm{~L} / \mathrm{min}$. The reactor is represented by a muffle furnace. It was heated at $600^{\circ} \mathrm{C}$ with a heating rate of $10^{\circ} \mathrm{C} / \mathrm{min}$. The reaction lasted for 2 hours. The HTC tests were instead conducted in an autoclave with a maximum capacity of $250 \mathrm{~mL}$. The autoclaves were filled to $70 \%$ of the volume with a mixture of biomass and distilled water with a weight ration of $20: 80$. The autoclave was then heated to $220^{\circ} \mathrm{C}$ in one hour; then it was left at constant temperature for five hours. The final pressure of the reactor ranged between 27 and 51 bar. The hydrochar was recovered by filtration and then dried. In [92] a vessel of volume 250 $\underline{\mathrm{mL}}$ was also used. This was charged with $21.32 \mathrm{~g}$ of solid digestate, $153.69 \mathrm{~g}$ of liquid digestate and $5.04 \mathrm{~g}$ of anhydrous citric acid powder (to control the $\mathrm{pH}$ ). The feedstock resulted to have $15 \mathrm{wt} . \%$ dry matter content and $\mathrm{pH}$ equal to 5 . The vessel was filled for $70 \%$ of the total volume. HTC was performed at 3 temperatures: $190^{\circ} \mathrm{C}, 220^{\circ} \mathrm{C}$ and $250^{\circ} \mathrm{C}$. The reactor heating phase lasted for 45 minutes, while the reaction lasted for 3 hours. During all the reaction phase the reagents were constantly mixed. In [95] olive stones are ground dried and sieved and then they were mixed with sulfuric acid in different concentrations $(70,80$ and $90 \%)$ in a mas ratio of $1 \mathrm{~g}$ of olive stone per 4 grams of sulfuric acid. The mixture was mixed for 4 hours at $85^{\circ} \mathrm{C}$ to assure penetration of sulfuric acid in the pores of the olive stone. After imbibition or impregnation, the olive stones loaded with sulfuric acid were carbonized in a vertical furnace at the temperature of $500^{\circ} \mathrm{C}$ with a flow of nitrogen equal to $200 \mathrm{~mL} / \mathrm{min}$. The heating rate was $3^{\circ} \mathrm{C} / \mathrm{min}$ and holding time was 2 hours. After cooling the obtained activated carbon it was 
washed with distilled water until reaching a $\mathrm{pH}$ of 6 in the residual washing liquid. Then it was dried again. In [96] olive stones were first pyrolyzed at $600^{\circ} \mathrm{C}$ for 1 hour in a muffle furnace; then chemical activation was performed with $\mathrm{KOH}$ at different concentrations ( 50 and $75 \% \mathrm{w} / \mathrm{w}$ ) at a ratio between $\underline{\mathrm{KOH}}$ and char of $1: 1$ in weight. Activation temperature was $900^{\circ} \mathrm{C}$ in nitrogen atmosphere for 1 hour.


was performed in a muffle furnace at the temperature of $650^{\circ} \mathrm{C}$ for 2 hours with a nitrogen flow of 150 $\mathrm{cm}^{3} / \mathrm{min}$ for 2 hours. Activated carbons were washed with a concentration of $0.5 \mathrm{~N} \mathrm{HCl}$ and then dried. Further detail on activation process are proposed in [102].

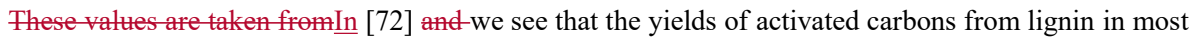
of the cases range from $20 \mathrm{wt} \%$ to $30 \mathrm{wt} \%$, referring to the initial total mass of lignin used. The most important aspect to take into consideration in the activation (especially if it is chemical) is the reactant and the ratio between it and the precursor). In [92] $\mathrm{KOH}$ is used as an activating agent.

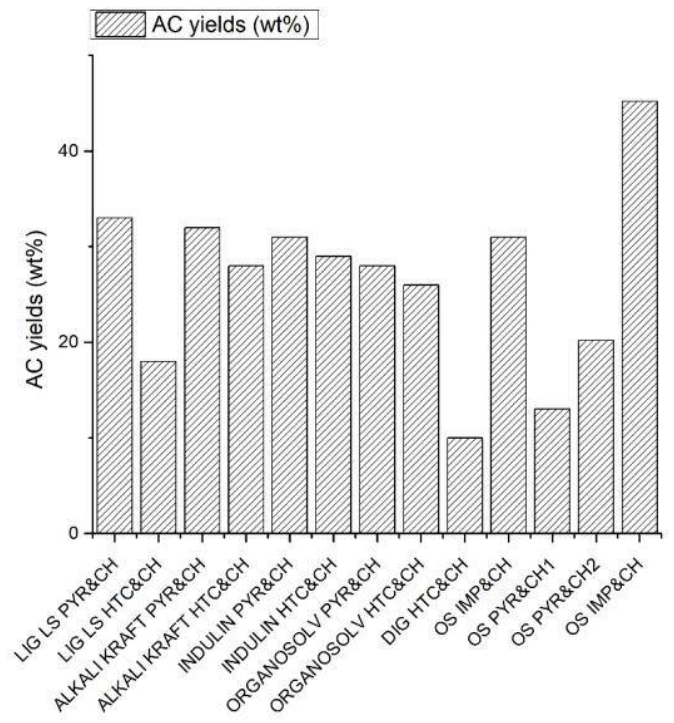

Figure 14: Activated carbon yields obtained with different activation methods and different lignins and lignin-rich substrates, where LIG represents Lignin, LS represents Low Sulfonate, PYR represents pyrolysis, CH represents Chemical Activation, HTC represents Hydrothermal 


$$
[72,92,95-97]
$$

$\mathrm{KOH}$ at first during activation reacts with the carbon of the hydrochar and forms $\mathrm{K}_{2} \mathrm{CO}_{3}$ and metallic $\mathrm{K}$ and releases $\mathrm{H}_{2}$. The unstable organic compounds of the hydrochar when heated gasify also and release from these reactions $\mathrm{CO}_{2}$, which is responsible of the increase in porosity. The metallic $\mathrm{K}$ which has been formed by the previous reactions finally reacts again with $\mathrm{C}$ and promotes further gasification. It is possible that the high ratio between $\mathrm{KOH}$ and hydrochar (equal to 4:1) is the reason why the activated carbon yield obtained with the digestate is quite low, if compared to that obtained with lignin. On the other hand the activated carbon from lignin, which is shown in Figure 14, has been obtained through $\mathrm{KOH}$ activation at similar conditions, as it is reported in [72]; so in general it can be inferred that activated carbon yields from digestate are usually lower than those obtained with lignin. This can be explained with the fact that the carbon contained in lignin is more thermally stable.

When we consider the case of olive stone, this is quite similar to that of digestate. The only cases in which higher yields are obtained are those in which activation is not performed with a two-step process, so we don't have two thermal treatments: carbonization and activation; but we have only impregnation, followed by activation. In this case the final yields of activated carbons can reach easily about $40 \mathrm{wt} \%$. The main differences between the yields of activated carbon obtained with lignin and those obtained with lignin-rich residues are due to the behavior of cellulose, hemicellulose and lignin during carbonization. As it has been previously reported, the concentration of lignin is high in pure lignin (obviously), then it decreases in digestate (also depending on the feedstock used in the anaerobic digestion process) and it decreases again in the olive stone.

Regarding the contribution of hemicellulose, cellulose and lignin to final activated carbon mass we can take into consideration the data reported in [69]. The contribution of lignin is estimated to be about 44.6 $\mathrm{wt} \%$, the contribution of cellulose is estimated at about $18.5 \mathrm{wt} \%$; the contribution of hemicellulose is estimated at about $36.9 \mathrm{wt} \%$. 
4.4.2 Further insights on the influence of process parameters on final porosity and activated carbon yields

As it can be seen from Table 6 an important parameter in the activation process is the burn-off, which can be calculated with the following simple equation [103]:

$$
\mathrm{BO}=(\mathrm{mi}-\mathrm{mf}) / \mathrm{mf}
$$

Where $\mathrm{mi}$ is the initial mass (d.a.f.b.) and $\mathrm{mf}$ is the final mass (d.a.f.b.) after activation. An interesting analysis on the effect of burn-off on the final properties of the activated carbon is reported in [104]. As we know the burn-off is dependent on both process variables: temperature and time of activation. It was observed that the $\mathrm{BO}$ has the most important influence on the development of the porosity, this is clearly shown in Figure 15

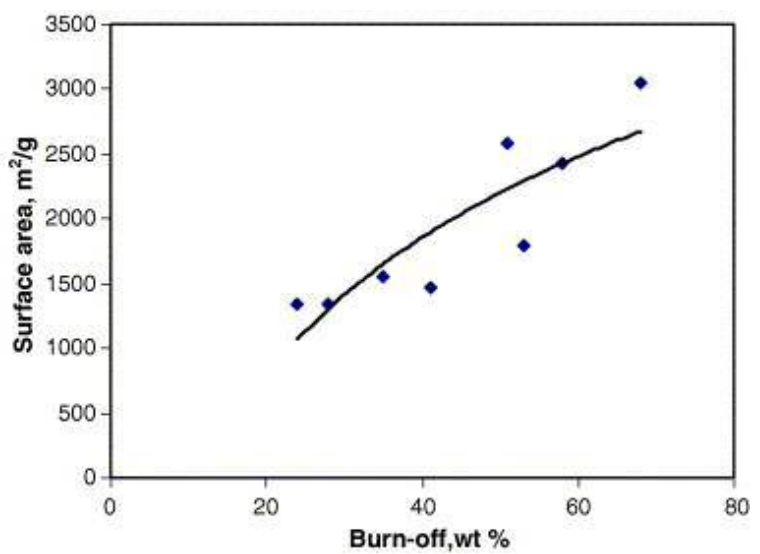

Figure 15: Influence of the burn-off on the development of the surface area in olive stone activated carbon [104] 
In the experiments of Zabanotou et al. [104] it is also shown that the methylene blue adsorption is proportional to the surface area of the charcoal, these experiments so confirm that BET analysis is important to understand what will be the adsorption capacity of the produced carbon.

\subsubsection{Lignin and lignin-rich substrates modification processes}

The most interesting way to modify the charcoal is to functionalize its surface as it is explained in [62]. In fact, the charcoal produced through pyrolysis and hydrothermal carbonization has generally a low number of functional groups, such as: $\mathrm{C}-\mathrm{O}-\mathrm{C}, \mathrm{C}=\mathrm{O}$ and $\mathrm{OH}$. It has also a limited surface area and porosity. Surface modification of the charcoal can be performed through the following processes_[105]:

- oxidation

- $\quad$ basic modification (eg. amination);

- $\quad$ acid modification (eg. sulfonation);

- metal salts or metal oxides modification

_ $\quad$ biochar modification by carbon material (carbon nanotubes and graphene);

- biochar composite material;

- $\quad$ biochar modification by ionic liquids

- $\quad$ graphitization of biochar

- $\quad$ heteroatom doped biochar

The first modificationOxidation can be performed using the following agents: $\mathrm{H}_{2} \mathrm{O}_{2}, \mathrm{O}_{3}, \mathrm{KMnO}_{4}$ and $\mathrm{HNO}_{3}[106-109]$. These reagents are useful if we want to introduce into the char functional groups such as carboxyl, phenolic hydroxyl, lactones and peroxides. Sulfonation is usually performed using $\mathrm{H}_{2} \mathrm{SO}_{4}$ and its derivatives (e.g. fuming $\mathrm{H}_{2} \mathrm{SO}_{4}$ and $\mathrm{CISO}_{3} \mathrm{H}$ ). Sulfonation is performed to introduce $\mathrm{SO}_{3} \mathrm{H}$ groups in the charcoal [110-114]. Other possible acids to be used in acid modification of biochar are: hydrochloric acid, sulfuric acid, nitric acid, phosphoric acid, oxalic acid and citric acid, according to [115]. 
Amination is usually performed through $\mathrm{NH}_{3}$ treatment at high temperatures [116-118]. Other possible modifications include the use of amino-containing compounds, such as: 3 -chloropropylamine, tris(2aminoethyl)amine, and polyethylenimine. These treatments are more environmentally friendly than the treatment with $\mathrm{NH}_{3}$ because the production of $\mathrm{NH}_{3}$ is highly energy intensive and also polluting. Amino loaded charcoal has the important advantage of being able to chemically retain acidic pollutants. Other common alkaline agents used in biochar modification are $\mathrm{KOH}$ and $\mathrm{NaOH}$.

Metal salts or metal oxides modification is used to enhance the adsorption of particular pollutants (eg. anionic dyes); increase magnetic properties by modifying biochar with iron; enhance catalytic properties of biochar $[105,119]$.

Carbon modification of biochar consists in using it as a support for more performing carbon materials, like nanotubes or graphene [120]. This biochar already represents a composite, other kind of composites based on biochar can be obtained when it is modified with clay, see [121]; also this type of modification can have significant effects on the performances of biochar in adsorption processes.

Biochar modification with ionic liquids is documented in the work of [122]. This is a quite new application. Ionic liquids are also used to graphitize biochar, as shown in [123]. Graphitized biochar can be produced by treating it at very high temperatures [124] and with different reagents its final use can be in Advanced Oxidation Processes (AOPs), as shown in [125].

A very common example of heteroatom doped biochar is that obtained suing urea to insert a $\mathrm{N}$ atom in the biochar, see [125]. Other possible doping can be performed also with Sulfur.

\subsubsection{Modification of lignin through the production of magnetic charcoal}

Another way to modify lignin is to produce from it magnetic charcoal. The process flow is shown in figure 16 , as it is reported in [126]. 



Figure 16: Magnetic lignin-based carbon nanoparticles production process, as reported in [126] 
In the particular case $5.4 \mathrm{~g}$ of ferric chloride hexahydrate are mixed together with $3.5 \mathrm{~g}$ of ferrous sulfate heptahydrate in $100 \mathrm{~mL}$ deionized water. Also $30 \mathrm{~mL}$ of $10 \mathrm{wt} \%$ ammonia are added to the solution and the temperature is increased to $90^{\circ} \mathrm{C} .3 \mathrm{~g}$ of Lignin were added to the solution, using again ammonia to regulate the $\mathrm{pH}$ and incubating the solution at $90^{\circ} \mathrm{C}$ for $2 \mathrm{~h}$. the detailed procedure is found in [126]. Once the reaction is completed the magnetic particles (made of lignin coated with iron oxide) were separated from the solution using a permanent magnet, they were then washed with ethanol and dried. Then the particles were carbonized in nitrogen atmosphere at $500^{\circ} \mathrm{C}$ for 3 hours. The adsorption capacity was tested using wastewaters polluted with methylene orange and the performance was interesting: $113 \mathrm{mg} / \mathrm{g}$ of adsorption capacity was reached, which proved to be quite high respect to the literature. This sorbent in fact has two big advantages:

- on one hand the nanoparticles and dissolve in the solution very efficiently and adsorb the polluting substances;

- on the other hand being magnetic, the sorbent can also be easily separated from the wastewater and recycled.

Similar other experiments have been put in place by [127], using lignin and dopamine they reached an adsorption capacity on $\mathrm{Cr}(\mathrm{III})$ equal to $44.56 \mathrm{mg} / \mathrm{g}$ which has proven to be quite higher respect to other sorbents developed in the literature. Even more interesting is the final price of the sorbent, which is equal to about $500 \$ / \mathrm{t}$ so more than half the price of conventional activated charcoal.

Other researchers [128] have produced composite magnetic lignin with good adsorption performances on Congo Red (198.24 mg/g) and Titan Yellow (192.51 mg/g).

Also red mud and lignin wastes can be used as raw materials to produce metal biochar composites [129], If the production of magnetic carbon and aerogels from lignin is quite common [130-134], the production of magnetic carbon from digestate and olive stone is more rare.

\section{The adsorption process theory}


Adsorption can be defined in [46] as the enrichment of a compound from a fluid phase on the surface of a solid (which in this case is the activated charcoal). Generally, the adsorption efficiency is proportional to the surface area of the sorbent (at least this is valid if we are talking about physisorption).

If we consider the adsorption process from a thermodynamic point of view, we have to take into consideration that in the adsorption process the Gibbs free energy is not only a function of the system temperature, pressure and composition (expressed in number of moles), but also is a function of the surface (indicated with the letter A). So, the change in the Gibbs free energy equation is given by:

where $\mathrm{S}$ is the Entropy, $\mathrm{V}$ is the volume, $\mu$ is the chemical potential and $\sigma$ is the surface free energy, which can be indicated also as the surface tension. When adsorption happens, the surface free energy decreases from a value of ows (surface tension at the interface between the water and the activated carbon) to the value of $\sigma$ as (surface tension between adsorbate and solid). The difference between the two surface tensions is proportional to the amount of compound which is adsorbed and it is indicated as the spreading pressure, $\pi$.

$$
\sigma \mathrm{ws}-\sigma \mathrm{as}=\pi>0
$$

The variation of enthalpy and the variation of entropy can be used to define the variation of the free energy during adsorption, assuming adsorption is a spontaneous process:

$$
\Delta \mathrm{Gads}=\Delta \mathrm{Hads}-\mathrm{T} \Delta \mathrm{ads}<0
$$

The reaction is negative because the adsorption process is considered to be spontaneous. Given that the adsorption process generally produces a decrease in the disorder of the system, the change of entropy is usually negative. If the change in entropy is negative, equation 7 implies that the change of enthalpy should be negative also, and so the reaction is exothermic (it releases heat in the environment). The adsorption enthalpy is an interesting parameter, which allows us also to evaluate the difference between different adsorption processes (e.g. chemisorption and physisorption). Physical adsorption is usually due to van der Waals forces (such as: dipole-dipole interactions, dispersion forces, induction forces). These interactions are relatively weak (the enthalpy in this case can be evaluated to be lower than 50 
$\mathrm{kJ} / \mathrm{mol}$ ). On the other hand, chemical sorption is based on chemical reactions which retain the adsorbate on the surface of the activated carbon (in this case the enthalpy is higher than $50 \mathrm{~kJ} / \mathrm{mol}$ ).

The adsorption process efficiency can be defined by the adsorption capacity, expressed in mg_adsorbate/g_adsorbent. This parameter can be referred to also as adsorbent loading. The loading or the adsorption capacity depends not only on the parameters of the adsorbent (such as its surface area and its functional groups) but also on the adsorption parameters (such as $\mathrm{pH}$, temperature, pressure etc.).

\section{Wastewaters treatment}

\subsection{Adsorption performance of activated carbon from lignin}

While some important reviews have been already published on the sorption capacity of activated charcoals produced from olive stones (as it will be shown in paragraph 6.2), no literature review is available on the adsorption of pollutant on activated charcoal produced from lignin. Some reviews are available on the adsorption which happens directly on the charcoal produced from lignin, without activation [135, 136]. 


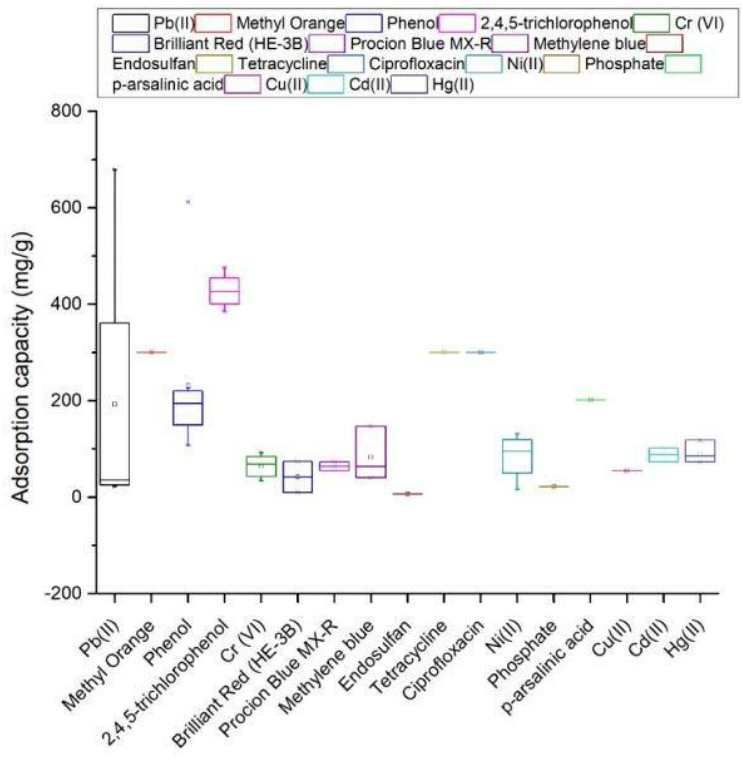

Figure 17: Adsorption capacity of activated carbon produced from lignin

From Figure 17 we see that the adsorption is very variable, depending on the characteristics of the activated carbons and on the process parameters. Generally, higher adsorption is measured for activated carbons with higher surface areas. Activated carbons produced from lignin have also important variations in the adsorption capacities of phenol, reaching very high values for 2,4,5-trichlorophenol.

\subsection{Adsorption performance activated carbons from digestate and olive stone}

As far as olive stone are concerned in the review presented in [101] it can be seen that the activated carbons produced from olive stones have very good adsorption performance, if compared with commercial activated carbons. 


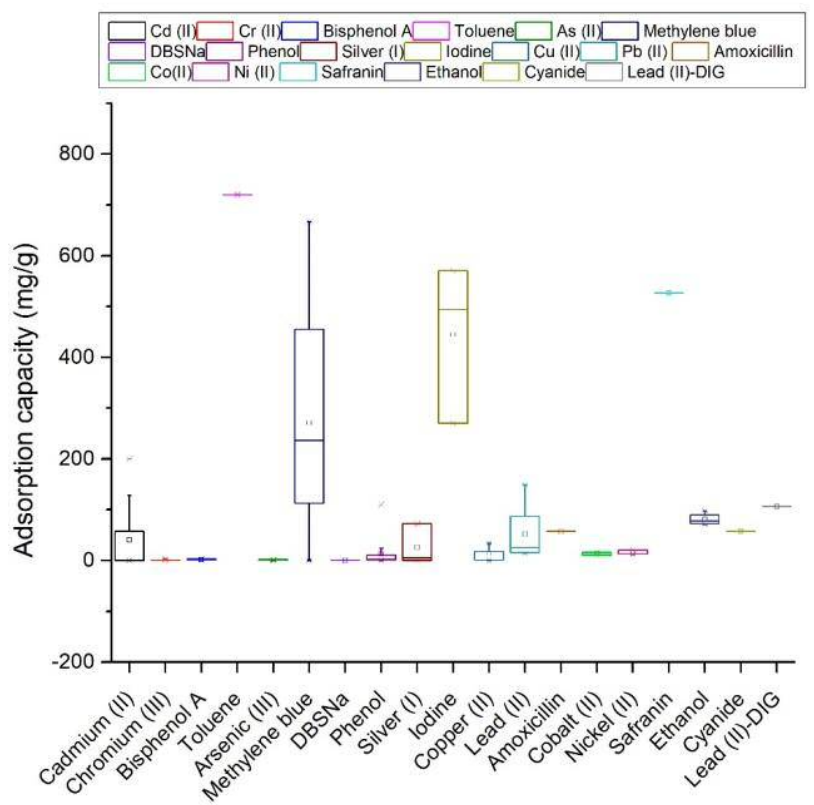

Figure 18: Adsorption capacity of activated carbons produced from olive stones and digestate [101]

The detailed adsorption capacities proposed in Figure 18 are taken from [101], which is a complete review on the performance of sorbents produced from olive stones. According to what is reported in [101], olive stone is a very competitive raw material for the production of activated carbon and can have interesting performances. Particularly interesting is the adsorption of phenolic compounds with activated carbons. This is the topic of the SURFOLY project recently founded under the PRIMA EU funds and managed by the University of Perugia.

7. Technical and Economic analysis on the production of activated charcoal from lignin rich biomass 


\subsection{Background}

In the work of [137] it is proposed a detailed analysis on the production of alternatives to petroleumbased polymers through technical lignins; where with the term "technical" the following types are indicated:

- lignosulfonates, which are obtained as byproducts of sulphite pulping;

- Kraft Lignin, which is produced from wood kraft pulping process;

- soda lignin, which is generated in the soda pulping process;

- hydrolysis lignin, obtained as a subproducts of second-generation ethanol production;

- organosolv lignin, which is produced from pulping processes that employ organic solvents to separate cellulose from lignin.

Dealing with the identification of best commercial products to be produced using lignin, a screening study [138] has selected the following promising products: phenol produced from Kraft lignin to be used in the synthesis of phenol-formaldehyde (PF) resins; polyols produced from lignosulfonate to be used in the synthesis of polyurethane (PU) foam; carbon fiber produced from organosolv lignin. In [138] it is presented also an interesting figure in which it is clearly identified the market price and the market size of different added value products which can be produced from lignin. The diameter of the bubbles in the graph is given by the product of the market value and the market price of the added value product. The percentage associated to each bubble represents the market share of the product respect to the total sum of the market shares of all the products. Three categories of final uses can be identified:

- high volume and low value (eg. bioenergy);

- low volume and high value (eg. carbon fibers);

- medium volume and medium value (eg. phenol). 
The dotted square in figure 19 represents the most interesting productions which can give the highest return. BTX, bitumen and phenols represent the markets with the highest volumes. Lignosulfonates can be successfully transformed in vanillin, additives and dispersants.

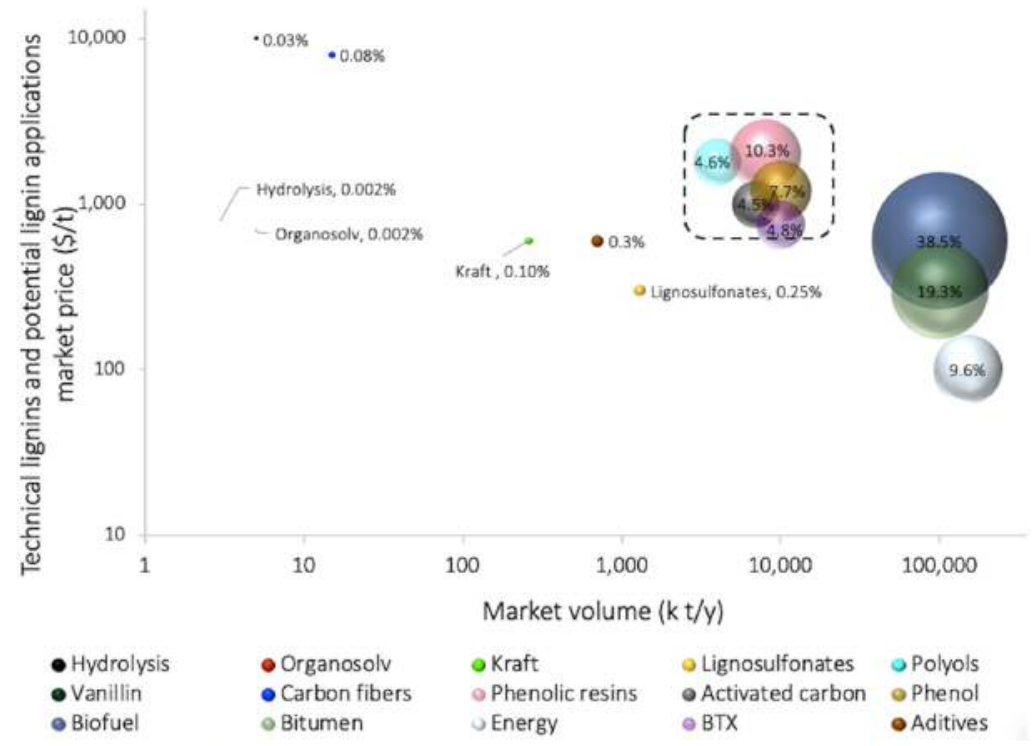

Figure 19: Potential market of added value products produced from lignin [137]

Other useful added value products are thermoplastics. The entire annual production of lignin could cover about $2 \%$ of the global consumption of plastics in the world [139]. The market of thermoplastics in fact is characterized by an annual demand of $280 \mathrm{Mt} / \mathrm{y}$ [140].

\subsection{Activated charcoal production costs}

An important work on the estimation of the production costs of activated carbons is reported in [33].The analysis starts with the identification of potential yields and also of product quality (based on surface area), see table 7 . 
Table 7: Activated carbon yields and surface areas [33]

\begin{tabular}{|c|c|c|c|c|c|}
\hline \multirow[t]{2}{*}{ Raw material } & \multirow{2}{*}{$\begin{array}{l}\text { Type of } \\
\text { activation }\end{array}$} & \multicolumn{3}{|c|}{ Activated carbon yield (wt\%) } & \multirow{2}{*}{$\begin{array}{c}\text { Surface } \\
\text { Area }\left(\mathrm{m}^{2} / \mathrm{g}\right)\end{array}$} \\
\hline & & Pyrolysis yield & $\begin{array}{l}\text { Activation } \\
\text { yield }\end{array}$ & $\begin{array}{l}\text { Total carbon } \\
\text { yield }\end{array}$ & \\
\hline Wood & $\begin{array}{l}\text { Activation with } \\
\text { steam }\end{array}$ & 25 & 50 & 12.5 & 800 \\
\hline Used tires & $\begin{array}{l}\text { Activation with } \\
\text { steam }\end{array}$ & 30 & 50 & 15 & 500 \\
\hline Pet coke & $\begin{array}{l}\text { Activation with } \\
\text { steam }\end{array}$ & 90 & 70 & 63 & 1000 \\
\hline Carbon Black & $\begin{array}{l}\text { Activation with } \\
\text { steam }\end{array}$ & 95 & 50 & 47.5 & 500 \\
\hline Charcoal & $\begin{array}{l}\text { Activation with } \\
\text { steam }\end{array}$ & 90 & 50 & 45 & 900 \\
\hline Lignite & $\begin{array}{l}\text { Activation with } \\
\text { steam }\end{array}$ & 52 & 30 & 15.6 & 800 \\
\hline Wood & $\begin{array}{l}\text { Activation with } \\
\mathrm{KOH}\end{array}$ & N/A & N/A & 22 & 800 \\
\hline Used tires & $\begin{array}{l}\text { Activation with } \\
\mathrm{KOH}\end{array}$ & N/A & N/A & 20 & 700 \\
\hline Pet coke & $\begin{array}{l}\text { Activation with } \\
\mathrm{KOH}\end{array}$ & N/A & $\mathrm{N} / \mathrm{A}$ & 45 & 3000 \\
\hline Carbon black & $\begin{array}{l}\text { Activation with } \\
\mathrm{KOH}\end{array}$ & N/A & N/A & 60 & 500 \\
\hline Charcoal & $\begin{array}{l}\text { Activation with } \\
\mathrm{KOH}\end{array}$ & N/A & N/A & 44 & 2000 \\
\hline Lignite & $\begin{array}{l}\text { Activation with } \\
\mathrm{KOH}\end{array}$ & N/A & $\mathrm{N} / \mathrm{A}$ & 25 & 2200 \\
\hline
\end{tabular}

The final costs of the produced activated carbon for a plant with production capacity of $4.5 \mathrm{t} /$ day are reported in figure 20. The two alternatives are compared (with the assumption that the raw material has zero cost of supply): chemical activation (with $\mathrm{KOH}$ ) and physical activation (with steam). We can see from figure 20 that in general chemical activation has better performance than physical activation, this is due to the higher yields. The payback period of the plants range from 3 to 12 years, depending on the feedstock. The best performances in physical activation are achieved by pet coke: 3.12 years. The best performance for chemical activation are achieved by carbon black: 3.94 years. 


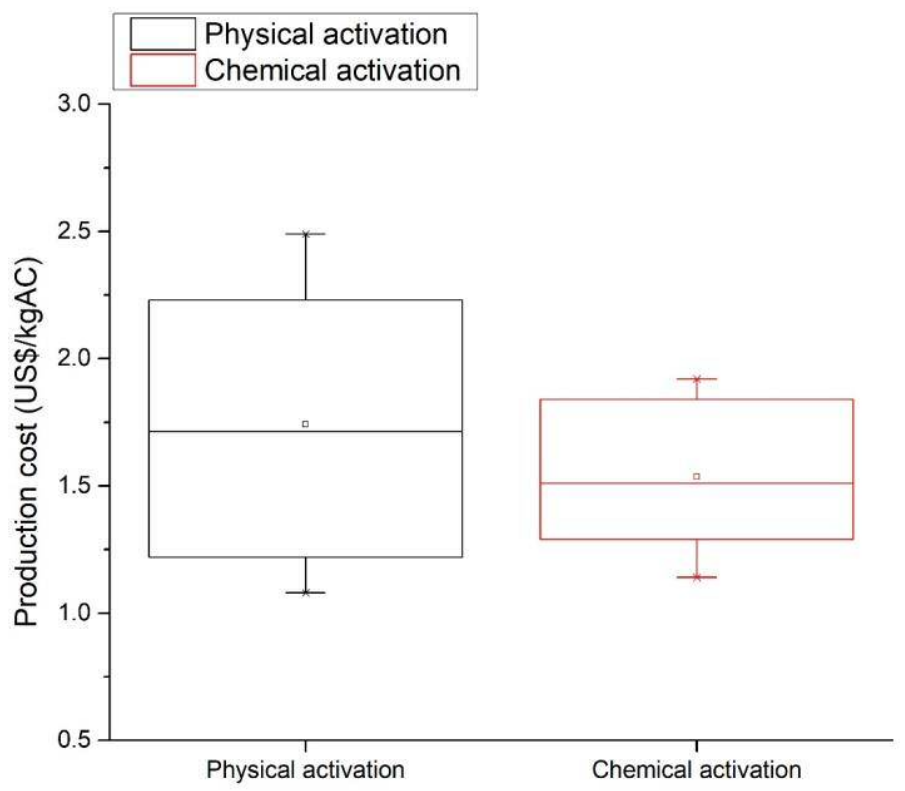

\section{Conclusions}

Lignin used as a precursor for the preparation of magnetic activated charcoal has been investigated and reviewed based on relevant articles published. Magnetic activated charcoal adsorbents are highly efficient for the removal of pollutants such as heavy metal ions, dyes, and organic and inorganic compounds. In past years a lot of low-cost biomass-based adsorbents has been synthesized and characterized, such as commercially activated carbon, but for large scale application they showed many complications, such as the separation process of activated carbon. On the other hand, magnetic activated materials showed great scope and application for wastewater treatment because of their physicochemical properties, large surface area and volume, great affinity toward pollutants and easy separation process. Based on detailed reviewed research articles it is concluded that the lignin based magnetic activated materials such as carbon nanotubes, nanoporous materials, are highly efficient for the wastewater treatment from small scale to large scale. 


\section{Acknowledgement}

This work is supported by the e-COST European Cooperation in Science and Technology, UK Biochar research center at Edinburgh University UK, the BioCarbUp project at SINTEF Energy Research and Biomass research center at Perugia University Italy.

\section{Reference}

1. Hu, J., Q. Zhang, and D.-J. Lee, Kraft lignin biorefinery: A perspective. Bioresource Technology, 2018. 247: p. 1181-1183.

2. Bajwa, D.S., et al., A concise review of current lignin production, applications, products and their environmental impact. Industrial Crops and Products, 2019. 139: p. 111526.

3. Ralph, J., C. Lapierre, and W. Boerjan, Lignin structure and its engineering. Current Opinion in Biotechnology, 2019. 56: p. 240-249.

4. Vanholme, R., et al., Lignin engineering. Current Opinion in Plant Biology, 2008. 11(3): p. 278285.

5. Noche, P.V.P.B., A review of the current digestate distribution models: storage and transport www.witpress.com, ISSN 1743-3541 (on-line) WIT Transactions on Ecology and The Environment, Vol 202, (C) 2016 WIT Press, doi:10.2495/WM160311, 2016.

6. Xue, S., et al., A systematic comparison of biogas development and related policies between China and Europe and corresponding insights. Renewable and Sustainable Energy Reviews, 2020. 117: p. 109474.

7. Rodríguez, G., et al., Olive stone an attractive source of bioactive and valuable compounds. Bioresource Technology, 2008. 99(13): p. 5261-5269.

8. Yahya, M.A., Z. Al-Qodah, and C.W.Z. Ngah, Agricultural bio-waste materials as potential sustainable precursors used for activated carbon production: A review. Renewable and Sustainable Energy Reviews, 2015. 46: p. 218-235.

9. Hagemann, N., et al., Activated Carbon, Biochar and Charcoal: Linkages and Synergies across Pyrogenic Carbon's ABCs. Water, 2018. 10(2): p. 182.

10. Wang, S., et al., Lignocellulosic biomass pyrolysis mechanism: A state-of-the-art review. Progress in Energy and Combustion Science, 2017. 62: p. 33-86.

11. Funke, A. and F. Ziegler, Hydrothermal carbonization of biomass: A summary and discussion of chemical mechanisms for process engineering. Biofuels, Bioproducts and Biorefining, 2010. 4(2): p. 160-177.

12. McDougall, G.J., Physical nature and manufacture of activated carbon. Journal of The South African Institute of Mining and Metallurgy, 1991. 91(4): p. 109-120.

13. Al-Qodah, Z. and R. Shawabkah, Production and characterization of granular activated carbon from activated sludge. Brazilian Journal of Chemical Engineering, 2009. 26(1): p. 127-136.

14. Cruz, G., et al., Production of activated carbon from cocoa (Theobroma cacao) pod husk. J. Civ. Environ. Eng., 2012. 2(2): p. 1-6.

15. Asadullah, M., et al., Adsorption studies on activated carbon derived from steam activation of jute stick char. Journal of Surface Science and Technology, 2007. 23(1-2): p. 73-80.

16. Donald, J., Y. Ohtsuka, and C. Xu, Effects of activation agents and intrinsic minerals on pore development in activated carbons derived from a Canadian peat. Materials Letters, 2011. 65(4): p. 744-747. 
17. Demiral, H., et al., Pore structure of activated carbon prepared from hazelnut bagasse by chemical activation. Surface and Interface Analysis, 2008. 40(3-4): p. 616-619.

18. Zhengrong, G. and W. Xiaomin, Carbon materials from high ash bio-char: a nanostructure similar to activated grapheme. Am Trans Eng Appl Sci, 2013. 2(1): p. 15-34.

19. Hayashi, J.i., et al., Preparing activated carbon from various nutshells by chemical activation with K2CO3. Carbon, 2002. 40(13): p. 2381-2386.

20. Adinata, D., W.M.A. Wan Daud, and M.K. Aroua, Preparation and characterization of activated carbon from palm shell by chemical activation with K2CO3. Bioresource Technology, 2007. 98(1): p. 145-149.

21. Jassim, A.N., et al., Preparation and characterization of activated carbon from Iraqi apricot stones. Can J Cheml Eng Tech, 2012. 3: p. 60-65.

22. Chiang, H.-L., C.P. Huang, and P.C. Chiang, The surface characteristics of activated carbon as affected by ozone and alkaline treatment. Chemosphere, 2002. 47(3): p. 257-265.

23. Oh, W.-C., H.-J. Lee, and J.-S. Bae, REMOVAL EFFICIENCY OF THE POLLUTANTS BY MULTILAYERED METAL TREATED CARBON FILTER. Environmental Engineering Research, 2004. 9(5): p. 193-200.

24. Puziy, A.M., et al., XPS and NMR studies of phosphoric acid activated carbons. Carbon, 2008. 46(15): p. 2113-2123.

25. Gaur, V. and P.A. Shankar, Surface modification of activated carbon for the removal of water impurities. Water Cond Purif, 2008: p. 1-5.

26. Li, L., P.A. Quinlivan, and D.R.U. Knappe, Effects of activated carbon surface chemistry and pore structure on the adsorption of organic contaminants from aqueous solution. Carbon, 2002. 40(12): p. 2085-2100.

27. Oh, W.C. and C.S. Lim, Metal elimination effect by sulfuric acid for Ag and Cu pre-treated activated carbon. Journal of Ceramic Processing Research, 2006. 7(2): p. 95-105.

28. Boretti, A. and L. Rosa, Reassessing the projections of the World Water Development Report. npj Clean Water, 2019. 2(1): p. 15

29. Mugagga, F. and B.B. Nabaasa, The centrality of water resources to the realization of Sustainable Development Goals (SDG). A review of potentials and constraints on the African continent. International Soil and Water Conservation Research, 2016. 4(3): p. 215-223.

30. Liu, J., et al., Nexus approaches to global sustainable development. Nature Sustainability, 2018. 1(9): p. 466-476.

31. Marsh, H. and F.R. Reinoso, Activated carbon. 2006: Elsevier.

32. MarketsandMarkets, Activated Carbon Market by Type (Powdered, Granular, Others (Pelletized, Bead)), Application (Liquid Phase (Water Treatment, Foods \& Beverages, Pharmaceutical \& Medical), Gaseous Phase (Industrial, Automotive)), Region - Global Forecast to 2021. 2017.

33. Stavropoulos, G.G. and A.A. Zabaniotou, Minimizing activated carbons production cost. Fuel Processing Technology, 2009. 90(7): p. 952-957.

34. Kim, M.-K. and K.-D. Zoh, Occurrence and removals of micropollutants in water environment. Environmental Engineering Research, 2016. 21(4): p. 319-332.

35. Mailler, R., et al., Study of a large scale powdered activated carbon pilot: Removals of a wide range of emerging and priority micropollutants from wastewater treatment plant effluents. Water Research, 2015. 72: p. 315-330.

36. Suhas, P.J.M. Carrott, and M.M.L. Ribeiro Carrott, Lignin - from natural adsorbent to activated carbon: A review. Bioresource Technology, 2007. 98(12): p. 2301-2312.

37. Xiang, W., et al., Biochar technology in wastewater treatment: A critical review. Chemosphere, 2020. 252: p. 126539.

38. Inyang, M.I., et al., A review of biochar as a low-cost adsorbent for aqueous heavy metal removal. Critical Reviews in Environmental Science and Technology, 2016. 46(4): p. 406-433. 
39. Wang, X., et al., Recent advances in biochar application for water and wastewater treatment: a review. PeerJ, 2020. 8: p. e9164-e9164.

40. Shaheen, S.M., et al., Wood-based biochar for the removal of potentially toxic elements in water and wastewater: a critical review. International Materials Reviews, 2019. 64(4): p. 216247.

41. Tang, Y., et al., Influence of pyrolysis temperature on production of digested sludge biochar and its application for ammonium removal from municipal wastewater. Journal of Cleaner Production, 2019. 209: p. 927-936.

42. Godwin, P.M., et al., Progress in Preparation and Application of Modified Biochar for Improving Heavy Metal Ion Removal From Wastewater. Journal of Bioresources and Bioproducts, 2019. 4(1): p. 31-42.

43. Kopecký, M., et al., Modified Biochar-A Tool for Wastewater Treatment. Energies, 2020. 13(20): p. 1-13.

44. Cooney, D.O., Adsorption design for wastewater treatment. 1998, United States: Lewis Publishers, Boca Raton, FL (United States).

45. Sciences, B.o.T.a.E.H.H.S.D.W.C.A.o.L., Drinking Water and Health,: Volume 2. 1980, Washington, DC: The National Academies Press. 408.

46. Worch, E., Adsorption Technology in Water Treatment: Fundamentals, Processes, and Modeling. 2012, Berlin, Boston: De Gruyter.

47. Ferhan Çeçen, Ö.A., Activated Carbon for Water and Wastewater Treatment, Wiley, Editor. 2011. p. 365-388.

48. Supanchaiyamat, N., et al., Lignin materials for adsorption: Current trend, perspectives and opportunities. Bioresource Technology, 2019. 272: p. 570-581.

49. Cotoruelo, L.M., et al., Activated Carbons from Lignin: Their Application in Liquid Phase Adsorption. Separation Science and Technology, 2007. 42(15): p. 3363-3389.

50. Rabinovich, M.L., et al., Carbon adsorbents from industrial hydrolysis lignin: The USSR/Eastern European experience and its importance for modern biorefineries. Renewable and Sustainable Energy Reviews, 2016. 57: p. 1008-1024.

51. Gordobil, O., et al., Assesment of technical lignins for uses in biofuels and biomaterials: Structure-related properties, proximate analysis and chemical modification. Industrial Crops and Products, 2016. 83: p. 155-165.

52. García, R., et al., Spanish biofuels heating value estimation. Part II: Proximate analysis data. Fuel, 2014. 117: p. 1139-1147.

53. Cordero, T., et al., Predicting heating values of lignocellulosics and carbonaceous materials from proximate analysis. Fuel, 2001. 80(11): p. 1567-1571.

54. Nevárez, L.A.M., et al., Biopolymer-based nanocomposites: effect of lignin acetylation in cellulose triacetate films. Science and Technology of Advanced Materials, 2011. 12(4): p. 045006.

55. Baumberger, S., et al., Molar mass determination of lignins by size-exclusion chromatography: towards standardisation of the method. Holzforschung, 2007. 61(4): p. 459-468.

56. Bartocci, P., et al., Kinetic Analysis of Digestate Slow Pyrolysis with the Application of the Master-Plots Method and Independent Parallel Reactions Scheme. Molecules, 2019. 24(9).

57. Barbanera, M., F. Cotana, and U. Di Matteo, Co-combustion performance and kinetic study of solid digestate with gasification biochar. Renewable Energy, 2018. 121: p. 597-605.

58. Fernández-Bolaños, J., et al., Characterization of the lignin obtained by alkaline delignification and of the cellulose residue from steam-exploded olive stones. Bioresource Technology, 1999. 68(2): p. 121-132.

59. Bartocci, P., et al., Pyrolysis of Olive Stone for Energy Purposes. Energy Procedia, 2015. 82: p. 374-380.

60. Chu, S., A.V. Subrahmanyam, and G.W. Huber, The pyrolysis chemistry of a 8-O-4 type oligomeric lignin model compound. Green Chemistry, 2013. 15(1): p. 125-136. 
61. Ben, H. and A.J. Ragauskas, NMR Characterization of Pyrolysis Oils from Kraft Lignin. Energy \& Fuels, 2011. 25(5): p. 2322-2332.

62. Liu, W.-J., H. Jiang, and H.-Q. Yu, Thermochemical conversion of lignin to functional materials: a review and future directions. Green Chemistry, 2015. 17(11): p. 4888-4907.

63. Rutherford, D.W., et al., Effect of formation conditions on biochars: Compositional and structural properties of cellulose, lignin, and pine biochars. Biomass and Bioenergy, 2012. 46: p. 693-701.

64. Caballero, J.A., A. Marcilla, and J.A. Conesa, Thermogravimetric analysis of olive stones with sulphuric acid treatment. Journal of Analytical and Applied Pyrolysis, 1997. 44(1): p. 75-88.

65. Caballero, J.A., et al., Pyrolysis kinetics of almond shells and olive stones considering their organic fractions. Journal of Analytical and Applied Pyrolysis, 1997. 42(2): p. 159-175.

66. Carrott, P.J.M., et al., Reactivity and porosity development during pyrolysis and physical activation in $\mathrm{CO} 2$ or steam of kraft and hydrolytic lignins. Journal of Analytical and Applied Pyrolysis, 2008. 82(2): p. 264-271.

67. Balwant Singh, M.C.A., Johannes Lehmann, Biochar, A Guide to Analytical Methods. ISBN 9781498765534, 2017.

68. Goldfarb, J.L., et al., Novel Integrated Biorefinery for Olive Mill Waste Management: Utilization of Secondary Waste for Water Treatment. ACS Sustainable Chemistry \& Engineering, 2017. 5(1): p. 876-884.

69. Boundzanga, H.M., et al., Contributions of hemicellulose, cellulose, and lignin to the mass and the porous characteristics of activated carbons produced from biomass residues by phosphoric acid activation. Biomass Conversion and Biorefinery, 2020.

70. Collard, F.-X. and J. Blin, A review on pyrolysis of biomass constituents: Mechanisms and composition of the products obtained from the conversion of cellulose, hemicelluloses and lignin. Renewable and Sustainable Energy Reviews, 2014. 38: p. 594-608.

71. Peterson, A.A., et al., Thermochemical biofuel production in hydrothermal media: A review of sub- and supercritical water technologies. Energy \& Environmental Science, 2008. 1(1): p. 3265.

72. Rodríguez Correa, C., et al., Influence of the Carbonization Process on Activated Carbon Properties from Lignin and Lignin-Rich Biomasses. ACS Sustainable Chemistry \& Engineering, 2017. 5(9): p. 8222-8233.

73. Kang, S., et al., A direct synthesis of adsorbable hydrochar by hydrothermal conversion of lignin. Energy Sources, Part A: Recovery, Utilization, and Environmental Effects, 2016. 38(9): p. $1255-1261$.

74. Missaoui, A., et al., Hydrothermal carbonization of dried olive pomace: Energy potential and process performances. Journal of Analytical and Applied Pyrolysis, 2017. 128: p. 281-290.

75. Cao, Z., et al., Hydrothermal carbonization of biogas digestate: Effect of digestate origin and process conditions. Waste Management, 2019. 100: p. 138-150.

76. Kang, S., et al., Characterization of Hydrochars Produced by Hydrothermal Carbonization of Lignin, Cellulose, $d$-Xylose, and Wood Meal. Industrial \& Engineering Chemistry Research, 2012. 51(26): p. 9023-9031.

77. Dizhbite, T., et al., Lignin - a useful bioresource for the production of sorption-active materials. Bioresource Technology, 1999. 67(3): p. 221-228.

78. Demirbas, A., Adsorption of lead and cadmium ions in aqueous solutions onto modified lignin from alkali glycerol delignication. Journal of Hazardous Materials, 2004. 109(1-3): p. 221-226.

79. Lalvani, S.B., A. Hübner, and T.S. Wiltowski, Chromium adsorption by lignin. Energy Sources, 2000. 22(1): p. 45-56.

80. Mackay, D. and P. Roberts, The influence of pyrolysis conditions on the subsequent gasification of lignocellulosic chars. Carbon, 1982. 20(2): p. 105-111.

81. Mackay, D. and P. Roberts, The dependence of char and carbon yield on lignocellulosic precursor composition. Carbon, 1982. 20(2): p. 87-94. 
82. Khezami, L., et al., Production and characterisation of activated carbon from wood components in powder: Cellulose, lignin, xylan. Powder Technology, 2005. 157(1): p. 48-56.

83. Rodríguez-Mirasol, J., T. Cordero, and J.J. Rodríguez, Activated Carbons from CO2 Partial Gasification of Eucalyptus Kraft Lignin. Energy and Fuels, 1993. 7(1): p. 133-138.

84. Hayashi, J., et al., Preparation of activated carbon from lignin by chemical activation. Carbon, 2000. 38(13): p. 1873-1878.

85. Baklanova, O.N., et al., Preparation of microporous sorbents from cedar nutshells and hydrolytic lignin. Carbon, 2003. 41(9): p. 1793-1800.

86. Kuznetsov, B.N. and M.L. Shchipko, The conversion of wood lignin to char materials in a fluidized bed of AlCuCr oxide catalysts. Bioresource Technology, 1995. 52(1): p. 13-19.

87. Gergova, K., N. Petrov, and S. Eser, Adsorption properties and microstructure of activated carbons produced from agricultural by-products by steam pyrolysis. Carbon, 1994. 32(4): $\mathrm{p}$. 693-702.

88. Gonzalez-Serrano, E., et al., Development of Porosity upon Chemical Activation of Kraft Lignin with $\mathrm{ZnCl} 2$. Industrial and Engineering Chemistry Research, 1997. 36(11): p. 4832-4838.

89. Gonzalez-Serrano, E., et al., Removal of water pollutants with activated carbons prepared from H3PO4 activation of lignin from kraft black liquors. Water Research, 2004. 38(13): p. 30433050.

90. Zou, Y. and B.X. Han, Preparation of activated carbons from Chinese coal and hydrolysis lignin. Adsorption Science and Technology, 2001. 19(1): p. 59-72.

91. Fierro, V., et al., Activated carbons prepared from kraft lignin by phosphoric acid impregnation. Proc. Carbon, 2003.

92. Zhao, X., et al., Fertilizer and activated carbon production by hydrothermal carbonization of digestate. Biomass Conversion and Biorefinery, 2018. 8(2): p. 423-436.

93. Bernardo, M., et al., Porous carbons derived from hydrothermally treated biogas digestate. Waste Management, 2020. 105: p. 170-179.

94. Chaturvedi, V., S. Usangonvkar, and M.V. Shelke, Synthesis of high surface area porous carbon from anaerobic digestate and it's electrochemical study as an electrode material for ultracapacitors. RSC Advances, 2019. 9(62): p. 36343-36350.

95. Yakout, S.M. and G. Sharaf El-Deen, Characterization of activated carbon prepared by phosphoric acid activation of olive stones. Arabian Journal of Chemistry, 2016. 9: p. S1155S1162.

96. Martínez, M.L., et al., Preparation and characteristics of activated carbon from olive stones and walnut shells. Industrial Crops and Products, 2006. 23(1): p. 23-28.

97. Kula, I., et al., Adsorption of Cd(II) ions from aqueous solutions using activated carbon prepared from olive stone by ZnCl2 activation. Bioresource Technology, 2008. 99(3): p. 492-501.

98. Uğurlu, M., A. Gürses, and M. Açıkyıldız, Comparison of textile dyeing effluent adsorption on commercial activated carbon and activated carbon prepared from olive stone by $\mathrm{ZnCl} 2$ activation. Microporous and Mesoporous Materials, 2008. 111(1): p. 228-235.

99. Moreno-Castilla, C., et al., Chemical and physical activation of olive-mill waste water to produce activated carbons. Carbon, 2001. 39(9): p. 1415-1420.

100. Yavuz, R., et al., Influence of preparation conditions on porous structures of olive stone activated by H3PO4. Fuel Processing Technology, 2010. 91(1): p. 80-87.

101. Saleem, J., et al., Production and applications of activated carbons as adsorbents from olive stones. Biomass Conversion and Biorefinery, 2019. 9(4): p. 775-802.

102. Norouzi, O., F.D. Maria, and A. Dutta, Biochar-based composites as electrode active materials in hybrid supercapacitors with particular focus on surface topography and morphology. Journal of Energy Storage, 2020. 29: p. 101291.

103. Alcaraz, L., et al., Preparation and characterization of activated carbons from winemaking wastes and their adsorption of methylene blue. Adsorption Science \& Technology, 2018. 36(56): p. 1331-1351. 
104. Zabaniotou, A., G. Stavropoulos, and V. Skoulou, Activated carbon from olive kernels in a twostage process: Industrial improvement. Bioresource Technology, 2008. 99(2): p. 320-326.

105. Wang, J. and S. Wang, Preparation, modification and environmental application of biochar: $A$ review. Journal of Cleaner Production, 2019. 227: p. 1002-1022.

106. Anfruns, A., et al., New insights into the influence of activated carbon surface oxygen groups on $\mathrm{H} 2 \mathrm{O} 2$ decomposition and oxidation of pre-adsorbed volatile organic compounds. Carbon, 2014. 77: p. 89-98.

107. Wu, L., et al., Effect of liquid-phase 03 oxidation of activated carbon on the adsorption of thiophene. Chemical Engineering Journal, 2014. 242: p. 211-219.

108. Sun, C., C.E. Snape, and H. Liu, Development of Low-Cost Functional Adsorbents for Control of Mercury ( $\mathrm{Hg}$ ) Emissions from Coal Combustion. Energy \& Fuels, 2013. 27(7): p. 3875-3882.

109. Gokce, Y. and Z. Aktas, Nitric acid modification of activated carbon produced from waste tea and adsorption of methylene blue and phenol. Applied Surface Science, 2014. 313: p. 352-359.

110. Dehkhoda, A.M., A.H. West, and N. Ellis, Biochar based solid acid catalyst for biodiesel production. Applied Catalysis A: General, 2010. 382(2): p. 197-204.

111. Dehkhoda, A.M. and N. Ellis, Biochar-based catalyst for simultaneous reactions of esterification and transesterification. Catalysis Today, 2013. 207: p. 86-92.

112. Kastner, J.R., et al., Catalytic esterification of fatty acids using solid acid catalysts generated from biochar and activated carbon. Catalysis Today, 2012. 190(1): p. 122-132.

113. Ormsby, R., J.R. Kastner, and J. Miller, Hemicellulose hydrolysis using solid acid catalysts generated from biochar. Catalysis Today, 2012. 190(1): p. 89-97.

114. Li, S., et al., Biochar based solid acid catalyst hydrolyze biomass. Journal of Environmental Chemical Engineering, 2013. 1(4): p. 1174-1181.

115. Rajapaksha, A.U., et al., Engineered/designer biochar for contaminant removal/immobilization from soil and water: potential and implication of biochar modification. Chemosphere, 2016. 148: p. 276-291.

116. Shafeeyan, M.S., et al., The application of response surface methodology to optimize the amination of activated carbon for the preparation of carbon dioxide adsorbents. Fuel, 2012. 94: p. 465-472.

117. Jansen, R.J.J. and H. van Bekkum, Amination and ammoxidation of activated carbons. Carbon, 1994. 32(8): p. 1507-1516.

118. Stöhr, B., H.P. Boehm, and R. Schlögl, Enhancement of the catalytic activity of activated carbons in oxidation reactions by thermal treatment with ammonia or hydrogen cyanide and observation of a superoxide species as a possible intermediate. Carbon, 1991. 29(6): p. 707720.

119. Salimi, P., et al., Magnetic biochar obtained through catalytic pyrolysis of macroalgae: A promising anode material for Li-ion batteries. Renewable Energy, 2019. 140: p. 704-714.

120. Inyang, M., et al., Synthesis, characterization, and dye sorption ability of carbon nanotubebiochar nanocomposites. Chemical Engineering Journal, 2014. 236: p. 39-46.

121. Premarathna, K.S.D., et al., Biochar-based engineered composites for sorptive decontamination of water: A review. Chemical Engineering Journal, 2019. 372: p. 536-550.

122. Zhang, C., et al., Effective transformation of cellulose to 5-hydroxymethylfurfural catalyzed by fluorine anion-containing ionic liquid modified biochar sulfonic acids in water. Cellulose, 2017. 24(1): p. 95-106.

123. Yu, Y., et al., lonic liquid-induced low temperature graphitization of cellulose-derived biochar for high performance sodium storage. Surface and Coatings Technology, 2021. 412: p. 127034.

124. Kamal, A.S., R. Othman, and N.H. Jabarullah, Preparation and synthesis of synthetic graphite from biomass waste: A review. Systematic Reviews in Pharmacy, 2020. 11(2): p. 881-894.

125. Zhou, X., et al., New notion of biochar: A review on the mechanism of biochar applications in advannced oxidation processes. Chemical Engineering Journal, 2021. 416: p. 129027. 
126. Ma, Y.-z., et al., Magnetic lignin-based carbon nanoparticles and the adsorption for removal of methyl orange. Colloids and Surfaces A: Physicochemical and Engineering Aspects, 2018. 559: p. 226-234.

127. Dai, L., et al., Green mussel-inspired lignin magnetic nanoparticles with high adsorptive capacity and environmental friendliness for chromium(III) removal. International Journal of Biological Macromolecules, 2019. 132: p. 478-486.

128. Huang, C., et al., Boosted selectivity and enhanced capacity of As (V) removal from polluted water by triethylenetetramine activated lignin-based adsorbents. International journal of biological macromolecules, 2019. 140: p. 1167-1174.

129. Cho, D.-W., et al., Fabrication and environmental applications of multifunctional mixed metalbiochar composites (MMBC) from red mud and lignin wastes. Journal of Hazardous Materials, 2019. 374: p. 412-419.

130. Jiang, C., et al., Construction of magnetic lignin-based adsorbent and its adsorption properties for dyes. Journal of hazardous materials, 2019. 369: p. 50-61.

131. Geng, J., F. Gu, and J. Chang, Fabrication of magnetic lignosulfonate using ultrasonic-assisted in situ synthesis for efficient removal of $\mathrm{Cr}($ ) and Rhodamine $B$ from wastewater. Journal of hazardous materials, 2019. 375: p. 174-181.

132. Zhang, Y., et al., Ultrafast adsorption of heavy metal ions onto functionalized lignin-based hybrid magnetic nanoparticles. Chemical Engineering Journal, 2019. 372: p. 82-91.

133. Wu, Q., et al., Lignin-based magnetic activated carbon for p-arsanilic acid removal: Applications and absorption mechanisms. Chemosphere, 2020. 258: p. 127276.

134. Li, Y., et al., Synthesis of magnetic lignin-based hollow microspheres: a highly adsorptive and reusable adsorbent derived from renewable resources. ACS Sustainable Chemistry \& Engineering, 2016. 4(10): p. 5523-5532.

135. Naseer, A., et al., Lignin and Lignin Based Materials for the Removal of Heavy Metals from Waste Water-An Overview. Zeitschrift für Physikalische Chemie, 2019. 233(3): p. 315-345.

136. Ge, Y. and Z. Li, Application of lignin and its derivatives in adsorption of heavy metal ions in water: a review. ACS Sustainable Chemistry \& Engineering, 2018. 6(5): p. 7181-7192.

137. Dessbesell, L., et al., Global lignin supply overview and kraft lignin potential as an alternative for petroleum-based polymers. Renewable and Sustainable Energy Reviews, 2020. 123: p. 109768.

138. Ahvazi, B., et al., Lignin profiling: a guide for selecting appropriate lignins as precursors in biomaterials development. ACS Sustainable Chemistry \& Engineering, 2016. 4(10): p. 50905105.

139. Berlin, A. and M. Balakshin, Industrial lignins: analysis, properties, and applications. Bioenergy Research: Advances and Applications, 2014: p. 315-336.

140. Manufacturers., P.E.A.o.P., Plastics - the facts 2017. 2018. 
Ms. Ref. No.: JAAP-D-21-00084R1

Title: Production and use of biochar from lignin and lignin-rich residues (such as digestate and olive stones) for wastewater treatment

We thank the editor and the reviewers for their interest in our work and for helpful comments that will greatly improve the manuscript and we have tried to do our best to respond to the points raised. The editor and the reviewers have brought up some very good points and we appreciate the opportunity to clarify them better. As indicated below, we have checked all the general and specific comments provided (here indicated in red color) and have made necessary changes accordingly to their indications. Our answers/actions are colored in black.

\section{Reviewer \#1:}

R1C\#1: There are three main elements convincing me to recommend this study for the publication after a major revision: i) Specific focus of authors on lignin-rich agricultural wastes ii). Considering the economic aspects iii) application of lignin-based activated char for wastewater treatment. The authors need to address all these concerns before we go any further:

Answer: We thank the reviewer for his help in improving the paper.

Action: We have addressed reviewers comments very carefully

R1C\#2: The title should be rewritten! It should be short, informative, and off course without parenthesis! The authors may replaced it with: "Production and application of biochar derived from lignin-rich residues for wastewater treatment"

Answer: We thank the reviewer for his help in improving the paper. 
Action: Title has been changed into "Production and application of biochar derived from lignin-rich residues for wastewater treatment"

R1C\#3: Since twelve scholars contributed for doing this research, the corresponding author would better draft a "Authorship Contribution" statement after the conclusion.

Answer: We thank the reviewer for his help in improving the paper.

Action: The author credit statement has been prepared and attached to the submission. Elsevier staff will then insert it in our paper once and if it will be accepted and if the proofs will be available.

R1C\#4: An abstract summarizes, usually in one paragraph of 300 words or less, the major aspects of the entire paper! Herein, $50 \%$ of the abstract is dedicated to the general information! Rewrite this part and focus on major findings and gaps!

Answer: We thank the reviewer for his help in improving the paper.

Action: The abstract has been changed into the following:

About 3 million tons of activated carbon are produced per year and it is mainly used for fluid purification. The objective of this review is to investigate the preparation and production of biochar from lignin which is an important resource available in great quantities (about 100 Million tons per year) and the practical application of it for wastewater treatment. Biochar can be produced through pyrolysis (at temperatures of $600-700^{\circ} \mathrm{C}$ ) and Hydrothermal carbonization (at temperature between 180 $300^{\circ} \mathrm{C}$ ). Subsequent activation can be performed in two ways (physical and chemical) usually at temperatures between $600-800^{\circ} \mathrm{C}$. Chemical activation has the advantage to lower the temperature and also to slightly increase the final yields. The quality of biochar and activated carbon produced from lignin-rich residue can be very high, even though the costs also are higher respect to other fossil derived materials (carbon black, lignite and pet coke).

R1C\#5: The English language used in this manuscript is relatively weak. Can the authors get this manuscript to be proofread by a colleague that is a native English speaker or perhaps with the help of professional English editing? 
Answer: We thank the reviewer for his help in improving the paper.

Action: The paper has been revised by a colleague who is mother tongue

R1C\#6: Page 4 and line 4, The three most abundant compounds on the earths crust are:

$\mathrm{SiO} 2$ (Silicon dioxide) - 42.86\%

$\mathrm{MgO} 2$ (Magnesium oxide) - 35.07\%

$\mathrm{FeO}$ (Ferrous oxide) $-8.97 \%$

You may change this sentence as follows:

"Lignin is the second most abundant biopolymer on earth!"

Answer: We thank the reviewer for his help in improving the paper.

Action: The sentence has been checked and rewritten into "Lignin is the second most abundant compound after cellulose in the world ecosystem."

R1C\#7: Page 4 line 52-59, I can't really follow this part! Please rewrite it.

Answer: We thank the reviewer for his help in improving the paper.

Action: The sentences have been re-written into:

"Together with lignin also lignin rich residues have to be considered, such as digestate and olive pits. Digestate has two fractions: one is liquid and one is solid. The solid can be separated by the liquid and contains a relevant concentration of lignin, because it cannot be digested by the microorganisms which populate the digester. We can calculate the European availability of digestate based on these assumptions: 
- a biogas plant of the power capacity of $500 \mathrm{kWe}$, produces about $10,000 \mathrm{t}$ of digestate, according to [1],

- the total installed capacity of biogas plants in Europe is equal to 12,000 MWe, according to [2].

From the above mentioned data the resulting production of digestate can be calculated and it is equal to about $240 \mathrm{Mt}$, which is a relevant amount.”

R1C\#8: Page 5, lines 13-17, We still can not understand what is the contribution of reference [8] in this field of study! Besides that sentences in lines 15-16 are not grammatically correct! alternative sentence can be as follows:

" In this study, lignin-rich agricultural wastes (e.g. coconut shell and palm shell) have been activated through chemical and physical methods"

Answer: We thank the reviewer for his help in improving the paper.

Action: I have described better the importance of reference [8], using the advised sentence: "" In this study, lignin-rich agricultural wastes (e.g. coconut shell and palm shell) have been activated through chemical and physical methods"

R1C\#9: Page 5, lines 20-22, absolutely the definition of activated carbon is wrong! Without doubt it is not produced from organic substrates. They can be activated by organic substrates! In addition to that, physical activation needs to be incorporated into this definition!

Answer: We thank the reviewer for his help in improving the paper. We have to take into consideration that the chemical definition of organic compound is: "Organic compound, any of a large class of chemical compounds in which one or more atoms of carbon are covalently linked to atoms of other elements, most commonly hydrogen, oxygen, or nitrogen. The few carbon-containing compounds not classified as organic include carbides, carbonates, and cyanides. In principle carbides can be used to produce porous material". So, we changed the sentence into the review substituting "organic" with "carbon-containing". If there is not carbon, I don't think it is possible to talk about activated carbon, so I believe we are in agreement with this new definition. 
Action: I have changed the sentence into: "Activated charcoal can be considered as a highly porous material, which can be produced from carbon containing substrates through chemical and physical activation and it is used for many applications, among them for the sorption of contaminants from fluids [3]."

R1C\#10: Page 6 and lines 24-27, the paragraph began with THOSE! Are you pointing out to specific functional groups! I cannot see anything about functional groups in the previous paragraph!

Answer: We thank the reviewer for his help in improving the paper.

Action: I have changed the sentence into: "The functional groups in activated carbons derive from the elements which are present in the raw material composition, some of those can be: $\mathrm{O}, \mathrm{S}, \mathrm{H}, \mathrm{N}, \mathrm{Cl}, \mathrm{K}$, $\mathrm{Na}, \mathrm{Mg}, \mathrm{Ca}[4-6] . "$

R1C\#11: It is really good to bring an example of new reactor but, in this case, we expect to hear about it's advantages and disadvantages! What is the main reason for authors that they have specifically focused on this reactor?

Answer: We thank the reviewer for his help in improving the paper.

Action: We have added the following description: " This reactor is capable to address the micropollutants problem which is of paramount importance in the tertiary wastewater treatment. Among micropollutants we find: pesticides, pharmaceuticals, cosmetics, flame retardants, perfumes, waterproofing agents, plasticizers and insulating foams [7]. The reactor is 5 meters high and has a surface area of $4 \mathrm{~m}^{2}$. The water flows upstream through a packed bed of pulverized activated carbon (PAC). New PAC is continuously injected into the reactor, while the same quantity of exhausted PAC is removed. The overall solid retention time of the PAC is about 5-7 days, while the total concentration of the PAC inside the reactor is 5-10 g/L."

R1C\#13: What is Harry March's book about? Citing without explanation!

Answer: We thank the reviewer for his help in improving the paper. 
Action: We have modified the citing sentence into: "Dealing with the AC market in the US, $50 \%$ of it is used in drinking water sanitation, $40 \%$ is used in wastewater treatment and the remaining is used in ground water treatment, as it is reported in the book of Harry Marsh and Francisco Rodríguez-Reinoso, which takes into account carbon porosity modelling, activation, use and applications of activated carbons [8]."

R1C\#14: Page 11 and lines 33-40, I was only wondering if wastewater treatment and technical economic performance can be considered as a production method of activated charcoal? Please rewrite this part!

Answer: We thank the reviewer for his help in improving the paper.

Action: We have modified figure 5 in this way:



Figure 5: Literature review, LIG = lignin; $\mathrm{HTC}=$ Hydrothermal Carbonization; $\mathrm{PH}=$ Physical; $\mathrm{CH}=$ chemical; DIG = digestate; OS = Olive Stones

We have in this way excluded the technical economic analysis and the wastewater treatment. Besides this we have re-written the paragraph in the following way:

"As it can be seen from Figure 5, the following topics have been identified for the production of activated charcoal from lignin: pyrolysis; hydrothermal carbonization (HTC); physical activation; chemical activation; modification. Besides these topics the review will provide also information on adsorption process modelling (Ad modelling); wastewater treatment and technical economic performance."

We have also deleted the following sentences: " This last aspect is considered only for lignin, while for digestate and olive stone it is neglected. This is due to the wider market which is now growing for lignin valorization, as also demonstrated by the EU cost action LIGNOCOST (https://lignocost.eu/). It can be 
easily understood that in the case of lignin it is very important to discern the most economically attractive uses."

R1C\#15: Page 11 and line 55, The sentence start with THIS! What is "this last aspect"? and the second part of sentence should be as follows: It is neglected for digested and olive stone!

Answer: We thank the reviewer for his help in improving the paper.

Action: The sentence has been deleted.

R1C\#16: Again line 42, the sentence starts with THIS! are you saying that lack of research on digested and olive stone is due to the growing market for lignin! It doesn't really make sense! Please clarify this section!

Answer: We thank the reviewer for his help in improving the paper.

Action: The sentence has been deleted.

R1C\#17: Page 16, line 47, please give examples of physical activations? Aren't they pyrolysis or HTC?

Answer: We thank the reviewer for his help in improving the paper.

Action: We have re-written and explained better the sentence:

"Another important aspect to take into consideration is that if we want to obtain activated carbon as a final product, we have to consider that two ways are possible: direct activation (physical or chemical) or thermal treatment (pyrolysis or HTC) which is then followed by activation (physical or chemical). In this sense biochar can be an intermediate product for activated charcoal production [9]. Concerning physical activation, this can be defined as a gasification process, performed using $\mathrm{CO} 2$ or steam as gasifying agents. Chemical activation is usually a pyrolysis process using acids or basic catalysts. These catalysts can be loaded into the raw materials pores through imbibition or simply mixed with the raw material particles through ball milling."

R1C\#18: Figure 14, The authors are comparing AC yields for different activation methods! The question is if they are obtained under the same reactor and operational conditions?

Answer: We thank the reviewer for his help in improving the paper.

Action: We have re-written and explained better the sentence:

"Dealing with the final yields of activated carbons, some values are presented in Figure 14. Dealing with reactor conditions, in [10] we see that pyrolysis is performed with a flow of nitrogen equal to 10 
$\mathrm{L} / \mathrm{min}$. The reactor is represented by a muffle furnace. It was heated at $600^{\circ} \mathrm{C}$ with a heating rate of $10^{\circ} \mathrm{C} / \mathrm{min}$. The reaction lasted for 2 hours. The HTC tests were instead conducted in an autoclave with a maximum capacity of $250 \mathrm{~mL}$. The autoclaves were filled to $70 \%$ of the volume with a mixture of biomass and distilled water with a weight ration of 20:80. The autoclave was then heated to $220^{\circ} \mathrm{C}$ in one hour; then it was left at constant temperature for five hours. The final pressure of the reactor ranged between 27 and 51 bar. The hydrochar was recovered by filtration and then dried. In [11] a vessel of volume $250 \mathrm{~mL}$ was also used. This was charged with $21.32 \mathrm{~g}$ of solid digestate, $153.69 \mathrm{~g}$ of liquid digestate and $5.04 \mathrm{~g}$ of anhydrous citric acid powder (to control the $\mathrm{pH}$ ). The feedstock resulted to have $15 \mathrm{wt} . \%$ dry matter content and $\mathrm{pH}$ equal to 5 . The vessel was filled for $70 \%$ of the total volume. HTC was performed at 3 temperatures: $190^{\circ} \mathrm{C}, 220^{\circ} \mathrm{C}$ and $250^{\circ} \mathrm{C}$. The reactor heating phase lasted for 45 minutes, while the reaction lasted for 3 hours. During all the reaction phase the reagents were constantly mixed. In [12] olive stones are ground dried and sieved and then they were mixed with sulfuric acid in different concentrations $(70,80$ and $90 \%)$ in a mas ratio of $1 \mathrm{~g}$ of olive stone per 4 grams of sulfuric acid. The mixture was mixed for 4 hours at $85^{\circ} \mathrm{C}$ to assure penetration of sulfuric acid in the pores of the olive stone. After imbibition or impregnation, the olive stones loaded with sulfuric acid were carbonized in a vertical furnace at the temperature of $500^{\circ} \mathrm{C}$ with a flow of nitrogen equal to 200 $\mathrm{mL} / \mathrm{min}$. The heating rate was $3^{\circ} \mathrm{C} / \mathrm{min}$ and holding time was 2 hours. After cooling the obtained activated carbon it was washed with distilled water until reaching a $\mathrm{pH}$ of 6 in the residual washing liquid. Then it was dried again. In [13] olive stones were first pyrolyzed at $600^{\circ} \mathrm{C}$ for 1 hour in a muffle furnace; then chemical activation was performed with $\mathrm{KOH}$ at different concentrations $(50$ and $75 \%$ $\mathrm{w} / \mathrm{w}$ ) at a ratio between $\mathrm{KOH}$ and char of 1:1 in weight. Activation temperature was $900^{\circ} \mathrm{C}$ in nitrogen atmosphere for 1 hour. In [14] olive stones are mixed with $\mathrm{ZnCl} 2$ at different concentrations $(10 \%, 20 \%$ and $30 \%$ ). Activation was performed in a muffle furnace at the temperature of $650^{\circ} \mathrm{C}$ for 2 hours with a nitrogen flow of $150 \mathrm{~cm}^{3} / \mathrm{min}$ for 2 hours. Activated carbons were washed with a concentration of 0.5 $\mathrm{N} \mathrm{HCl}$ and then dried."

R1C\#19: Various new chemical and physical activations have been mesmerized here: 10.1016/j.est.2020.101291. I recommend this work to strengthen your review paper!

Answer: We thank the reviewer for his help in improving the paper.

Action: We have cited the paper: "Further detail on activation process are proposed in [15]."

R1C\#20: Figure 16 needs to be designed again! Add thermochemical and separation methods! Plus the last arrow named "study" is unknown! What is this for?

Answer: We thank the reviewer for his help in improving the paper. We have explained all the processes in detail in a new figure.

Action: We have added the following figure: 


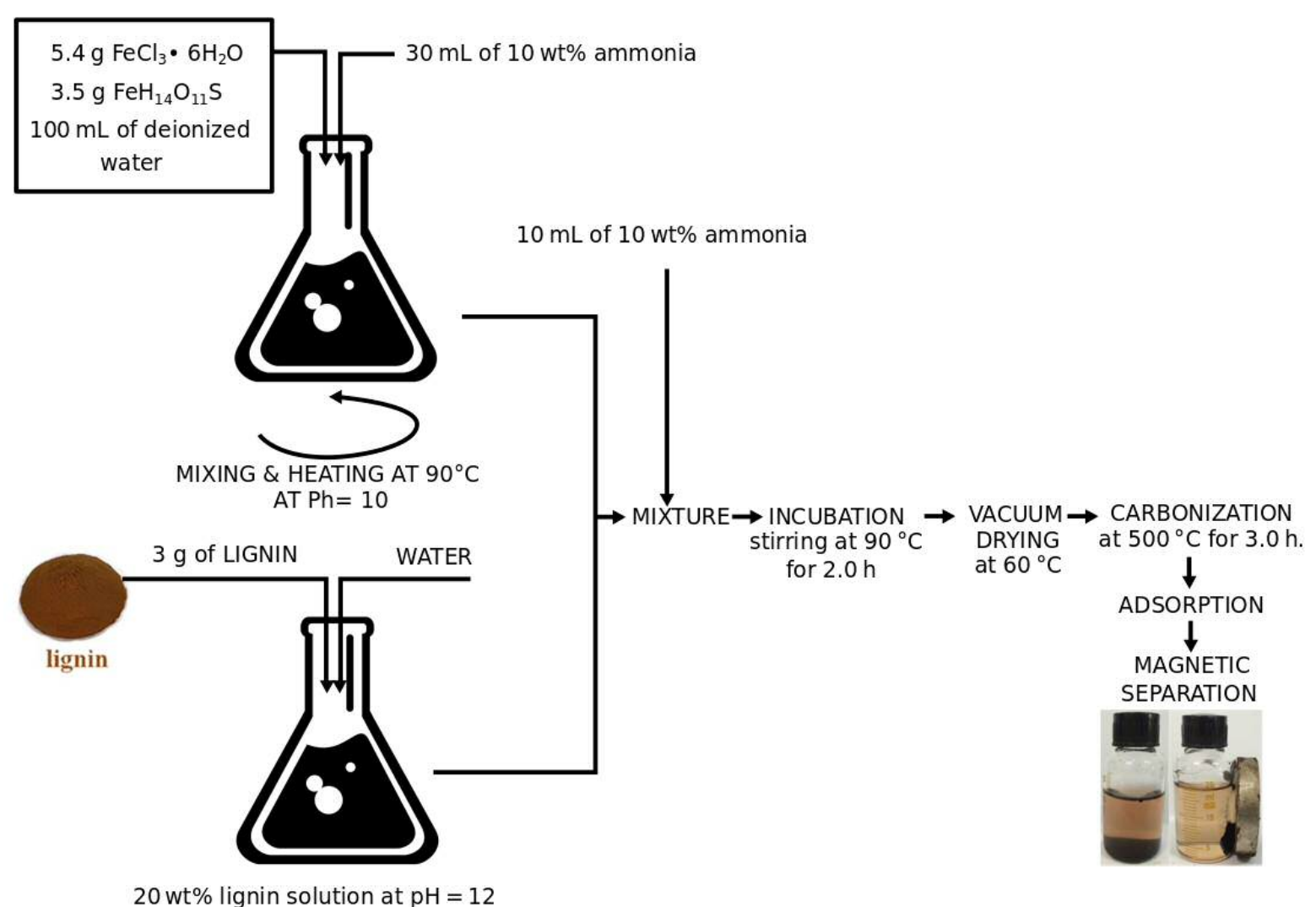

\section{Reviewer \#2:}

R2C\#1: In this paper (JAAP-D-21-00084), the authors consulted a large amount of literature and collected a large amount of data. This paper reviewed the adsorption research of biochar from many aspects. However, there are still some errors and improper statements in the current manuscript. Therefore, a minor revision is necessary and significant improvements are suggested before publication. The specific comments are as follows:

Answer: We thank the reviewer for his help in improving the paper.

Action: We have carefully performed the advised changes.

R2C\#2: The title. It is recommended to delete the words "(such as digestate and olive stones)".

Answer: We thank the reviewer for his help in improving the paper. 
Action: Title has been changed into "Production and application of biochar derived from lignin-rich

residues for wastewater treatment"

R2C\#3: The title of this paper is about biochar, but the author mentioned activated carbon many times in the manuscript and used a lot of space to introduce it.

Answer: We thank the reviewer for his help in improving the paper.

Action: We thank the reviewer for this kind comment, biochar production and activation has been

explained better in the following paragraph:

"Dealing with the final yields of activated carbons, some values are presented in Figure 14. Dealing with reactor conditions, in [10] we see that pyrolysis is performed with a flow of nitrogen equal to 10 $\mathrm{L} / \mathrm{min}$. The reactor is represented by a muffle furnace. It was heated at $600^{\circ} \mathrm{C}$ with a heating rate of $10^{\circ} \mathrm{C} / \mathrm{min}$. The reaction lasted for 2 hours. The HTC tests were instead conducted in an autoclave with a maximum capacity of $250 \mathrm{~mL}$. The autoclaves were filled to $70 \%$ of the volume with a mixture of biomass and distilled water with a weight ration of $20: 80$. The autoclave was then heated to $220^{\circ} \mathrm{C}$ in one hour; then it was left at constant temperature for five hours. The final pressure of the reactor ranged between 27 and 51 bar. The hydrochar was recovered by filtration and then dried. In [11] a vessel of volume $250 \mathrm{~mL}$ was also used. This was charged with $21.32 \mathrm{~g}$ of solid digestate, $153.69 \mathrm{~g}$ of liquid digestate and $5.04 \mathrm{~g}$ of anhydrous citric acid powder (to control the $\mathrm{pH}$ ). The feedstock resulted to have $15 \mathrm{wt} . \%$ dry matter content and $\mathrm{pH}$ equal to 5 . The vessel was filled for $70 \%$ of the total volume. HTC was performed at 3 temperatures: $190^{\circ} \mathrm{C}, 220^{\circ} \mathrm{C}$ and $250^{\circ} \mathrm{C}$. The reactor heating phase lasted for 45 minutes, while the reaction lasted for 3 hours. During all the reaction phase the reagents were constantly mixed. In [12] olive stones are ground dried and sieved and then they were mixed with sulfuric acid in different concentrations $(70,80$ and $90 \%)$ in a mas ratio of $1 \mathrm{~g}$ of olive stone per 4 grams of sulfuric acid. The mixture was mixed for 4 hours at $85^{\circ} \mathrm{C}$ to assure penetration of sulfuric acid in the pores of the olive stone. After imbibition or impregnation, the olive stones loaded with sulfuric acid were carbonized in a vertical furnace at the temperature of $500^{\circ} \mathrm{C}$ with a flow of nitrogen equal to 200 $\mathrm{mL} / \mathrm{min}$. The heating rate was $3^{\circ} \mathrm{C} / \mathrm{min}$ and holding time was 2 hours. After cooling the obtained activated carbon it was washed with distilled water until reaching a $\mathrm{pH}$ of 6 in the residual washing liquid. Then it was dried again. In [13] olive stones were first pyrolyzed at $600^{\circ} \mathrm{C}$ for 1 hour in a muffle furnace; then chemical activation was performed with $\mathrm{KOH}$ at different concentrations $(50$ and $75 \%$ $\mathrm{w} / \mathrm{w}$ ) at a ratio between $\mathrm{KOH}$ and char of $1: 1$ in weight. Activation temperature was $900^{\circ} \mathrm{C}$ in nitrogen atmosphere for 1 hour. In [14] olive stones are mixed with $\mathrm{ZnCl} 2$ at different concentrations $(10 \%, 20 \%$ and $30 \%$ ). Activation was performed in a muffle furnace at the temperature of $650^{\circ} \mathrm{C}$ for 2 hours with a nitrogen flow of $150 \mathrm{~cm}^{3} / \mathrm{min}$ for 2 hours. Activated carbons were washed with a concentration of 0.5 $\mathrm{N} \mathrm{HCl}$ and then dried."

R2C\#4: In the section of 1.2 Charcoal and activated charcoal production, the definition of activated charcoal is too general. The definition was inappropriate and unclear. In addition, the introduction of biochar should be added to the paper.

Answer: We thank the reviewer for his help in improving the paper. 
Action: We have inserted the following explanation:

"Charcoal (also indicated as char) is the solid product of the pyrolysis of biomass, this can be used in many ways, if it is used as soil amendment it is often addressed as "biochar", while if it is used as a fuel it is addressed as "biocarbon". Charcoal can be used in many cases as a precursor of activated carbon.

In this paper we consider a particular kind of biomass, which is represented by lignin rich biomass. This is very favorable to be used to produce charcoal and activated carbon because the yields of solid products obtained from the pyrolysis of lignin is surely greater than that obtained from cellulose and hemicellulose."

R2C\#5: The names of pyrolysis products in the manuscript include biochar, char, charcoal, etc. They are not the same carbon material.

Answer: We thank the reviewer for his help in improving the paper. We have explained about this in the previous point.

Action: See previous point number 4.

R2C\#6: In the section of 4.4.3 Lignin and lignin-rich substrates modification processes. The author's classification of biochar modification methods is unreasonable. For example, sulfuric acid can also change the properties of biochar through oxidation; nitric acid may provide biochar with nitrogenous groups such as amino groups. Furthermore, the modification methods of biochar are far more than the three mentioned in this section. Why were only these three introduced? Compared with the modification methods not introduced, what are their unique advantages?

Answer: We thank the reviewer for his help in improving the paper.

Action: The paragraph has been completely re-written thanks for this comment:

The most interesting way to modify the charcoal is to functionalize its surface as it is explained in [16]. In fact, the charcoal produced through pyrolysis and hydrothermal carbonization has generally a low number of functional groups, such as: $\mathrm{C}-\mathrm{O}-\mathrm{C}, \mathrm{C}=\mathrm{O}$ and $\mathrm{OH}$. It has also a limited surface area and porosity. Surface modification of the charcoal can be performed through the following processes [17]:

- oxidation

- basic modification (eg. amination);

- $\quad$ acid modification (eg. sulfonation);

- metal salts or metal oxides modification

- biochar modification by carbon material (carbon nanotubes and graphene); 
- biochar composite material;

- biochar modification by ionic liquids

- graphitization of biochar

- heteroatom doped biochar

Oxidation can be performed using the following agents: $\mathrm{H}_{2} \mathrm{O}_{2}, \mathrm{O}_{3}, \mathrm{KMnO}_{4}$ and $\mathrm{HNO}_{3}$ [18-21]. These reagents are useful if we want to introduce into the char functional groups such as carboxyl, phenolic hydroxyl, lactones and peroxides. Sulfonation is usually performed using $\mathrm{H}_{2} \mathrm{SO}_{4}$ and its derivatives (e.g. fuming $\mathrm{H}_{2} \mathrm{SO}_{4}$ and $\mathrm{CISO}_{3} \mathrm{H}$ ). Sulfonation is performed to introduce $\mathrm{SO}_{3} \mathrm{H}$ groups in the charcoal [2226]. Other possible acids to be used in acid modification of biochar are: hydrochloric acid, sulfuric acid, nitric acid, phosphoric acid, oxalic acid and citric acid, according to [27].

Amination is usually performed through $\mathrm{NH}_{3}$ treatment at high temperatures [28-30]. Other possible modifications include the use of amino-containing compounds, such as: 3-chloropropylamine, tris(2aminoethyl)amine, and polyethylenimine. These treatments are more environmentally friendly than the treatment with $\mathrm{NH}_{3}$ because the production of $\mathrm{NH}_{3}$ is highly energy intensive and also polluting. Amino loaded charcoal has the important advantage of being able to chemically retain acidic pollutants. Other common alkaline agents used in biochar modification are $\mathrm{KOH}$ and $\mathrm{NaOH}$.

Metal salts or metal oxides modification is used to enhance the adsorption of particular pollutants (eg. anionic dyes); increase magnetic properties by modifying biochar with iron; enhance catalytic properties of biochar [17, 31].

Carbon modification of biochar consists in using it as a support for more performing carbon materials, like nanotubes or graphene [32]. This biochar already represents a composite, other kind of composites based on biochar can be obtained when it is modified with clay, see [33]; also this type of modification can have significant effects on the performances of biochar in adsorption processes.

Biochar modification with ionic liquids is documented in the work of [34]. This is a quite new application. Ionic liquids are also used to graphitize biochar, as shown in [35]. Graphitized biochar can 
be produced by treating it at very high temperatures [36] and with different reagents its final use can be in Advanced Oxidation Processes (AOPs), as shown in [37].

A very common example of heteroatom doped biochar is that obtained suing urea to insert a $\mathrm{N}$ atom in the biochar, see [37]. Other possible doping can be performed also with Sulfur.

R2C\#7: "Amino loaded charcoal has the important advantage of being able to chemically retain acidic pollutants." What does it mean? Please introduce in detail.

Answer: We thank the reviewer for his help in improving the paper. We have explained about this in the previous point.

Action: See previous point.

R2C\#8: "Lignin used as a precursor for the preparation of magnetic activated charcoal has been investigated and reviewed based on relevant articles published." The authors did not have much introduction to magnetic biochar.

Answer: We thank the reviewer for his help in improving the paper. We have explained about this in the previous point.

Action: See previous point.

\section{Bibliography}

1. Noche, P.V.P.B., A review of the current digestate distribution models: storage and transport www.witpress.com, ISSN 1743-3541 (on-line) WIT Transactions on Ecology and The Environment, Vol 202, (C) 2016 WIT Press, doi:10.2495/WM160311, 2016.

2. Xue, S., et al., A systematic comparison of biogas development and related policies between China and Europe and corresponding insights. Renewable and Sustainable Energy Reviews, 2020. 117: p. 109474.

3. Hagemann, N., et al., Activated Carbon, Biochar and Charcoal: Linkages and Synergies across Pyrogenic Carbon's ABCs. Water, 2018. 10(2): p. 182.

4. Chiang, H.-L., C.P. Huang, and P.C. Chiang, The surface characteristics of activated carbon as affected by ozone and alkaline treatment. Chemosphere, 2002. 47(3): p. 257-265.

5. Oh, W.-C., H.-J. Lee, and J.-S. Bae, REMOVAL EFFICIENCY OF THE POLLUTANTS BY MULTILAYERED METAL TREATED CARBON FILTER. Environmental Engineering Research, 2004. 9(5): p. 193-200.

6. Puziy, A.M., et al., XPS and NMR studies of phosphoric acid activated carbons. Carbon, 2008. 46(15): p. 2113-2123. 
7. Kim, M.-K. and K.-D. Zoh, Occurrence and removals of micropollutants in water environment. Environmental Engineering Research, 2016. 21(4): p. 319-332.

8. Marsh, H. and F.R. Reinoso, Activated carbon. 2006: Elsevier.

9. Suhas, P.J.M. Carrott, and M.M.L. Ribeiro Carrott, Lignin - from natural adsorbent to activated carbon: A review. Bioresource Technology, 2007. 98(12): p. 2301-2312.

10. Rodríguez Correa, C., et al., Influence of the Carbonization Process on Activated Carbon Properties from Lignin and Lignin-Rich Biomasses. ACS Sustainable Chemistry \& Engineering, 2017. 5(9): p. 8222-8233.

11. Zhao, X., et al., Fertilizer and activated carbon production by hydrothermal carbonization of digestate. Biomass Conversion and Biorefinery, 2018. 8(2): p. 423-436.

12. Yakout, S.M. and G. Sharaf El-Deen, Characterization of activated carbon prepared by phosphoric acid activation of olive stones. Arabian Journal of Chemistry, 2016. 9: p. S1155S1162.

13. Martínez, M.L., et al., Preparation and characteristics of activated carbon from olive stones and walnut shells. Industrial Crops and Products, 2006. 23(1): p. 23-28.

14. Kula, I., et al., Adsorption of Cd(II) ions from aqueous solutions using activated carbon prepared from olive stone by $\mathrm{ZnCl} 2$ activation. Bioresource Technology, 2008. 99(3): p. 492501.

15. Norouzi, O., F.D. Maria, and A. Dutta, Biochar-based composites as electrode active materials in hybrid supercapacitors with particular focus on surface topography and morphology. Journal of Energy Storage, 2020. 29: p. 101291.

16. Liu, W.-J., H. Jiang, and H.-Q. Yu, Thermochemical conversion of lignin to functional materials: a review and future directions. Green Chemistry, 2015. 17(11): p. 4888-4907.

17. Wang, J. and S. Wang, Preparation, modification and environmental application of biochar: $A$ review. Journal of Cleaner Production, 2019. 227: p. 1002-1022.

18. Anfruns, A., et al., New insights into the influence of activated carbon surface oxygen groups on $\mathrm{H} 2 \mathrm{O} 2$ decomposition and oxidation of pre-adsorbed volatile organic compounds. Carbon, 2014. 77: p. 89-98.

19. Wu, L., et al., Effect of liquid-phase $\mathrm{O3}$ oxidation of activated carbon on the adsorption of thiophene. Chemical Engineering Journal, 2014. 242: p. 211-219.

20. Sun, C., C.E. Snape, and H. Liu, Development of Low-Cost Functional Adsorbents for Control of Mercury (Hg) Emissions from Coal Combustion. Energy \& Fuels, 2013. 27(7): p. 3875-3882.

21. Gokce, Y. and Z. Aktas, Nitric acid modification of activated carbon produced from waste tea and adsorption of methylene blue and phenol. Applied Surface Science, 2014. 313: p. 352359.

22. Dehkhoda, A.M., A.H. West, and N. Ellis, Biochar based solid acid catalyst for biodiesel production. Applied Catalysis A: General, 2010. 382(2): p. 197-204.

23. Dehkhoda, A.M. and N. Ellis, Biochar-based catalyst for simultaneous reactions of esterification and transesterification. Catalysis Today, 2013. 207: p. 86-92.

24. Kastner, J.R., et al., Catalytic esterification of fatty acids using solid acid catalysts generated from biochar and activated carbon. Catalysis Today, 2012. 190(1): p. 122-132.

25. Ormsby, R., J.R. Kastner, and J. Miller, Hemicellulose hydrolysis using solid acid catalysts generated from biochar. Catalysis Today, 2012. 190(1): p. 89-97.

26. Li, S., et al., Biochar based solid acid catalyst hydrolyze biomass. Journal of Environmental Chemical Engineering, 2013. 1(4): p. 1174-1181.

27. Rajapaksha, A.U., et al., Engineered/designer biochar for contaminant removal/immobilization from soil and water: potential and implication of biochar modification. Chemosphere, 2016. 148: p. 276-291.

28. Shafeeyan, M.S., et al., The application of response surface methodology to optimize the amination of activated carbon for the preparation of carbon dioxide adsorbents. Fuel, 2012. 94: p. 465-472. 
29. Jansen, R.J.J. and H. van Bekkum, Amination and ammoxidation of activated carbons. Carbon, 1994. 32(8): p. 1507-1516.

30. Stöhr, B., H.P. Boehm, and R. Schlögl, Enhancement of the catalytic activity of activated carbons in oxidation reactions by thermal treatment with ammonia or hydrogen cyanide and observation of a superoxide species as a possible intermediate. Carbon, 1991. 29(6): p. 707720.

31. Salimi, P., et al., Magnetic biochar obtained through catalytic pyrolysis of macroalgae: $A$ promising anode material for Li-ion batteries. Renewable Energy, 2019. 140: p. 704-714.

32. Inyang, M., et al., Synthesis, characterization, and dye sorption ability of carbon nanotubebiochar nanocomposites. Chemical Engineering Journal, 2014. 236: p. 39-46.

33. Premarathna, K.S.D., et al., Biochar-based engineered composites for sorptive decontamination of water: A review. Chemical Engineering Journal, 2019. 372: p. 536-550.

34. Zhang, C., et al., Effective transformation of cellulose to 5-hydroxymethylfurfural catalyzed by fluorine anion-containing ionic liquid modified biochar sulfonic acids in water. Cellulose, 2017. 24(1): p. 95-106.

35. Yu, Y., et al., lonic liquid-induced low temperature graphitization of cellulose-derived biochar for high performance sodium storage. Surface and Coatings Technology, 2021. 412: p. 127034.

36. Kamal, A.S., R. Othman, and N.H. Jabarullah, Preparation and synthesis of synthetic graphite from biomass waste: A review. Systematic Reviews in Pharmacy, 2020. 11(2): p. 881-894.

37. Zhou, X., et al., New notion of biochar: A review on the mechanism of biochar applications in advannced oxidation processes. Chemical Engineering Journal, 2021. 416: p. 129027. 
Biochar can be produced through pyrolysis (at temperatures of $600-700^{\circ} \mathrm{C}$ )

Hydrothermal carbonization is performed at temperatures between $180-300^{\circ} \mathrm{C}$.

Activation can be performed in two ways (physical and chemical)

Activation temperature ranges between $600-800^{\circ} \mathrm{C}$.

Chemical activation has the advantage to lower the final activation temperature 


\section{Production and use of biochar from lignin and lignin-rich residues (such as digestate and olive stones) for wastewater treatment}

Eid Gul ${ }^{\mathrm{a}}$, Khalideh Al Bkoor Alrawashdeh ${ }^{\mathrm{b}}$, Ondrej Masek ${ }^{\mathrm{c}}, \emptyset_{\text {yvind Skreiberg }}^{\mathrm{d}}$, Andrea Corona ${ }^{\mathrm{e}}$, Mauro Zampillie, Liang Wang ${ }^{\mathrm{c}}$, Petros Samaras ${ }^{\mathrm{f}}$, Qing Yang ${ }^{\mathrm{g}}$, Hewen Zhou ${ }^{\mathrm{g}}$, Pietro Bartocci ${ }^{\mathrm{e}}$, Francesco Fantozzi ${ }^{\mathrm{e}}$


Perugia, Italy

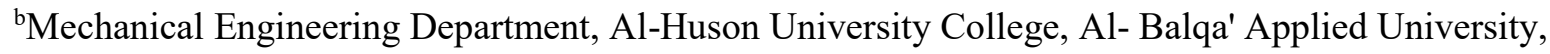
Al-Huson- Irbid, P. O. Box 50, 21510, Jordan

${ }^{ }$UK Biochar Research Centre, School of GeoSciences, University of Edinburgh, Edinburgh, EH9 3FF, United Kingdom

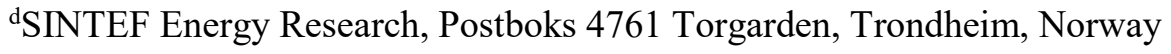

eDepartment of Engineering, University of Perugia, Via G. Duranti 67, Perugia, 06125, Italy

fLaboratory of Technologies of Environmental Protection and Utilization of Food By-Products,

Department of Food Science and Technology, International Hellenic University, Thessaloniki, GR57400, Greece

${ }^{g}$ State Key Laboratory of Coal Combustion, Huazhong University of Science and Technology, Wuhan 430074, PR China

${ }^{\mathrm{h}}$ China-EU Institute for Clean and Renewable Energy, Huazhong University of Science and Technology, Wuhan 430074, PR China

iDepartment of New Energy Science and Technology, School of Energy and Power Engineering, ${ }^{j}$ Huazhong University of Science and Technology, Wuhan 430074, PR China John A. Paulson School of Engineering and Applied Sciences, Harvard University, Cambridge, MA 02138, USA 
Abstract: Clean water is an essential source of life, and its demand is continuously increasing with the rapid growth in population, while the freshwater reserves are also depleting. A large amount of wastewater is released by different industries, which is affecting the environment as well as polluting the freshwater reserves. Recycling and treatment of wastewater are highly essential to meet the demand for clean water and to protect the environment. Activated carbon can be used in primary, secondary and tertiary wastewater treatment steps. It can be used to capture pollutants which stop microbial activity or to produce clean water with high purity. About 3 million tons of activated carbon are produced per year and it is mainly used for fluid purification. The objective of this review is to investigate the preparation and production of biochar from lignin which is an important resource available in great quantities (about 100 Million tons per year) and the practical application of it for wastewater treatment. Biochar can be produced through pyrolysis (at temperatures of $600-700^{\circ} \mathrm{C}$ ) and Hydrothermal carbonization (at temperature between $180-300^{\circ} \mathrm{C}$ ). Subsequent activation can be performed in two ways (physical and chemical) usually at temperatures between $600-800^{\circ} \mathrm{C}$. The quality of biochar and activated carbon produced from lignin-rich residue can be very high, even though the costs also are higher respect to other fossil derived materials (carbon black, lignite and pet coke).

Keywords, Biochar technologies; Wastewater treatment, Heavy metals; Dyes; Pyrolysis; HTC

\section{INTRODUCTION}

\subsection{Lignin as a subproduct}

Lignin is becoming a more and more abundant resource, as this is a subproduct of many important industrial sectors. It can for example be produced from the paper industry, by recovering it from the black liquor fraction. The total lignin amount produced by the pulping industry is estimated to be around 40 million tons per year [1]. This lignin accounts for about $55 \%$ of the total lignin production [2]. The remaining production is represented mainly by lignosulfonate lignin (a byproduct from the production of wood pulp), while a small part is represented by organosolv lignin (mainly coming from $2^{\text {nd }}$ 
generation bioethanol production). The total lignin production in 2015 was estimated to be about 100 tons per year, and it is forecasted to increase of about $20 \%$ in 2025 [2]. Lignin is the second most abundant compound after cellulose in the plant world.



Figure 1. Lignin model structures. Model lignin oligomers are shown for: (a) A gymnosperm/softwood, (b) An angiosperm/dicot/hardwood, and (c) A (commelinid) monocot [3].

Lignin is a branched polymer, where the different units can be classified in $\mathrm{H}, \mathrm{G}$ and $\mathrm{S}$ monolignols [3]. The composition of lignin varies between different vegetal phyla. The detailed biological synthesis of the monolignols is shown in [4].

Lignin can be used to produce many chemicals and materials, among which: adhesives, carbon fibers, thermoplastics, emulsifiers, concrete mixtures etc. These routes are under analysis in many projects at European level and especially under the LIGNOCOST action, which is chaired by Wageningen University (Netherland) and co-chaired by VTT (Finland), see: https://lignocost.eu/.

Together with lignin also lignin rich residues have to be considered, such as digestate (at least the solid separated part) and olive pits. If we assume that for an average biogas plant of the power capacity of $500 \mathrm{kWe}$,about $10,000 \mathrm{t}$ of digestate are produced [5], given a total installed capacity of 12,000 MWe in the EU [6] we can assume a production of digestate of about $240 \mathrm{Mt}$, which is relevant. 
Assuming that the digestate has a remaining solid content of $10 \%$ (which can be also much higher), we

have a production of solid digestate of about $24 \mathrm{Mt}$ per year. If we consider olive stones, we have to take into account that the average global production of olives is about $3 \mathrm{Mt}$ per year, they contain about $18 \mathrm{wt} \%$ [7] of stones and so about $0.54 \mathrm{Mt}$ of olive stones are produced per year.

\subsection{Charcoal and activated charcoal production}

All these lignin rich bio-based compounds can be used to produce activated charcoal, see for example [8]. In this contribution we see that agricultural residues, which are rich in lignin are e.g. coconut shell and palm shell. So, what is activated charcoal and how can we produce it? Activated charcoal can be considered as a highly porous material, which can be produced from organic substrates and it is used for many applications, among them for the sorption of contaminants from fluids [9]. The production of activated carbon is usually more complex than that of biochar. Assuming that activated carbon is produced from biomass, biochar can be a precursor in its supply chain. So, if biochar can be produced through pyrolysis and hydrothermal carbonization (HTC), as a second step activation is then required to produce the final activated carbon from it. We don't consider gasification as a thermal treatment to produce biochar because in the case of activated carbons the biochar obtained from gasification would have a high ash content and this can limit the activation phase and the formation of a high porosity material.

As we will see in this review, activation can be performed by using chemical and physical methods, the final aim of this step is to increase the porosity of the biochar, which can be measured with the Brunauer-Emmett-Teller (BET) analysis. Dealing with pyrolysis, this is a thermal treatment, which happens in the absence of oxygen and produces three phases: a liquid (pyrolysis oil) a solid (char) and a gas (pyrogas). The process begins at temperature around $300^{\circ} \mathrm{C}$ and can continue till very high temperatures are reached (usually not more than $900^{\circ} \mathrm{C}$ ) [10]. Like the pyrolysis process, also hydrothermal carbonization is a biochar production process, which happens at temperatures of about $180-300^{\circ} \mathrm{C}$ in a suspension containing biomass and water, with a pressure high enough to prevent water evaporation, for several hours [11]. Main reaction mechanisms happening in the HTC process are hydrolysis, dehydration, decarboxylation, aromatization, and condensation polymerization. 
Physical activation can be performed using gaseous reagents (air or $\mathrm{CO}_{2}$ ), steam, or both [12]. The temperature usually is about $700^{\circ} \mathrm{C}$ [13]. In chemical activation the temperature is lower, compared to the physical one (about $500^{\circ} \mathrm{C}$ ). In both types of activation, the chemical reactions happening are mainly based on oxidation. In the first case oxidation is performed by gases or steam (in a similar way in which the gasification process is performed) and in the second case oxidation is performed by chemical agents which are adsorbed on the charcoal powder to be activated. Chemical agents can be $\mathrm{ZnCl}_{2}$ and $\mathrm{H}_{3} \mathrm{PO}_{4}$ [14-16]; $\mathrm{H}_{2} \mathrm{SO}_{4}, \mathrm{~K}_{2} \mathrm{~S}$ and $\mathrm{KCNS}$ [17]; $\mathrm{HNO}_{3}, \mathrm{H}_{2} \mathrm{O}_{2}, \mathrm{KMnO}_{4}$ and $\left(\mathrm{NH}_{4}\right)_{2} \mathrm{~S}_{2} \mathrm{O}_{8}$ [13]; $\mathrm{NaOH}$ and $\mathrm{KOH}$ $[18] ; \mathrm{K}_{2} \mathrm{CO}_{3}[19,20]$. The surface area yields are a key aspect for both chemical and physical activation.

The versatile characteristics of charcoal and its capacity to adsorb many pollutants are due to two mechanisms: chemisorption and physisorption. The chemisorption mechanism is due to the presence of functional groups in the porous internal surface of the activated charcoal [21].

Those functional groups derive from the elements which are present in the activated charcoal composition, some of those can be: $\mathrm{O}, \mathrm{S}, \mathrm{H}, \mathrm{N}, \mathrm{Cl}, \mathrm{K}, \mathrm{Na}, \mathrm{Mg}, \mathrm{Ca}$ [22-24]. Oxygen for example can form many functional groups, such as carboxyl, carbonyl, phenols, lactone and others [25-27]. The groups which are available on the surface can be classified as protonated $\left(\mathrm{C}-\mathrm{OH}_{2}{ }^{+}\right)$, neutral $(\mathrm{COH})$ or ionized $\left(\mathrm{CO}^{-}\right)$. The groups are shown in Figure 2, as measured with IR.

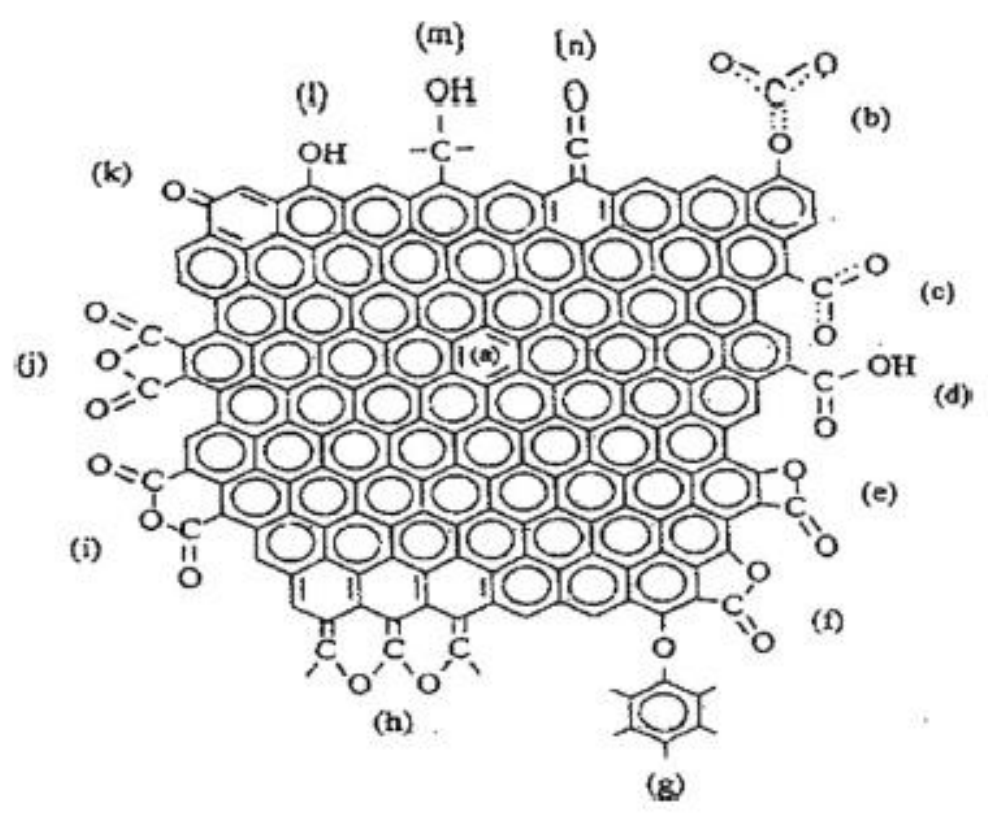


Figure 2. IR-active functional groups on carbon surface: (a) aromatic $\mathrm{C}^{1 / 4} \mathrm{C}$ stretching; (b) and (c) carboxyl-carbonates; (d) carboxylic acid; (e) lactone(4-memberedring); (f) lactone(5-memberedring); (g) ether bridge; (h) cyclic ether; (i) cyclican hydride (5-membered ring); (j) cyclican hydride (6membered-ring); (k) quinine; (l) phenol; (m) alcohol; and (n) ketene [8]

\subsection{Wastewater treatment}

The physisorption and chemisorption mechanisms can be used for water purification, which is the subject of this work. Clean water is the most essential source for all living species and the clean water reserves are now decreasing [28]. If we consider the UN SDG 6 (sustainable management of water and sanitation for all), this is linked with many other SDGs (particularly SDG 1 (No poverty), 2 (Zero hunger), 3 (Good health and well-being), 14 (Life below water) and 15 (Life on land)) [29]. This importance is highly felt in African territories. Another way to consider the importance of water is the so-called Food-Energy-Water NEXUS which has already been shown to involve a great part of the 17 UN SDGs [30]. The use of charcoal in water treatment is done with the aim of reducing three types of contaminants [31]:

- Natural organic matter (NOM, mainly consisting of residues of the metabolism of living things);

- Synthetic organic matter (e.g. oil, benzene and toluene, phenols and chlorophenols, trichloromethane and carbon tetrachloride, detergents, pesticides, dyes, surfactants etc.);

- by-products of chemical water treatment (for example the byproducts of the drinking water disinfection step, which is usually done with chlorine compounds and it is followed by the treatment with activated charcoal to adsorb the formed trihalomethanes).

Dealing with the AC market in the US, $50 \%$ of it is used in drinking water sanitation, $40 \%$ is used in wastewater treatment and the remaining is used in ground water treatment [31]. The total market of activated charcoal was about 2.7 Mt in 2015 and it is projected to reach about 5.4 Mt in 2021 for a total market value of 8.1 billion dollars with a unit price of $1.5 € / \mathrm{kg}$ [32]. Higher values are reported by [33], so this can be evaluated as a very interesting market and as mentioned before, the 
total production of lignin worldwide can easily cover the current demand of activated charcoal, with interesting economic benefits.

Wastewater treatment can be divided into the following phases:

1. the first (or pre-treatment) stage happens when the effluent contains toxic substances, which can influence the activity of the biological treatment. In this phase we can apply redox reactions, followed by precipitation to separate metals; ozonation followed by filters based on granular $\mathrm{AC}$, to eliminate big organic molecules; air stripping to eliminate light organics and ammonia;

2. secondary treatment is based on the use of lime and other chemicals, followed by nitration and neutralization using acids or bases; this will remove suspended solids, oils and floating materials; then follows the removal of proteins, starches and sugars and phenols by biological treatment in aerobic conditions;

3. the tertiary phase consists of the removal of inorganic and organic compounds by adsorption, obtaining an extremely pure effluent with $99 \%$ BOD reduction.

The use of activated charcoal in the above-mentioned cleaning processes can be done in many ways: it can be inserted as an adsorbent after the primary and after the secondary biological processes directly in the reactors; or it can be used in a separate reactor (especially during the tertiary treatment). An example of $20 \mathrm{~m}^{3}$ reactor used with powdered activated carbon (PAC) is shown in Figure 3. 


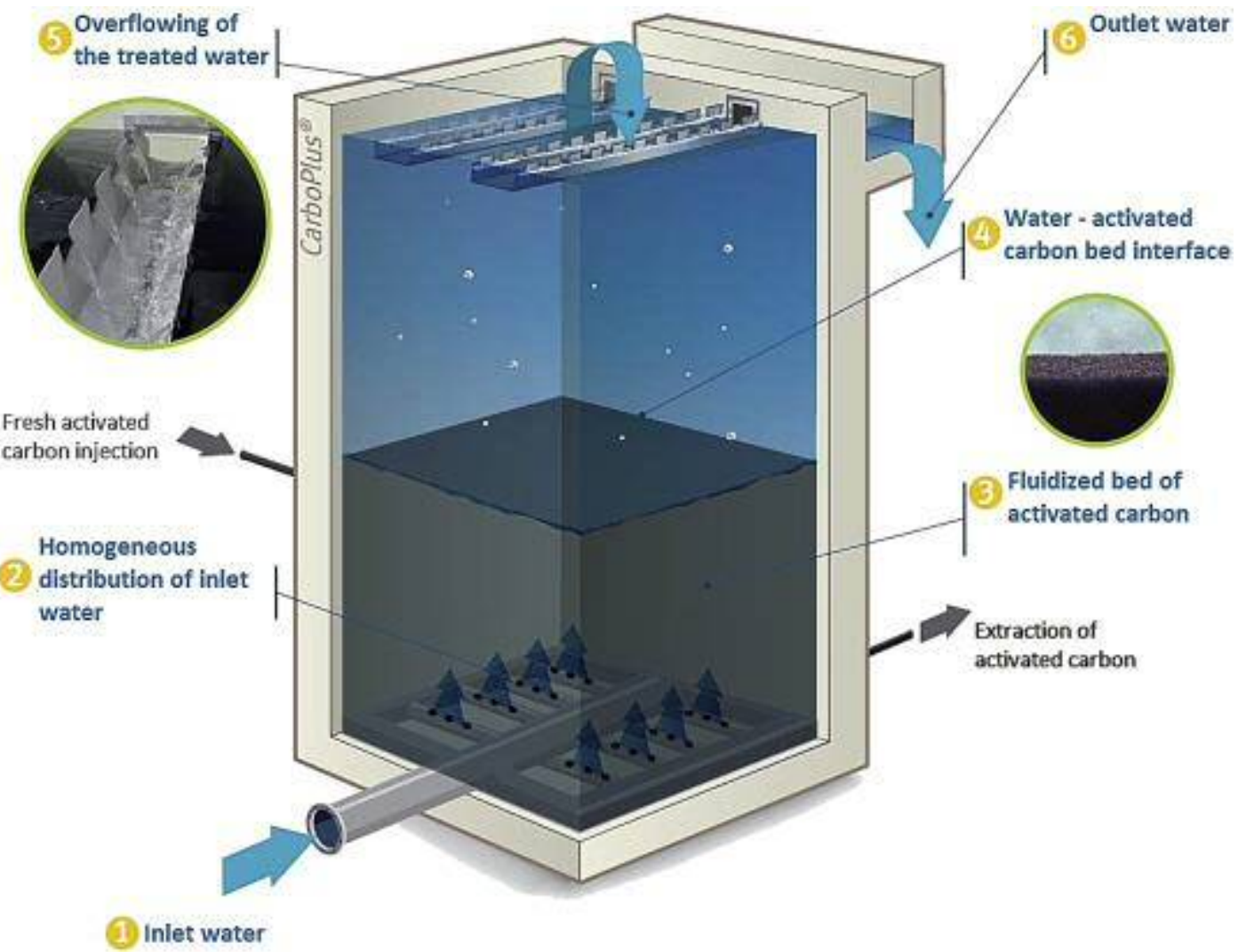

Figure 3: Layout of the $20 \mathrm{~m}^{3}\left(5 \mathrm{~m} \times 4 \mathrm{~m}^{2}\right)$ CarboPlus ${ }^{\circledR}$ pilot (SAUR source), adapted from [34]

\section{AIM OF THE WORK AND METHODS}

Few reviews are available on the topic of activated charcoal production from lignin (or lignin rich residues) and its use in wastewater treatment. One is that presented by [35], but in that work it is missing a detailed part on adsorption performance, which is only treated shortly. Besides this, economic considerations on the feasibility of the whole supply chain are missing and also the comparison with other possible uses of lignin. The works [36-39] take into consideration the production and the use of biochar in wastewater treatment, but the quality and properties of biochar are much different from those of activated charcoal. According to [40], if digestate sludge has a porosity of $1.92 \mathrm{~m}^{2} / \mathrm{g}$, the porosity of biochar is about $20.86 \mathrm{~m}^{2} / \mathrm{g}$. This is very low, if we consider that the porosity of activated charcoal can reach more than $2000 \mathrm{~m}^{2} / \mathrm{g}$ [35]. Other works [41, 42] take into consideration the modification of biochar through the use of chemicals, oxidation, carboxylation and amination, treatment with organic 
solvents and use of Fe to produce magnetic biochar, and the use of biochar in the adsorption of heavy metals is also considered. Still modified biochar is different from activated charcoal.



(a)

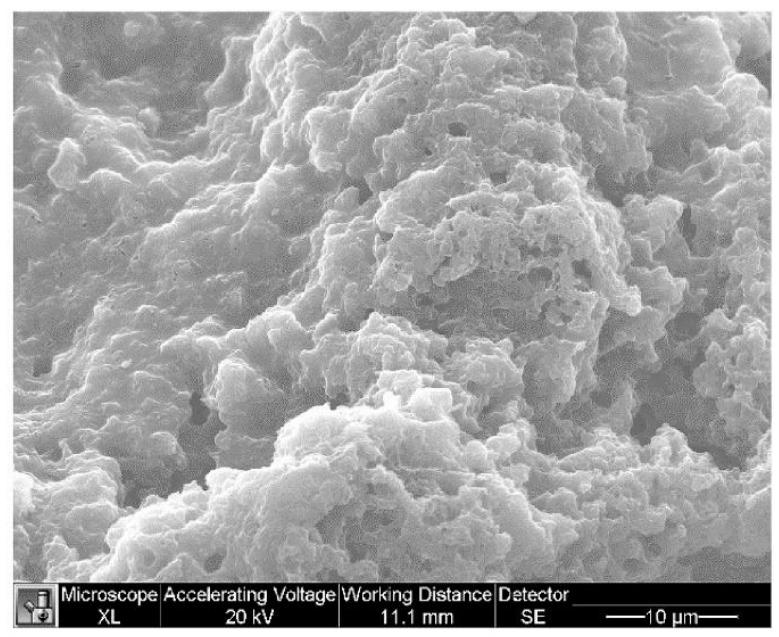

(b)

Figure 4: SEM image of (a) digested sludge and (b) biochar sample BC450 [40].

Dealing with the use of activated carbon and more broadly with the application of adsorption in WWTP, some relevant books have been written, such as: [43-46]. To these important publications it has to be added also the book of Harry Marsh on activated carbon production [31]. We also have to remember the review of lignin materials adsorption capacities [47], this is an important work showing all the sorbents which can be derived from lignin and their sorption capacity, nevertheless the work is not sufficiently focused on activated carbons. The work [48] is focused on lignin activated carbon production and modeling of the adsorption process, but little information is available on the actual adsorption capacity. Also the work [49] is very general, adsorption application are not dealt with in detail and lignin-rich residues are not taken into account.

So, none of the above-mentioned works gets a sufficiently detailed insight on lignin activated charcoal production and use in wastewater treatment and to the best of the authors' knowledge, there is no work considering the economic aspects of activated carbon production from lignin and comparing the economic performance with other possible uses.

For these reasons this works aims at: 
- describing biochar production technologies from lignin and examine lignin pyrolysis and HTC, focusing on yields, solid products characterization (through BET, ashes, total porous volume analysis etc.) and chemical and kinetic aspects;

- describing the activation step, taking into consideration the chemical activation process and also the physical activation process;

- describing the pollutants adsorption process, focusing on process parameters, efficiency adsorption capacity, activated charcoal dose, process kinetics;

- describing the pollutants adsorption performance of activated charcoal derived from lignin compared to other activated charcoals;

- compare the economic feasibility of producing activated charcoal from lignin with other possible uses.

To do this, detailed searches have been performed in google scholar using the keywords shown in table S1 of the supplementary material. About 348 papers in the literature have been consulted. Their distribution among the main topics of research is shown in Figure 5.

As it can be seen from Figure 5, about 8 hot topics have been identified for the production of activated charcoal from lignin: pyrolysis; hydrothermal carbonization (HTC); physical activation; chemical activation; modification; adsorption process modelling (Ad modelling); wastewater treatment and technical economic performance. This last aspect is considered only for lignin, while for digestate and olive stone it is neglected. This is due to the wider market which is now growing for lignin valorization, as also demonstrated by the EU cost action LIGNOCOST (https://lignocost.eu/). It can be easily understood that in the case of lignin it is very important to discern the most economically attractive uses. Dealing with the pyrolysis conversion technology, which can be both conventional pyrolysis or microwave pyrolysis, much research has been done with digestate, while with olive stone more research is needed. For this last residue of the olive production the most interesting technologies are based on activation. Chemical and physical activation are performed for both olive stones and lignin; while for digestate no activation is performed. 


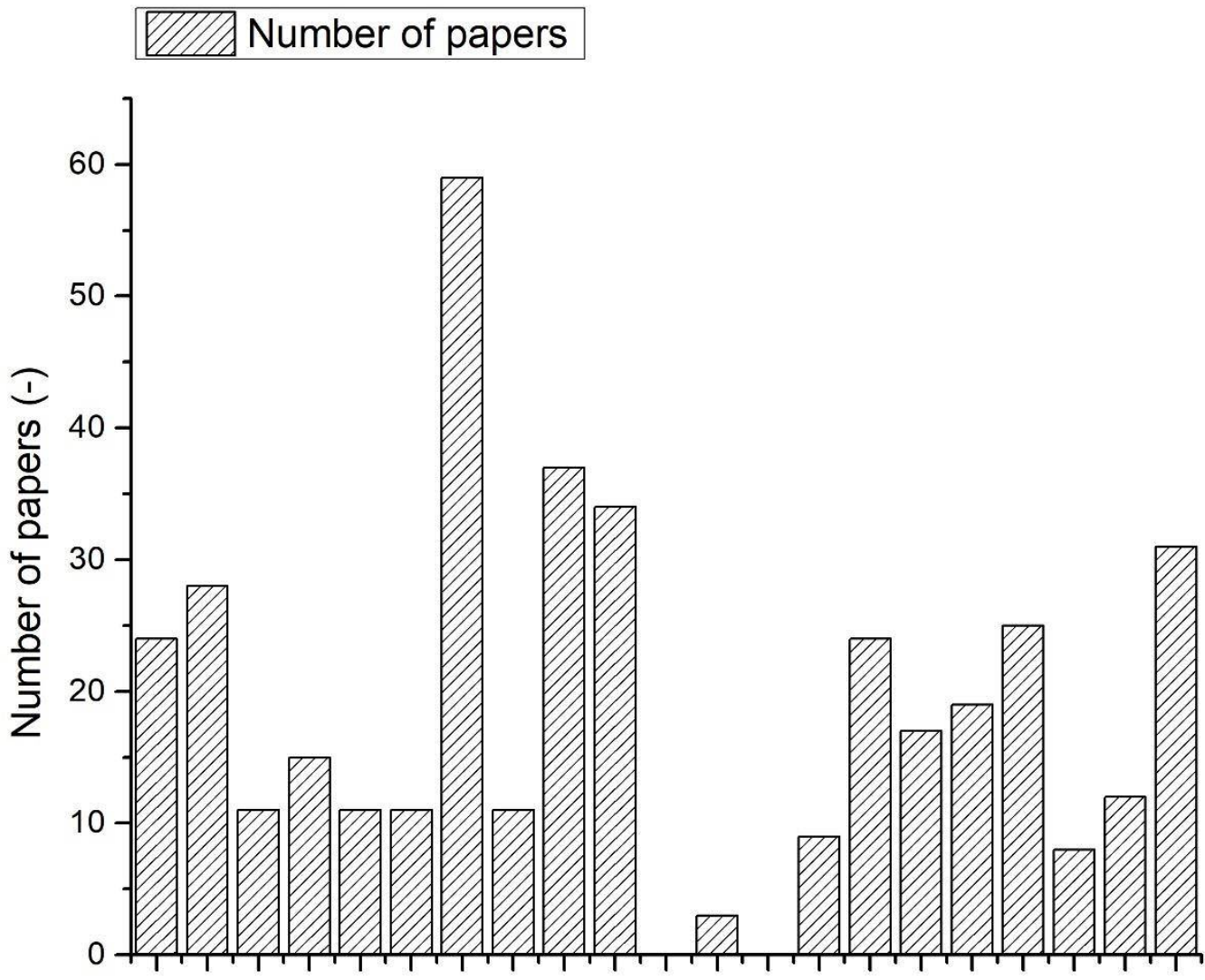

Figure 5: Literature review, $\mathrm{LIG}=$ lignin; $\mathrm{HTC}=$ Hydrothermal Carbonization; $\mathrm{PH}=$ Physical; $\mathrm{CH}=$ chemical $\mathrm{Ad}=$ Adsorption $; \mathrm{WW}=$ Wastewater; $\mathrm{TEA}=$ Technoeconomic analysis $; \mathrm{DIG}=$ digestate; OS $=$ Olive Stones

We will deal in the following sections with: lignin, digestate and olive stones characterization and thermal treatment, charcoal modification and activation, wastewaters treatment and technical economic feasibility of producing activated carbons from lignin. 


\section{LIGNIN, DIGESTATE AND OLIVE STONES CHARACTERIZATION}

\subsection{Lignin characterization}

The most important lignin characteristics are clearly presented in [50], these are reported also in Table

1. Different lignins are taken into consideration: organosolv eucalyptus lignin, kraft eucalyptus lignin, organosolv spruce lignin, kraft spruce lignin.

Table 1: Lignin characterization [50]

\begin{tabular}{|l|c|c|c|c|}
\hline Parameter & $\begin{array}{c}\text { Organosolv } \\
\text { eucalyptus lignin }\end{array}$ & $\begin{array}{c}\text { Kraft eucalyptus } \\
\text { lignin }\end{array}$ & $\begin{array}{c}\text { Organosolv } \\
\text { spruce lignin }\end{array}$ & $\begin{array}{c}\text { Kraft spruce } \\
\text { lignin }\end{array}$ \\
\hline Klason lignin (\%) & 83.7 & 58.6 & 94.3 & 88.5 \\
\hline $\begin{array}{l}\text { Acid soluble lignin } \\
\text { (\%) }\end{array}$ & 1.6 & 6.3 & 3.1 & 2.3 \\
\hline Ash (\%) & 3.6 & 22.4 & 3.2 & 2.5 \\
\hline Total sugars (\%) & 2.9 & 2.2 & 0.5 & 1.0 \\
\hline C (\%) & 61.4 & 49.8 & 68.8 & 63.7 \\
\hline H (\%) & 6.0 & 5.0 & 6.3 & 6.1 \\
\hline N (\%) & 0.13 & 0.11 & 0.08 & 0.10 \\
\hline S (\%) & 0.06 & 0.78 & 0.20 & 1.45 \\
\hline Number-average \\
molecular weight
\end{tabular}


It can be seen from Table 1 that kraft lignins have usually higher content of nitrogen and sulfur compared to organosolv lignins. The presence of sulfur can be explained with the fact that some acids used for lignin isolation can remain in the compound when analyzed. Organosolv lignin has a high carbon content so it is the more suitable for active carbon production. Organosolv lignin is also purer than kraft lignin, having higher Klason lignin concentration. Lignin molecular weight average (Mw) can be different depending on the feedstock and the extraction process [53]. For this reason, the samples shown in Table 1 have values that differ in an important way and this is due probably to the fact that they have been extracted in two different ways. The polydispersivity (PDI) values are generally high for all the samples considered, which is confirmed also by [54]. From the proximate analysis we can see that the moisture content is very low, so lignin can be transformed easily with thermochemical processes. Also the ash content is quite limited (with the exception of eucalyptus kraft lignin), while fixed carbon content is important and this means that we expect interesting yields of charcoal after the thermal treatment. Lignins have also an interesting heating value.

\subsection{Digestate characterization}

In Table 2 we find the characterization analysis of a digestate obtained from a biogas plant realized in a farm in the Umbria region (Italy), which is mainly fed with energy crops (maize and sorghum silage). Compared with other digestates, which are obtained when the anaerobic digestion plant is fed with animal wastes, the ones obtained using energy crops have surely a higher content of lignin. In this case the lignin content is about $41 \mathrm{wt} \%$. The high content of lignin implies also an interesting heating value of the residue. Ash concentration is also important, if compared for example with that of pure lignin. The heating value is slightly lower than that of lignin, the same is also for the fixed carbon content. This means that pure lignin is potentially a better substrate for activated carbon production. Digestate produced from energy crops seems to have better characteristics, if compared with olive stones, for example. 
Table 2: Digestate characterization $[55,56]$

\begin{tabular}{|l|l|l|}
\hline Parameter & Value & Unit of measure \\
\hline Ash & 12.38 & wt $\%$ d.b. \\
\hline Volatile matter & 67.07 & wt $\%$ d.b. \\
\hline Fixed carbon & 20.55 & wt $\%$ d.b. \\
\hline VM/FC & 3.29 & wt $\%$ d.b. \\
\hline C & 42.52 & wt $\%$ d.b. \\
\hline H & 5.94 & wt $\%$ d.b. \\
\hline N & 1.79 & wt $\%$ d.b. \\
\hline O & 49.75 & wt $\%$ d.b. \\
\hline Cellulose & 21.64 & wt $\%$ d.b. \\
\hline Hemicellulose & 15.08 & wt $\%$ d.b. \\
\hline Lignin & 40.88 & wt $\%$ d.b. \\
\hline Extractives & 10.02 & wt $\%$ d.b. \\
\hline Higher Heating Value & 19.74 & MJ $/ \mathrm{kg}$ d.b. \\
\hline
\end{tabular}

\subsection{Olive stones characterization}

If we consider olive stones, they have a lignin content of about $26.5 \pm 0.42 \mathrm{wt} \%$, according to [57]. Other components are cellulose $(31.9 \pm 0.34 \mathrm{wt} \%)$ and hemicellulose $(21.9 \pm 1.62 \mathrm{wt} \%)$ [57]. Lignin content is lower than that of the digestate reported in Table 2; this explains also the reason why the fixed carbon content is lower than that of digestate. It seems that olive stones can give less yield of charcoal compared to the other two considered raw materials (lignin and digestate). The advantage for the olive stones is that they have a lower moisture content, compared to olive pomace and so they can be easily be converted through thermochemical processes. Cellulose and hemicellulose will produce some charcoal also even though with less efficiency, compared to lignin. 
Table 3: Olive stones and olive pomace characterization [58]

\begin{tabular}{|l|l|l|}
\hline Parameter & Olive Stone & Wet Pomace \\
\hline Moisture (wt\% d.b.) & 4.53 & 49.02 \\
\hline Ash (wt\% d.b.) & 0.49 & 0.84 \\
\hline Volatiles (wt\% d.b.) & 87.06 & 42.35 \\
\hline Fixed carbon (wt\% d.b.) & 12.45 & 7.79 \\
\hline C & 50.00 & 55.54 \\
\hline H & 6.17 & 7.98 \\
\hline N & 0.42 & 1.98 \\
\hline O & 43.41 & 34.5 \\
\hline HHV (wt\% w.b.) & 19.21 & 5.7 \\
\hline
\end{tabular}

\section{BIOCHAR PRODUCTION FROM LIGNIN RICH SUBSTRATES}

\subsection{Biochar production technologies from lignin-rich substrates}

Biochar production technologies are basically thermochemical processes. They can be pyrolysis, gasification and hydrothermal carbonization. Gasification is not considered in this work because it produces a charcoal which has a high concentration of ashes. This can generally limit the porosity of the charcoal and so limit its adsorption efficiency. Another important aspect to take into consideration is that if we want to obtain activated carbon as a final product, we have to consider that two ways are possible: direct activation (physical or chemical) or thermal treatment (pyrolysis or HTC), followed by activation. In this sense biochar can be an intermediate product for activated charcoal production [35].

\subsection{Lignin and lignin-rich residues pyrolysis}


From a chemical point of view, during pyrolysis lignin decomposition starts with the breaking of the bonds which are weaker (e.g. hydrogen bonds and $\mathrm{C}-\mathrm{OH}$ bonds), and with the increase of temperature stronger bonds are broken, such as the $\beta-\mathrm{O}-4$ linkages. In the first low-temperature phase of the pyrolysis process aldehydes, toluols, styrenes, and guaiacyl hydroxyls are formed. In the second step of the pyrolysis, which happens at higher temperatures, p-hydroxy-phenols, catechols, and cresols are produced. When the $\beta-\mathrm{O}-4$ linkages are broken, free radicals are liberated and they start the depolymerization reaction of lignin [59-61]. The radicals can form compounds like vanillin and 2methoxy-4-methylphenol. The formation of important quantities of radicals starts the chain propagation reaction. At temperatures higher than $350^{\circ} \mathrm{C}$ through the random repolymerization of radicals, biochar is formed [59].



Figure 6: Pyrolysis of lignin, depolymerization mechanism [61]

A key parameter to take into consideration when performing lignin pyrolysis is the effect of temperature on biochar yield. This is reported for example in [62], but it can also be derived from TG diagrams, given that the residue that it is weighted by the thermal balance is the charcoal itself. So, if we consider 
the values presented in the TG diagram shown in [50] we can derive the values reported in Figure 7 on char yields obtained during lignin pyrolysis.

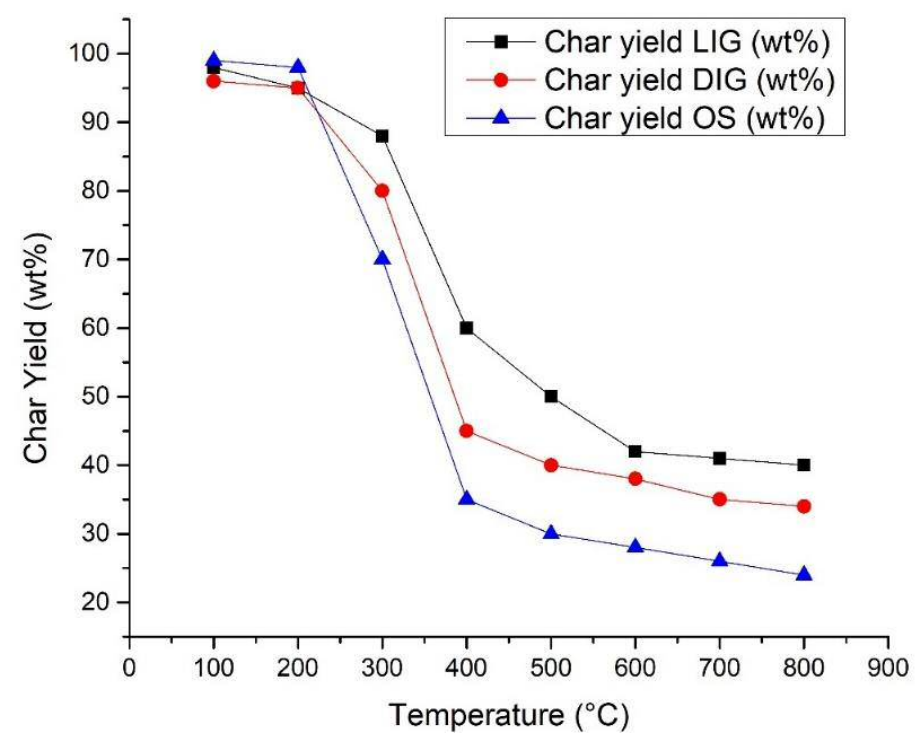

Figure 7: Comparison of TG curves between: lignin [50], digestate [55] and olive stones [63, 64]

Another important aspect is the effect of temperature on the porosity of the final material, as reported in [65].




Figure 8: Surfaces areas of charcoals produced from different lignins and lignin-rich residues [65-67]

As it can be seen from Figure 8, different types of lignin and also the lignin-rich residues seem to have a similar surface area. It is important so, to understanding the role played by hemicellulose, cellulose and lignin on porosity development and main characteristics [68]. To consider the effect of the three components of biomass the TG and DTG diagrams shown in Figure 9 can be useful.
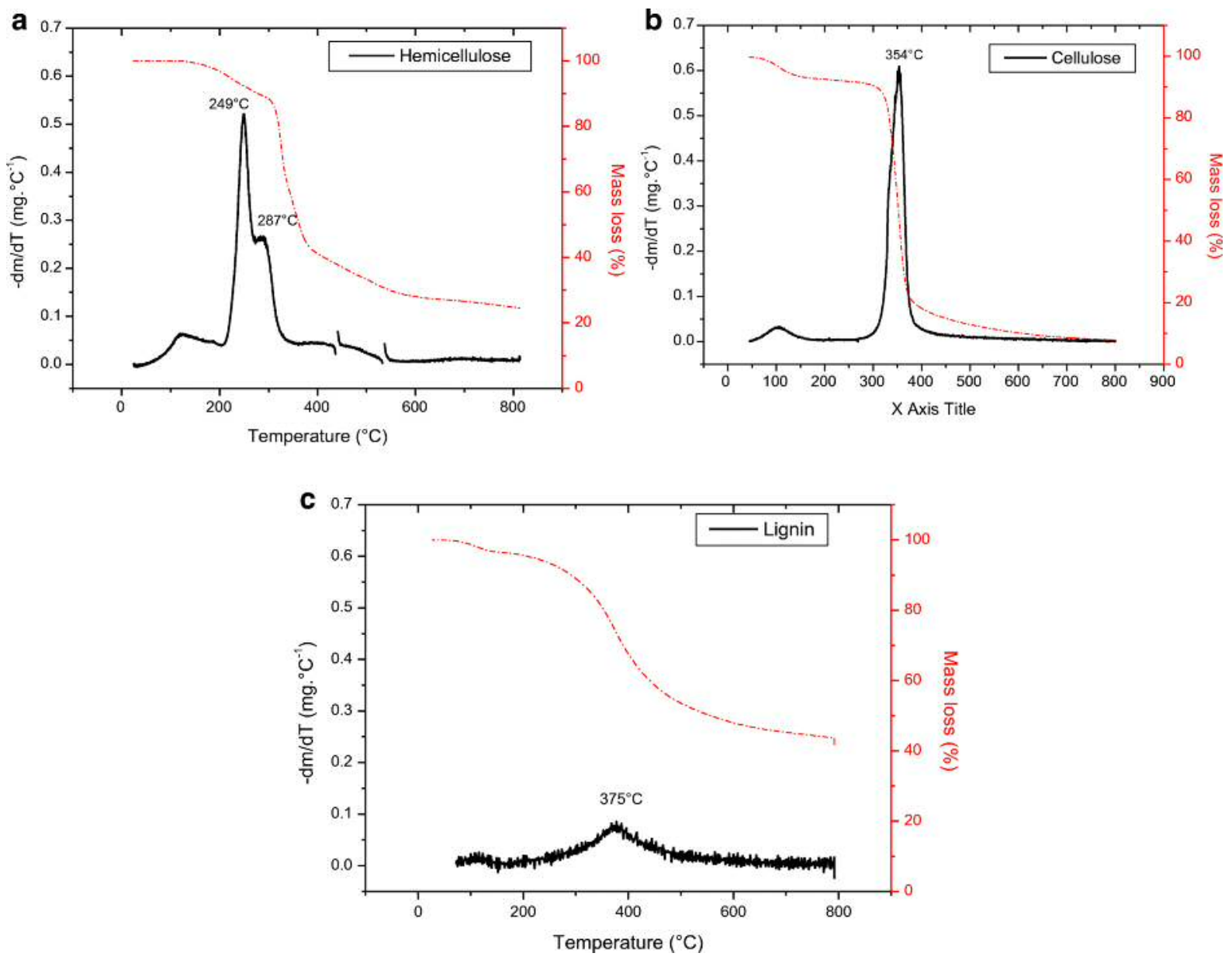

Figure 9: Thermal behavior of lignin, cellulose and hemicellulose [68]

It can be seen from Figure 9 that the total mass losses (in \%) for hemicellulose, cellulose and lignin are $76.5 \%, 80.9 \%$ and $55.1 \%$. So, the final charcoal yields at $800^{\circ} \mathrm{C}$ are $23.5 \%$ (for hemicellulose), $19.1 \%$ (for cellulose) and $45.9 \%$ (for lignin). From this data it seems that lignin is the major contributor to charcoal formation, but it is not so simple as it seems. In the study of Boundzanga et al. [68], in fact, an 
interesting method to calculate the contribution of hemicellulose, cellulose and lignin to the final mass of the formed charcoal is proposed. The contribution is estimated using a predictive method based on Cagnon equations [69], such as:

$$
\mathrm{Y}=100-((1-\mathrm{x}) \cdot 100)
$$

with:

$$
\mathrm{x}=\mathrm{H} \cdot \mathrm{y}_{\mathrm{c}, \mathrm{H}}+\mathrm{C} \cdot \mathrm{y}_{\mathrm{c}, \mathrm{C}}+\mathrm{L} \cdot \mathrm{y}_{\mathrm{c}, \mathrm{L}}
$$

being $\mathrm{Y}$ the charcoal yield expressed in percentage. $\mathrm{H}, \mathrm{C}$ and $\mathrm{L}$ are respectively the percentage of hemicellulose, cellulose and lignin in the precursor (in \%) and $\mathrm{y}_{\mathrm{c}, \mathrm{i}}$ are the heat treatment yields of each individual component (in \%).

Considering the initial mass of the raw material, the contribution of each component can be calculated based on the following equation, which takes into consideration, as an example, lignin:

$$
\mathrm{L}_{\mathrm{c}}=\left(1-\left(\mathrm{x}-\left(\mathrm{L} \cdot \mathrm{y}_{\mathrm{c}, \mathrm{L}}\right) / \mathrm{x}\right) \cdot 100\right.
$$

Where $\mathrm{L}_{\mathrm{c}}$ is the production of charcoal from the lignin in the sample after pyrolysis (expressed in wt\%), $\mathrm{x}$ is the calculated char mass after heat treatment, $\mathrm{y}_{\mathrm{c}, \mathrm{L}}$ is the yield of charcoal from the pyrolysis of pure lignin (expressed in \%). If we consider the values of the contributions of cellulose, hemicellulose and lignin to char formation, from olive pomace, reported in [68], these are the following: $36.9 \mathrm{wt} \%$ (hemicellulose), $18.5 \mathrm{wt} \%$ (cellulose) and $44.6 \mathrm{wt} \%$ (lignin). Based on these data lignin cannot be considered as the major component of charcoal, also cellulose and hemicellulose are playing an important role. 


\subsection{Lignin and lignin-rich residues HTC}

Hydrothermal carbonization of biomass is a thermal treatment which happens in the liquid phase at moderate temperature and high pressure (above the saturation pressure of water) [70]. The most common reactions in hydrothermal treatment of biomass are: the cleavage of C-O-C and C-C bonds; de-methoxylation; alkylation, and condensation. The cleavage of the $\beta-\mathrm{O}-4$ linkages and ${ }^{\alpha} \mathrm{C}-{ }^{\beta} \mathrm{C}$ linkages happens first, while aromatic bonds are not broken during HTC. The changes in structure of char during HTC of lignin are presented in [1]. Usually, lignin decomposition increases with the increase of temperature. With higher temperature HTC char tends to have a more crystalline structure; besides above $350^{\circ} \mathrm{C}$ many functional groups tend to disappear and only $\mathrm{OH}$ groups are left.

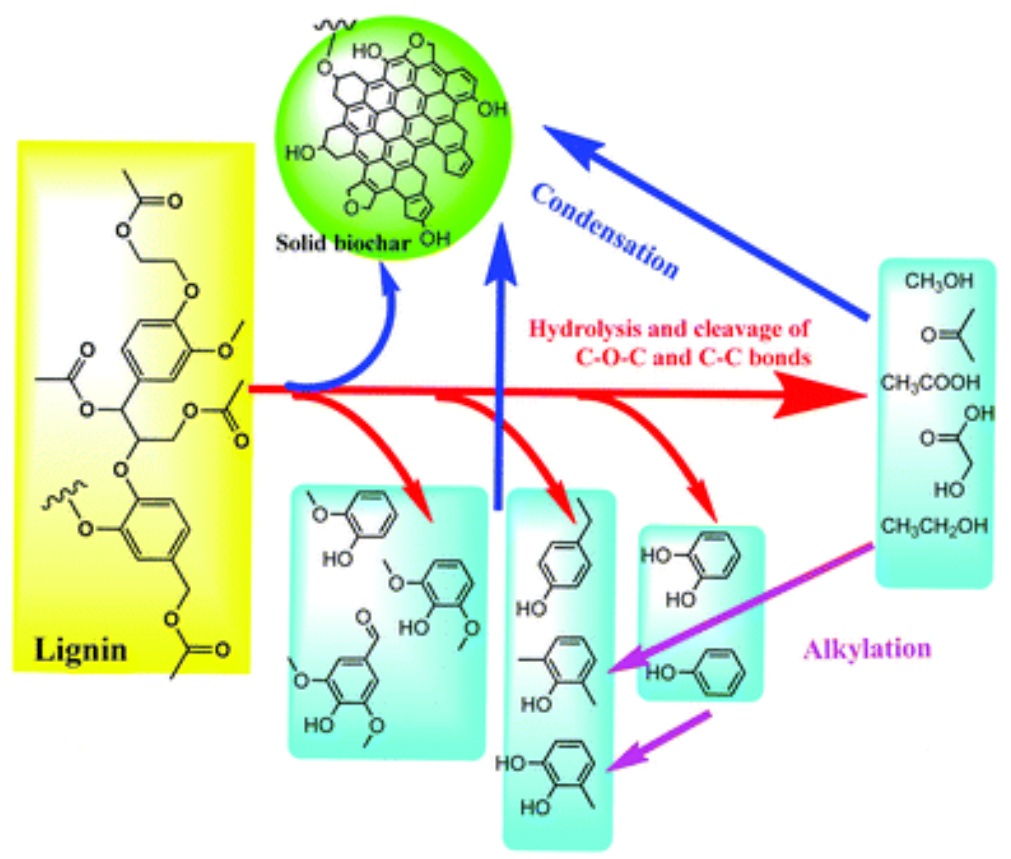

Figure 10: Mechanism of lignin HTC [61]

If compared with lignin pyrolysis, lignin HTC generally yields more charcoal, but this is a less stable product, so when activation is performed the final yield of activated product is in many cases less for HTC than for pyrolysis [71]. 
Dealing with the porosity of the obtained hydrochars, few data are available. This is mainly because a simple HTC treatment does not produce a sufficiently porous carbon and the hydrochar has to be activated in a second step, to have a final product to be used as an adsorbent. The porosity of lignin hydrochar, obtained with a thermal treatment lasting 4 hours at a temperature equal to $360^{\circ} \mathrm{C}$, is about $12.5 \mathrm{~m}^{2} / \mathrm{g}$ [72]. This value is much lower than that of pyrochar.

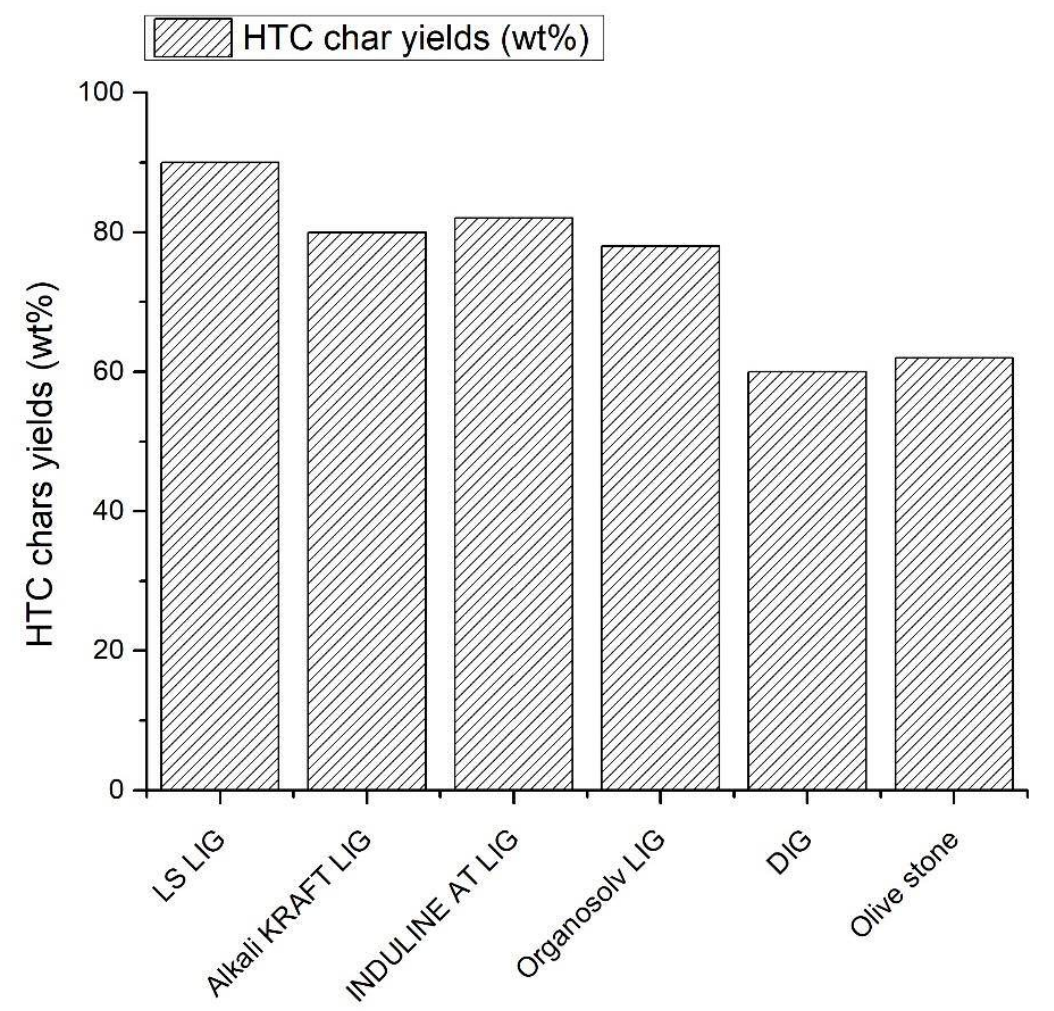

Figure 11: Hydrochar yields obtained at a temperature of $220^{\circ} \mathrm{C}[71,73,74]$, where $\mathrm{LS}=$ Low sulfonate; LIG = Lignin; DIG = digestate

Where Indulin AT is a type of lignin derived from a purified form of kraft pine lignin. It has to be considered that the yields of hydrochar obtained with digestate and olive stones at the same temperature of $220^{\circ} \mathrm{C}$ (typical of wet torrefaction) are much lower than those obtained from lignin. This can be explained with the following facts: 
-first the yields reported in Figure 11 with regard to lignins are maybe too high if we consider that [75] reports a yield of hydrochar at $225^{\circ} \mathrm{C}$ equal to $60 \%$;

- general hydrochar yields obtained with lignin are higher than those obtained with cellulose and hemicellulose;

- this is due to the fact that the phenolic structure of lignin is more thermally stable.

It has also to be considered that HTC temperature has an important effect on lignin hydrochar yields, as it is reported in [74] and this is shown in Figure 12.

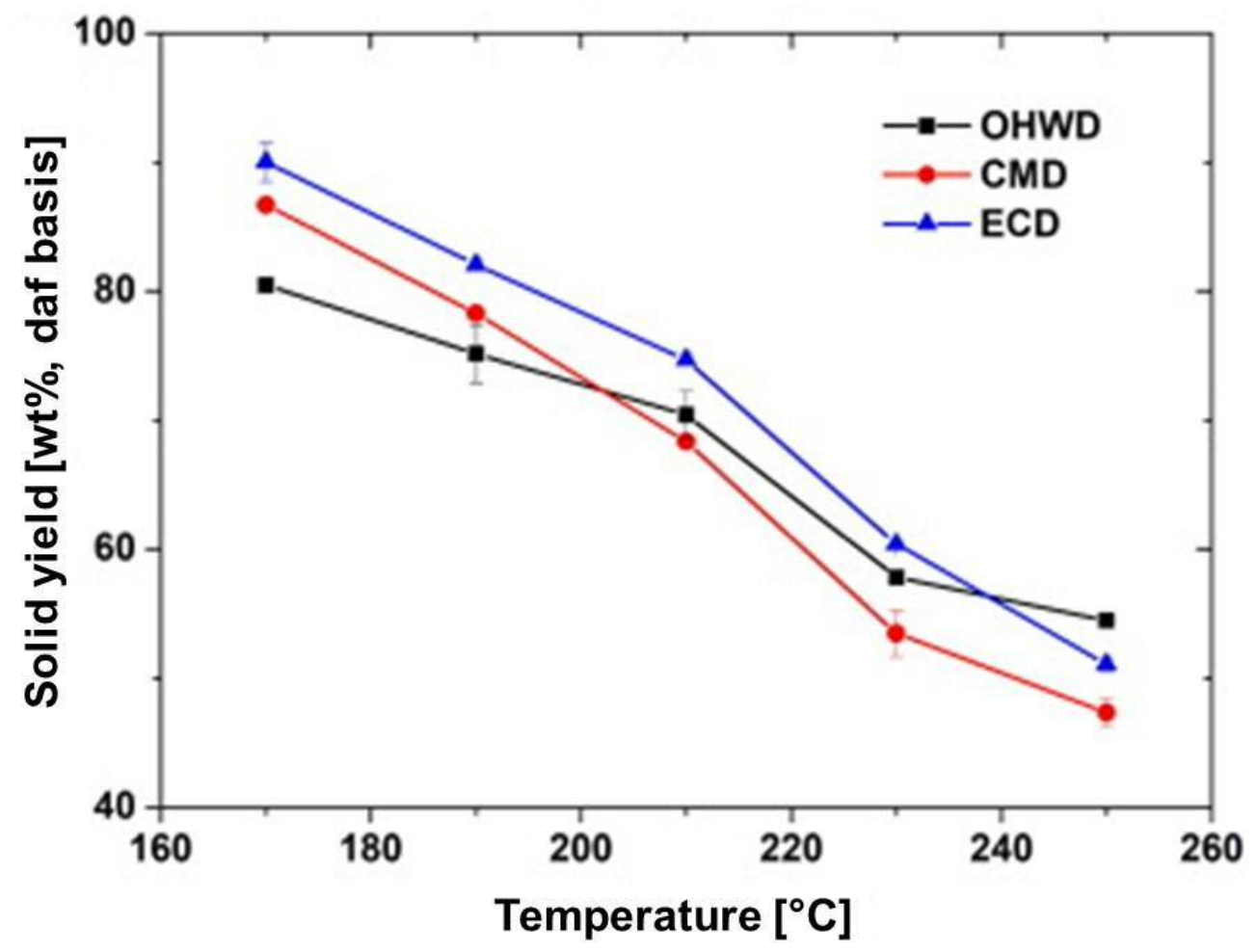

Figure 12: Effect of temperature on hydrochar yields [74], where OHWD = organic household waste digestate $\mathrm{CMD}=\mathrm{Cow}$ Manure Digestate $\mathrm{ECD}=$ energy crops digestate. 
From Figure 12 it can be seen that compared to biochar obtained from pyrolysis the yields of hydrochar are generally higher, this is due to the lower process temperature which makes hydrochar in general more reactive than pyrolysis biochar.

\subsection{Biochar modification processes}

\subsubsection{Influence of process parameters on final porosity and activated carbon yields}

Given that lignin has a good sorption capacity, even without being modified, and also a high carbon content, it is an ideal raw material for the production of activated carbons [35, 76-78]. As reported by Mackay and Roberts $[79,80]$ the final porosity and textural characteristics of activated carbons strongly depend on both raw materials properties and the process parameters. Dealing with raw materials properties, the influence of their carbon content, lignin content and fixed carbon content have been clearly explained in the previous paragraphs. We have also to take into consideration that the contents of cellulose, hemicellulose and lignin have important effects on the final porosity of the material. In fact, in cellulose charcoal the volume occupied by mesopores is $82 \%$ of the total porosity volume; in the hemicellulose charcoal the volume occupied by the mesopores is about $45 \%$ of the total, while the micropores occupy about $54 \%$ of the total; in the lignin the volume occupied by the micropores is about $63 \%$ of the total [68]. Depending on the final application the average diameter of the obtained pores can be changed by changing the raw material. The important parameters that have to be taken into account when dealing with activation are shown in Table 4.

Table 4: Key Parameters during chemical and physical activation of lignin [35] 


\begin{tabular}{|c|c|c|c|c|c|c|}
\hline Source & Precursor & Activation & Temperature & Time & $\begin{array}{l}\text { Surface } \\
\text { area } \\
\left(\mathrm{m}^{2} / \mathrm{g}\right)\end{array}$ & $\begin{array}{l}\text { Micropore } \\
\text { volume } \\
\left(\mathrm{cm}^{3} / \mathrm{g}\right)\end{array}$ \\
\hline [81] & Indulin $\mathrm{C}^{\mathrm{a}}$ & $\begin{array}{l}(\mathrm{Ph}) \\
\text { Carbonization } \\
\text { with } \mathrm{N}_{2}\end{array}$ & $300^{\circ} \mathrm{C}$ & $1 \mathrm{~h}$ & $<10$ & $<0.01$ \\
\hline \multirow[t]{4}{*}{ [82] } & \multirow[t]{4}{*}{ Kraft Lignin } & \multirow{2}{*}{$\begin{array}{l}(\mathrm{Ph}) \\
\text { Carbonization } \\
\text { with } \mathrm{N}_{2} \text { Activation } \\
\text { with } \mathrm{CO}_{2}\end{array}$} & $350^{\circ} \mathrm{C}$ & $2 \mathrm{~h}$ & \multirow[t]{2}{*}{1613} & \multirow[t]{2}{*}{0.47} \\
\hline & & & $800^{\circ} \mathrm{C}$ & $40 \mathrm{~h}$ & & \\
\hline & & \multirow{2}{*}{$\begin{array}{l}(\mathrm{Ph}) \\
\text { Carbonization } \\
\text { with } \mathrm{N}_{2} \text { Activation } \\
\text { with } \mathrm{CO}_{2}\end{array}$} & $350^{\circ} \mathrm{C}$ & $2 \mathrm{~h}$ & \multirow[t]{2}{*}{1853} & \multirow[t]{2}{*}{0.57} \\
\hline & & & $850^{\circ} \mathrm{C}$ & $20 \mathrm{~h}$ & & \\
\hline [83] & Lignin $^{\mathrm{b}}$ & $\begin{array}{l}(\mathrm{Ph}) \\
\text { Carbonization } \\
\text { with } \mathrm{N}_{2}\end{array}$ & $500-900^{\circ} \mathrm{C}$ & - & $10-50$ & - \\
\hline \multirow[t]{2}{*}{ [84] } & \multirow{2}{*}{$\begin{array}{l}\text { Hydrolytic } \\
\text { lignin }\end{array}$} & \multirow{2}{*}{$\begin{array}{l}(\mathrm{Ph}) \\
\text { Carbonization } \\
\text { with Ar Activation } \\
\text { with steam }\end{array}$} & $600^{\circ} \mathrm{C}$ & $2 \mathrm{~h}$ & \multirow[t]{2}{*}{865} & \multirow[t]{2}{*}{0.365} \\
\hline & & & $800^{\circ} \mathrm{C}$ & - & & \\
\hline \multirow[t]{2}{*}{ [85] } & \multirow{2}{*}{$\begin{array}{l}\text { Hydrolytic } \\
\text { lignin }\end{array}$} & \multirow{2}{*}{$\begin{array}{l}(\mathrm{Ph}) \text { carbonization } \\
\text { with Ar Activation } \\
\text { with steam }\end{array}$} & $700^{\circ} \mathrm{C}$ & - & \multirow[t]{2}{*}{769} & \multirow[t]{2}{*}{-} \\
\hline & & & $780^{\circ} \mathrm{C}$ & - & & \\
\hline [86] & $\begin{array}{l}\text { Hydrolytic } \\
\text { lignin }\end{array}$ & $\begin{array}{l}\text { (Ph) Activation } \\
\text { with steam }\end{array}$ & $700^{\circ} \mathrm{C}$ & $2 \mathrm{~h}$ & - & 0.33 \\
\hline [81] & Indulin $\mathrm{C}^{\mathrm{a}}$ & $\begin{array}{l}\text { (Ch) carbonization } \\
\text { and Activation } \\
\text { with } \mathrm{KOH} \\
\text { (Lignin:KOH = } \\
4: 1)\end{array}$ & $700^{\circ} \mathrm{C}$ & 1 & 514 & 0.214 \\
\hline [83] & Lignin $^{b}$ & $\begin{array}{l}(\mathrm{Ch}) \\
\mathrm{H}_{2} \mathrm{PO}_{4}, \quad \mathrm{~K}_{2} \mathrm{CO}_{3}, \\
\mathrm{Na}_{2} \mathrm{CO}_{3}, \\
\mathrm{NaOH} \text {. } \\
\text { Impregnation ratio } \\
(1)\end{array}$ & - & - & $\begin{array}{l}800- \\
2000\end{array}$ & - \\
\hline [87] & Kraft Lignin & $\begin{array}{l}(\mathrm{Ch}): \mathrm{ZnCl}_{2} \text {, } \\
\text { Lignin:1:2.3 }\end{array}$ & $500^{\circ} \mathrm{C}$ & $1 \mathrm{~h}$ & 1800 & 1.039 \\
\hline [88] & Kraft Lignin & $\begin{array}{l}(\mathrm{Ch}): \quad \mathrm{H}_{3} \mathrm{PO} 4, \\
\text { Lignin: } \mathrm{H}_{3} \mathrm{PO}_{4}: 1: 2\end{array}$ & $427^{\circ} \mathrm{C}$ & $2 h$ & 1459 & 0.82 \\
\hline [89] & $\begin{array}{l}\text { Hydrolysis } \\
\text { lignin }\end{array}$ & $\begin{array}{l}\text { (Ch): } \\
\text { Carbonization and } \\
\text { Activation with } \\
\text { KOH. } \\
\text { Lignin:KOH: 1:4 }\end{array}$ & $850^{\circ} \mathrm{C}$ & 15 & 2753 & 1.37 \\
\hline [90] & Kraft Lignin & $\begin{array}{l}(\mathrm{Ch}) \quad \mathrm{H}_{3} \mathrm{PO}_{4} . \\
\text { Lignin:H3PO4: } \\
1: 1.4\end{array}$ & $600^{\circ} \mathrm{C}$ & $1 \mathrm{~h}$ & 1370 & 0.78 \\
\hline
\end{tabular}


As it can be seen from table 4 that an important parameter is the process temperature, this has influence

on both yields and porosity. A clear view of the effects on porosity is shown in Figure 13 where SEM images of activated carbon produced from lignin at different temperatures are shown.
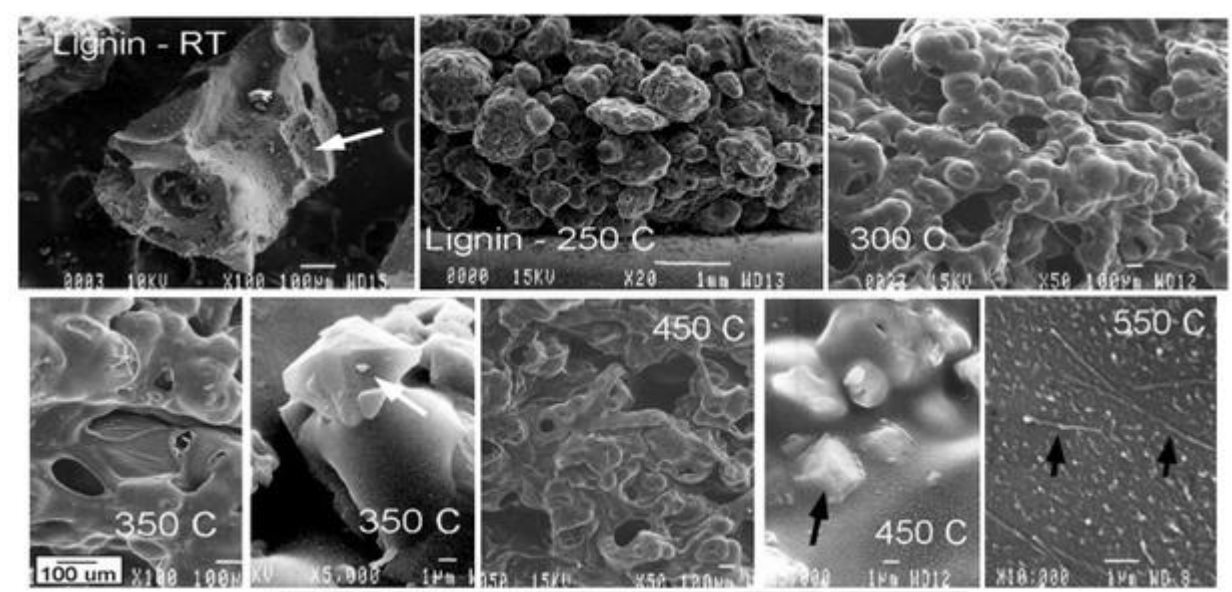

Figure 13: SEM images of lignin and lignin charcoals produced at different temperatures [61]

Table 5: Key Parameters during chemical and physical activation of digestate

\begin{tabular}{|c|c|c|c|c|c|c|}
\hline \multicolumn{7}{|c|}{ ACTIVATION OF DIGESTATE } \\
\hline Source & Precursor & Activation & Temperature & Time & $\begin{array}{l}\text { Surface } \\
\text { area } \\
\left(\mathrm{m}^{2} / \mathrm{g}\right)\end{array}$ & $\begin{array}{l}\text { Micropore } \\
\text { volume } \\
\left(\mathrm{cm}^{3} / \mathrm{g}\right)\end{array}$ \\
\hline \multirow[t]{2}{*}{ [91] } & \multirow[t]{2}{*}{ Digestate } & \multirow{2}{*}{$\begin{array}{l}\text { HTC and (Ch) } \\
\text { KOH:Char: } 4: 1\end{array}$} & $190^{\circ} \mathrm{C}$ & $3 \mathrm{~h}$ & \multirow[t]{2}{*}{854} & \multirow[t]{2}{*}{0.324} \\
\hline & & & $600^{\circ} \mathrm{C}$ & $2 \mathrm{~h}$ & & \\
\hline \multirow[t]{2}{*}{ [91] } & \multirow[t]{2}{*}{ Digestate } & \multirow{2}{*}{$\begin{array}{l}\text { HTC and (Ch) } \\
\text { KOH:Char: } 4: 1\end{array}$} & $220^{\circ} \mathrm{C}$ & $3 \mathrm{~h}$ & \multirow[t]{2}{*}{1178} & \multirow[t]{2}{*}{0.440} \\
\hline & & & $600^{\circ} \mathrm{C}$ & $2 \mathrm{~h}$ & & \\
\hline \multirow[t]{2}{*}{ [91] } & \multirow[t]{2}{*}{ Digestate } & \multirow{2}{*}{$\begin{array}{l}\text { HTC and (Ch) } \\
\text { KOH:Char: } 4: 1\end{array}$} & $250^{\circ} \mathrm{C}$ & $3 \mathrm{~h}$ & \multirow[t]{2}{*}{1609} & \multirow[t]{2}{*}{0.596} \\
\hline & & & $600^{\circ} \mathrm{C}$ & $2 \mathrm{~h}$ & & \\
\hline \multirow[t]{2}{*}{ [91] } & \multirow{2}{*}{$\begin{array}{l}\text { Leached } \\
\text { Digestate }\end{array}$} & \multirow{2}{*}{$\begin{array}{l}\text { HTC and (Ch) } \\
\text { KOH:Char: } 4: 1\end{array}$} & $190^{\circ} \mathrm{C}$ & $3 \mathrm{~h}$ & \multirow[t]{2}{*}{1180} & \multirow[t]{2}{*}{0.502} \\
\hline & & & $600^{\circ} \mathrm{C}$ & $2 \mathrm{~h}$ & & \\
\hline \multirow[t]{2}{*}{ [91] } & \multirow{2}{*}{$\begin{array}{l}\text { Leached } \\
\text { Digestate }\end{array}$} & \multirow{2}{*}{$\begin{array}{l}\text { HTC and (Ch) } \\
\text { KOH:Char: 4:1 }\end{array}$} & $220^{\circ} \mathrm{C}$ & $3 \mathrm{~h}$ & \multirow[t]{2}{*}{1317} & \multirow[t]{2}{*}{0.563} \\
\hline & & & $600^{\circ} \mathrm{C}$ & $2 \mathrm{~h}$ & & \\
\hline \multirow[t]{2}{*}{ [91] } & \multirow{2}{*}{$\begin{array}{l}\text { Leached } \\
\text { Digestate }\end{array}$} & \multirow{2}{*}{$\begin{array}{l}\text { HTC and (Ch) } \\
\text { KOH:Char: } 4: 1\end{array}$} & $250^{\circ} \mathrm{C}$ & $3 \mathrm{~h}$ & \multirow[t]{2}{*}{1762} & \multirow[t]{2}{*}{0.665} \\
\hline & & & $600^{\circ} \mathrm{C}$ & $2 \mathrm{~h}$ & & \\
\hline \multirow[t]{2}{*}{ [92] } & \multirow[t]{2}{*}{ Digestate } & HTC and (Ch) & $250^{\circ} \mathrm{C}$ & $1 \mathrm{~h}$ & \multirow[t]{2}{*}{1106} & \multirow[t]{2}{*}{0.54} \\
\hline & & KOH:Char: 3:1 & $600^{\circ} \mathrm{C}$ & $2 \mathrm{~h}$ & & \\
\hline
\end{tabular}




\begin{tabular}{|c|c|c|c|c|c|c|}
\hline \multirow[t]{2}{*}{ [92] } & \multirow[t]{2}{*}{ Digestate } & \multirow{2}{*}{$\begin{array}{l}\text { HTC with } \mathrm{H}_{2} \mathrm{SO}_{4} \\
\text { and } \quad(\mathrm{Ch}) \\
\text { KOH:Char: } 3: 1\end{array}$} & $250^{\circ} \mathrm{C}$ & $1 \mathrm{~h}$ & \multirow[t]{2}{*}{503} & \multirow[t]{2}{*}{0.30} \\
\hline & & & $600^{\circ} \mathrm{C}$ & $2 \mathrm{~h}$ & & \\
\hline \multirow[t]{2}{*}{ [93] } & \multirow[t]{2}{*}{ Digestate } & \multirow[t]{2}{*}{$\begin{array}{l}\text { Carbonization and } \\
\text { (Ch) KOH:char: }\end{array}$} & $\begin{array}{ll}400^{\circ} \mathrm{C} & + \\
850^{\circ} \mathrm{C} & \\
\end{array}$ & $\begin{array}{l}1 \mathrm{~h}+3.5 \\
\mathrm{~h}\end{array}$ & \multirow[t]{2}{*}{1754} & \multirow[t]{2}{*}{-} \\
\hline & & & $850^{\circ} \mathrm{C}$ & $1 \mathrm{~h}$ & & \\
\hline
\end{tabular}

Table 6: Key Parameters during chemical and physical activation of olive stone; $\mathrm{Ch}=$ Chemical activation; $\mathrm{Ph}=$ physical activation; $\mathrm{BO}=\mathrm{Burn}$-off

\begin{tabular}{|c|c|c|c|c|c|c|}
\hline \multicolumn{7}{|c|}{ ACTIVATION OF OLIVE STONE } \\
\hline Source & Precursor & Activation & Temperature & Time & $\begin{array}{l}\text { Surface } \\
\text { area } \\
\left(\mathrm{m}^{2} / \mathrm{g}\right)\end{array}$ & $\begin{array}{l}\text { Micropore } \\
\text { volume } \\
\left(\mathrm{cm}^{3} / \mathrm{g}\right)\end{array}$ \\
\hline [94] & Olive stone & $\begin{array}{l}\text { (Ch) Impregnation } \\
\text { with H3PO4 (60 } \\
\text { wt\%) and } \\
\text { carbonization }\end{array}$ & $500^{\circ} \mathrm{C}$ & $2 \mathrm{~h}$ & 257 & 0.123 \\
\hline [94] & Olive stone & $\begin{array}{l}\text { (Ch) Impregnation } \\
\text { with H3PO4 (70 } \\
\text { wt\%) and } \\
\text { carbonization }\end{array}$ & $500^{\circ} \mathrm{C}$ & $2 \mathrm{~h}$ & 779 & 0.35 \\
\hline [94] & Olive Stone & $\begin{array}{l}\text { (Ch) Impregnation } \\
\text { with H3PO4 (80 } \\
\text { wt\%) and } \\
\text { carbonization }\end{array}$ & $500^{\circ} \mathrm{C}$ & $2 \mathrm{~h}$ & 1218 & 0.6 \\
\hline \multirow[t]{2}{*}{ [95] } & \multirow[t]{2}{*}{ Olive Stone } & \multirow{2}{*}{$\begin{array}{l}\text { Carbonization and } \\
(\mathrm{Ch}) \quad \mathrm{KOH} \\
(50 \mathrm{wt} \%) \text { :Char: } 1: 1\end{array}$} & $600^{\circ} \mathrm{C}$ & $1 \mathrm{~h}$ & \multirow[t]{2}{*}{-} & \multirow[t]{2}{*}{-} \\
\hline & & & $900^{\circ} \mathrm{C}$ & $3 \mathrm{~h}$ & & \\
\hline \multirow[t]{2}{*}{ [95] } & \multirow{2}{*}{ Olive Stone } & \multirow{2}{*}{$\begin{array}{l}\text { Carbonization and } \\
(\mathrm{Ch}) \quad \mathrm{KOH} \\
(75 \mathrm{wt} \%) \text { :Char: } 1: 1\end{array}$} & $600^{\circ} \mathrm{C}$ & $1 \mathrm{~h}$ & \multirow[t]{2}{*}{ - } & \multirow[t]{2}{*}{-} \\
\hline & & & $900^{\circ} \mathrm{C}$ & $3 \mathrm{~h}$ & & \\
\hline$[96,97]$ & Olive stone & $\begin{array}{l}\text { (Ch) Impregnation } \\
\text { with } \quad \mathrm{ZnCl}_{2} \\
(20 \mathrm{wt} \%)\end{array}$ & $650^{\circ} \mathrm{C}$ & $2 \mathrm{~h}$ & 790.25 & - \\
\hline \multirow[t]{2}{*}{ [98] } & \multirow[t]{2}{*}{ Olive stone } & \multirow{2}{*}{$\begin{array}{l}\text { Carbonization and } \\
\text { (Ch) KOH:char: } \\
0.5: 1\end{array}$} & $350^{\circ} \mathrm{C}$ & $1 \mathrm{~h}$ & \multirow[t]{2}{*}{1500} & \multirow[t]{2}{*}{0.31} \\
\hline & & & $800^{\circ} \mathrm{C}$ & $2 \mathrm{~h}$ & & \\
\hline \multirow[t]{2}{*}{ [98] } & \multirow[t]{2}{*}{ Olive stone } & \multirow{2}{*}{$\begin{array}{l}\text { Carbonization and } \\
\text { (Ch) KOH:char: } \\
1: 1\end{array}$} & $350^{\circ} \mathrm{C}$ & $1 \mathrm{~h}$ & \multirow[t]{2}{*}{1635} & \multirow[t]{2}{*}{0.52} \\
\hline & & & $800^{\circ} \mathrm{C}$ & $2 \mathrm{~h}$ & & \\
\hline \multirow[t]{2}{*}{ [98] } & \multirow[t]{2}{*}{ Olive stone } & \multirow{2}{*}{$\begin{array}{l}\text { Carbonization and } \\
\text { (Ch) KOH:char: } \\
2: 1\end{array}$} & $350^{\circ} \mathrm{C}$ & $1 \mathrm{~h}$ & \multirow[t]{2}{*}{1768} & \multirow[t]{2}{*}{0.80} \\
\hline & & & $800^{\circ} \mathrm{C}$ & $2 \mathrm{~h}$ & & \\
\hline \multirow[t]{2}{*}{ [98] } & \multirow[t]{2}{*}{ Olive stones } & \multirow{2}{*}{$\begin{array}{l}\text { Carbonization and } \\
(\mathrm{Ch}) \quad \mathrm{H}_{3} \mathrm{PO}_{4} \\
(75 \mathrm{wt} \%) \text { :char: } \\
2.4: 1 \text {; steam }\end{array}$} & $350^{\circ} \mathrm{C}$ & $1 \mathrm{~h}$ & \multirow[t]{2}{*}{393} & \multirow[t]{2}{*}{0.12} \\
\hline & & & $500^{\circ} \mathrm{C}$ & $1 \mathrm{~h}$ & & \\
\hline \multirow[t]{2}{*}{ [98] } & \multirow[t]{2}{*}{ Olive stones } & \multirow{2}{*}{$\begin{array}{l}\text { Carbonization and } \\
(\mathrm{Ph}) \mathrm{CO}_{2}\end{array}$} & $350^{\circ} \mathrm{C}$ & $1 \mathrm{~h}$ & 584 & 0.11 \\
\hline & & & $840^{\circ} \mathrm{C}$ & $11 \% \mathrm{BO}$ & & \\
\hline [98] & Olive stones & Carbonization and & $350^{\circ} \mathrm{C}$ & $1 \mathrm{~h}$ & 793 & 0.14 \\
\hline & & $(\mathrm{Ph}) \mathrm{CO}_{2}$ & $840^{\circ} \mathrm{C}$ & $27 \% \mathrm{BO}$ & & \\
\hline [98] & Olive stones & & $350^{\circ} \mathrm{C}$ & $1 \mathrm{~h}$ & 1038 & 0.17 \\
\hline
\end{tabular}




\begin{tabular}{|l|l|l|l|l|l|l|}
\hline & & $\begin{array}{l}\text { Carbonization and } \\
(\mathrm{Ph}) \mathrm{CO}_{2}\end{array}$ & $840^{\circ} \mathrm{C}$ & $57 \% \mathrm{BO}$ & & \\
\hline$[99]$ & Olive stone & $\begin{array}{l}\text { (Ch) Impregnation } \\
\text { with } \\
(50 \mathrm{wt} \%) \text { :char } \\
10 \mathrm{ml} / \mathrm{g}\end{array}$ & $400^{\circ} \mathrm{C}$ & $2 \mathrm{~h}$ & 1740 & 0.89 \\
\hline
\end{tabular}

Those shown in Table 6 are only some examples on the production of activated carbons from olive stones, they are interesting because they show the influence of different activating agents. It is shown in the literature also that chemical activation is more effective than physical activation in many cases [98]. Chemical activation is generally preferred for olive stones (and also other precursors). More activation examples performed with olive stones are presented in the review [100]. From this review we can see that about 25 chemical activation tests have been performed in the literature, while the performed physical activation tests are only 2. Generally chemical activation produces activated carbons with higher porosity, compared to physical activation.

Dealing with the final yields of activated carbons, some values are presented in Figure 14. These values are taken from [71] and we see that the yields of activated carbons from lignin in most of the cases range from $20 \mathrm{wt} \%$ to $30 \mathrm{wt} \%$, referring to the initial total mass of lignin used. The most important aspect to take into consideration in the activation (especially if it is chemical) is the reactant and the ratio between it and the precursor). In [91] $\mathrm{KOH}$ is used as an activating agent. 




Figure 14: Activated carbon yields obtained with different activation methods and different lignins and lignin-rich substrates $[71,91,94-96]$

$\mathrm{KOH}$ at first during activation reacts with the carbon of the hydrochar and forms $\mathrm{K}_{2} \mathrm{CO}_{3}$ and metallic $\mathrm{K}$ and releases $\mathrm{H}_{2}$. The unstable organic compounds of the hydrochar when heated gasify also and release from these reactions $\mathrm{CO}_{2}$, which is responsible of the increase in porosity. The metallic $\mathrm{K}$ which has been formed by the previous reactions finally reacts again with $\mathrm{C}$ and promotes further gasification. It is possible that the high ratio between $\mathrm{KOH}$ and hydrochar (equal to 4:1) is the reason why the activated carbon yield obtained with the digestate is quite low, if compared to that obtained with lignin. On the other hand the activated carbon from lignin, which is shown in Figure 14, has been obtained through $\mathrm{KOH}$ activation at similar conditions, as it is reported in [71]; so in general it can be inferred that activated carbon yields from digestate are usually lower than those obtained with lignin. This can be explained with the fact that the carbon contained in lignin is more thermally stable. When we consider the case of olive stone, this is quite similar to that of digestate. The only cases in which higher yields are obtained are those in which activation is not performed with a two-step process, so we don't have two thermal treatments: carbonization and activation; but we have only impregnation, followed 
by activation. In this case the final yields of activated carbons can reach easily about $40 \mathrm{wt} \%$. The main differences between the yields of activated carbon obtained with lignin and those obtained with ligninrich residues are due to the behavior of cellulose, hemicellulose and lignin during carbonization. As it has been previously reported, the concentration of lignin is high in pure lignin (obviously), then it decreases in digestate (also depending on the feedstock used in the anaerobic digestion process) and it decreases again in the olive stone.

Regarding the contribution of hemicellulose, cellulose and lignin to final activated carbon mass we can take into consideration the data reported in [68]. The contribution of lignin is estimated to be about 44.6 $\mathrm{wt} \%$, the contribution of cellulose is estimated at about $18.5 \mathrm{wt} \%$; the contribution of hemicellulose is estimated at about $36.9 \mathrm{wt} \%$.

\subsubsection{Further insights on the influence of process parameters on final porosity and activated carbon yields}

As it can be seen from Table 6 an important parameter in the activation process is the burn-off, which can be calculated with the following simple equation [101]:

$$
\mathrm{BO}=(\mathrm{mi}-\mathrm{mf}) / \mathrm{mf}
$$

Where $\mathrm{mi}$ is the initial mass (d.a.f.b.) and $\mathrm{mf}$ is the final mass (d.a.f.b.) after activation. An interesting analysis on the effect of burn-off on the final properties of the activated carbon is reported in [102]. As we know the burn-off is dependent on both process variables: temperature and time of activation. It was 
observed that the $\mathrm{BO}$ has the most important influence on the development of the porosity, this is clearly shown in Figure 15.

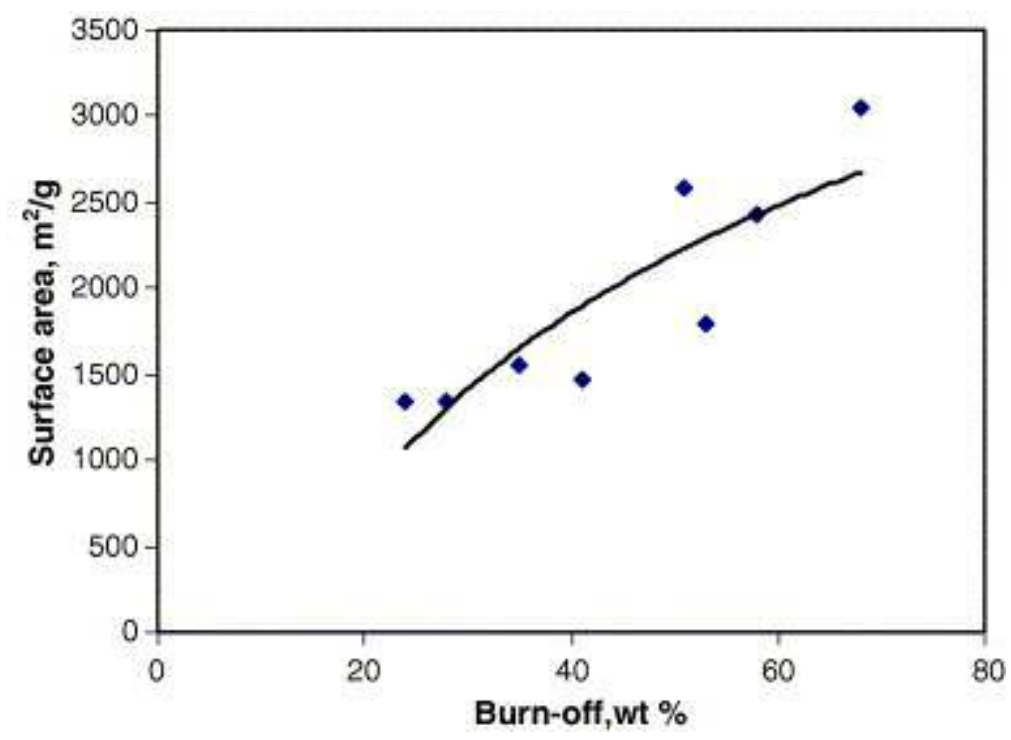

Figure 15: Influence of the burn-off on the development of the surface area in olive stone activated carbon [102]

In the experiments of Zabanotou et al. [102] it is also shown that the methylene blue adsorption is proportional to the surface area of the charcoal, these experiments so confirm that BET analysis is important to understand what will be the adsorption capacity of the produced carbon.

\subsubsection{Lignin and lignin-rich substrates modification processes}

The most interesting way to modify the charcoal is to functionalize its surface as it is explained in [61]. In fact, the charcoal produced through pyrolysis and hydrothermal carbonization has generally a low number of functional groups, such as: $\mathrm{C}-\mathrm{O}-\mathrm{C}, \mathrm{C}=\mathrm{O}$ and $\mathrm{OH}$. It has also a limited surface area and porosity. Surface modification of the charcoal can be performed through the following processes:

- oxidation

- amination 
- sulfonation

The first modification can be performed using the following agents: $\mathrm{H}_{2} \mathrm{O}_{2}, \mathrm{O}_{3}, \mathrm{KMnO}_{4}$ and $\mathrm{HNO}_{3}$ [103106]. These reagents are useful if we want to introduce into the char functional groups such as carboxyl, phenolic hydroxyl, lactones and peroxides. Sulfonation is usually performed using $\mathrm{H}_{2} \mathrm{SO}_{4}$ and its derivatives (e.g. fuming $\mathrm{H}_{2} \mathrm{SO}_{4}$ and $\mathrm{CISO}_{3} \mathrm{H}$ ). Sulfonation is performed to introduce $\mathrm{SO}_{3} \mathrm{H}$ groups in the charcoal [107-111]. Amination is usually performed through $\mathrm{NH}_{3}$ treatment at high temperatures [112-114]. Other possible modifications include the use of amino-containing compounds, such as: 3chloropropylamine, tris(2-aminoethyl)amine, and polyethylenimine. These treatments are more environmentally friendly than the treatment with $\mathrm{NH}_{3}$ because the production of $\mathrm{NH}_{3}$ is highly energy intensive and also polluting. Amino loaded charcoal has the important advantage of being able to chemically retain acidic pollutants.

\subsubsection{Modification of lignin through the production of magnetic charcoal}

Another way to modify lignin is to produce from it magnetic charcoal. The process flow is shown in figure 16, as it is reported in [115]. 


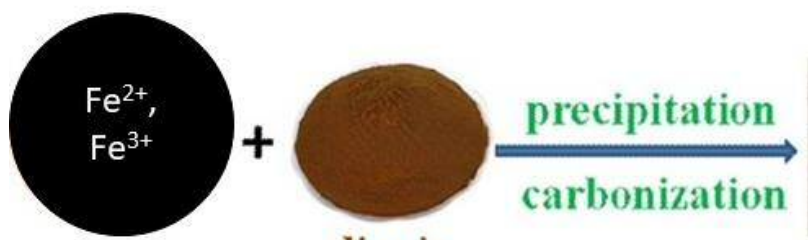
lignin carbonization


separation
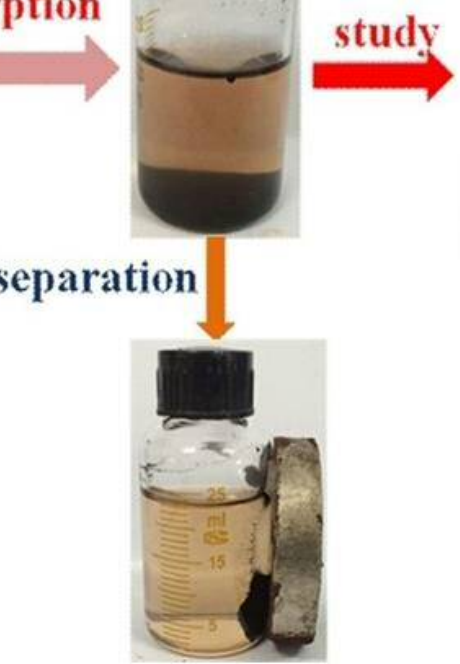

Figure 16: Magnetic lignin-based carbon nanoparticles production process, as reported in [115]

In the particular case $5.4 \mathrm{~g}$ of ferric chloride hexahydrate are mixed together with $3.5 \mathrm{~g}$ of ferrous sulfate heptahydrate in $100 \mathrm{~mL}$ deionized water. Also $30 \mathrm{~mL}$ of $10 \mathrm{wt} \%$ ammonia are added to the solution and the temperature is increased to $90^{\circ} \mathrm{C} .3 \mathrm{~g}$ of Lignin were added to the solution, using again ammonia to regulate the $\mathrm{pH}$ and incubating the solution at $90^{\circ} \mathrm{C}$ for $2 \mathrm{~h}$. the detailed procedure is found in [115]. Once the reaction is completed the magnetic particles (made of lignin coated with iron oxide) were separated from the solution using a permanent magnet, they were then washed with ethanol and dried. Then the particles were carbonized in nitrogen atmosphere at $500^{\circ} \mathrm{C}$ for 3 hours. The adsorption capacity was tested using wastewaters polluted with methylene orange and the performance was interesting: $113 \mathrm{mg} / \mathrm{g}$ of adsorption capacity was reached, which proved to be quite high respect to the literature. This sorbent in fact has two big advantages:

- on one hand the nanoparticles and dissolve in the solution very efficiently and adsorb the polluting substances; 
- on the other hand being magnetic, the sorbent can also be easily separated from the wastewater and recycled.

Similar other experiments have been put in place by [116], using lignin and dopamine they reached an adsorption capacity on $\mathrm{Cr}(\mathrm{III})$ equal to $44.56 \mathrm{mg} / \mathrm{g}$ which has proven to be quite higher respect to other sorbents developed in the literature. Even more interesting is the final price of the sorbent, which is equal to about $500 \$ / t$ so more than half the price of conventional activated charcoal.

Other researchers [117] have produced composite magnetic lignin with good adsorption performances on Congo Red (198.24 mg/g) and Titan Yellow (192.51 mg/g).

Also red mud and lignin wastes can be used as raw materials to produce metal biochar composites [118], If the production of magnetic carbon and aerogels from lignin is quite common [119-123], the production of magnetic carbon from digestate and olive stone is more rare.

\section{The adsorption process theory}

Adsorption can be defined in [45] as the enrichment of a compound from a fluid phase on the surface of a solid (which in this case is the activated charcoal). Generally, the adsorption efficiency is proportional to the surface area of the sorbent (at least this is valid if we are talking about physisorption). If we consider the adsorption process from a thermodynamic point of view, we have to take into consideration that in the adsorption process the Gibbs free energy is not only a function of the system temperature, pressure and composition (expressed in number of moles), but also is a function of the surface (indicated with the letter A). So, the change in the Gibbs free energy equation is given by:

where $\mathrm{S}$ is the Entropy, $\mathrm{V}$ is the volume, $\mu$ is the chemical potential and $\sigma$ is the surface free energy, which can be indicated also as the surface tension. When adsorption happens, the surface free energy decreases from a value of ows (surface tension at the interface between the water and the activated carbon) to the value of $\sigma a s$ (surface tension between adsorbate and solid). The difference between the 
two surface tensions is proportional to the amount of compound which is adsorbed and it is indicated as the spreading pressure, $\pi$.

$$
\sigma \mathrm{ws}-\sigma \mathrm{as}=\pi>0
$$

The variation of enthalpy and the variation of entropy can be used to define the variation of the free energy during adsorption, assuming adsorption is a spontaneous process:

$$
\Delta \text { Gads }=\Delta \text { Hads }-\mathrm{T} \Delta \text { ads }<0
$$

The reaction is negative because the adsorption process is considered to be spontaneous. Given that the adsorption process generally produces a decrease in the disorder of the system, the change of entropy is usually negative. If the change in entropy is negative, equation 7 implies that the change of enthalpy should be negative also, and so the reaction is exothermic (it releases heat in the environment). The adsorption enthalpy is an interesting parameter, which allows us also to evaluate the difference between different adsorption processes (e.g. chemisorption and physisorption). Physical adsorption is usually due to van der Waals forces (such as: dipole-dipole interactions, dispersion forces, induction forces). These interactions are relatively weak (the enthalpy in this case can be evaluated to be lower than 50 $\mathrm{kJ} / \mathrm{mol}$ ). On the other hand, chemical sorption is based on chemical reactions which retain the adsorbate on the surface of the activated carbon (in this case the enthalpy is higher than $50 \mathrm{~kJ} / \mathrm{mol}$ ).

The adsorption process efficiency can be defined by the adsorption capacity, expressed in mg_adsorbate/g_adsorbent. This parameter can be referred to also as adsorbent loading. The loading or the adsorption capacity depends not only on the parameters of the adsorbent (such as its surface area and its functional groups) but also on the adsorption parameters (such as $\mathrm{pH}$, temperature, pressure etc.).

\section{Wastewaters treatment}

\subsection{Adsorption performance of activated carbon from lignin}

While some important reviews have been already published on the sorption capacity of activated charcoals produced from olive stones (as it will be shown in paragraph 6.2), no literature review is 
available on the adsorption of pollutant on activated charcoal produced from lignin. Some reviews are available on the adsorption which happens directly on the charcoal produced from lignin, without activation $[124,125]$.

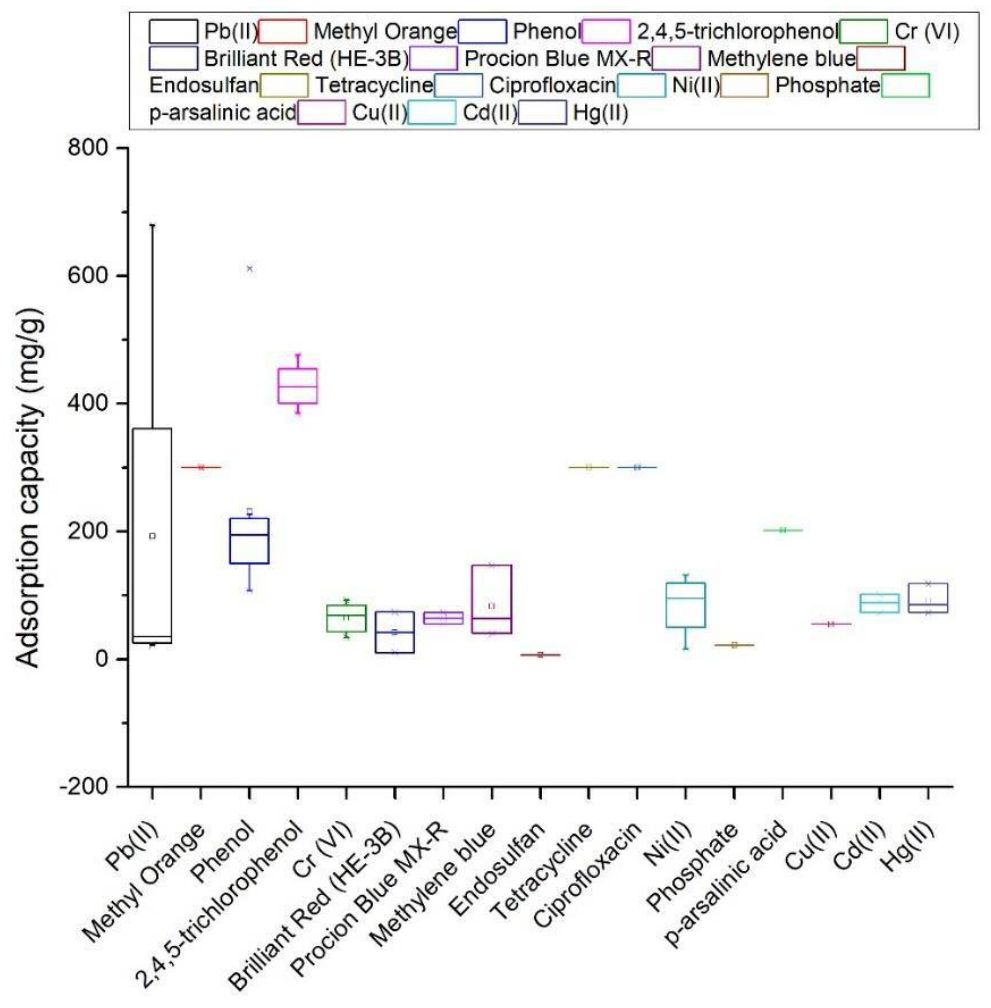

Figure 17: Adsorption capacity of activated carbon produced from lignin

From Figure 17 we see that the adsorption is very variable, depending on the characteristics of the activated carbons and on the process parameters. Generally, higher adsorption is measured for activated carbons with higher surface areas. Activated carbons produced from lignin have also important variations in the adsorption capacities of phenol, reaching very high values for 2,4,5-trichlorophenol.

\subsection{Adsorption performance activated carbons from digestate and olive stone}


As far as olive stone are concerned in the review presented in [100] it can be seen that the activated carbons produced from olive stones have very good adsorption performance, if compared with commercial activated carbons.

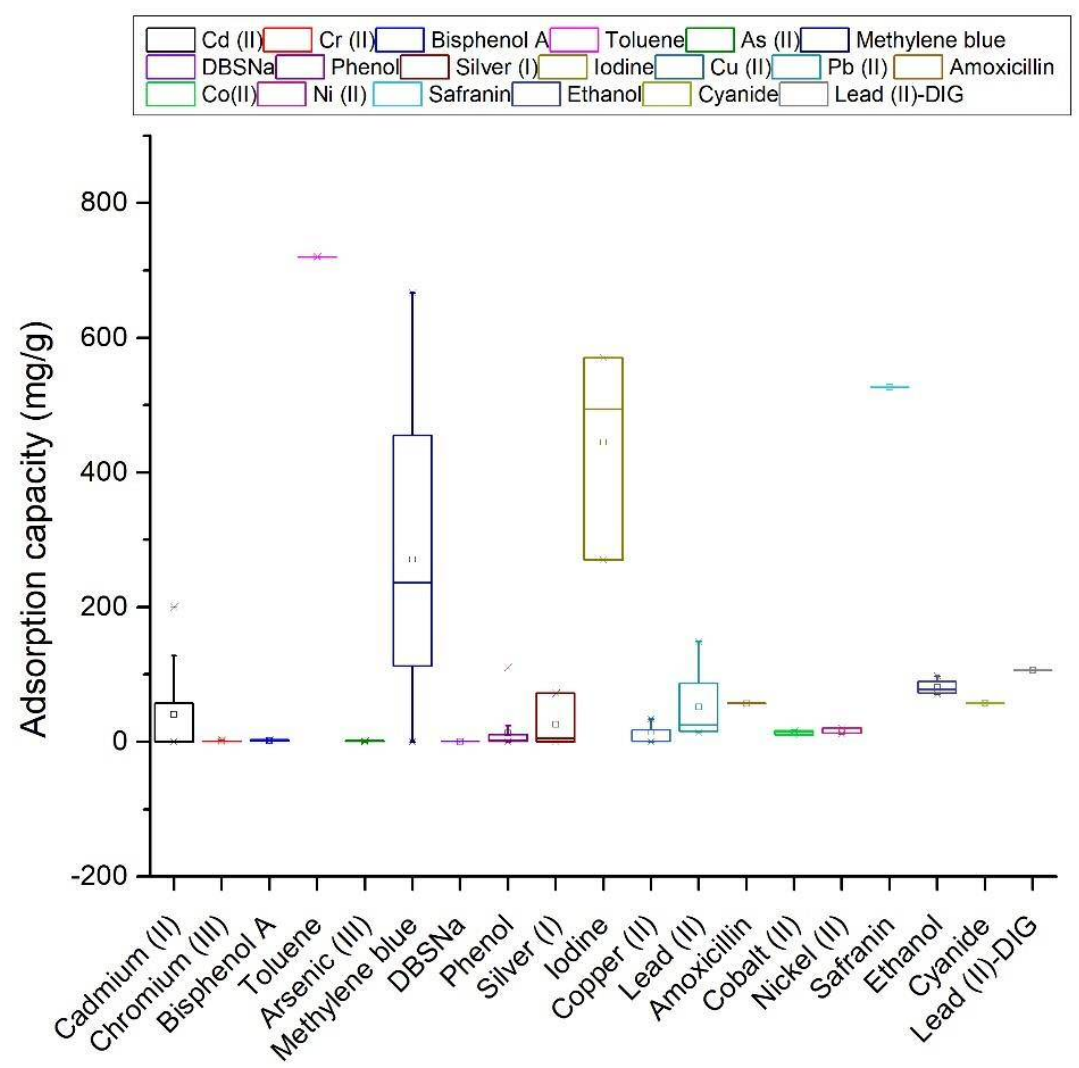

Figure 18: Adsorption capacity of activated carbons produced from olive stones and digestate [100]

The detailed adsorption capacities proposed in Figure 18 are taken from [100], which is a complete review on the performance of sorbents produced from olive stones. According to what is reported in [100], olive stone is a very competitive raw material for the production of activated carbon and can have interesting performances. Particularly interesting is the adsorption of phenolic compounds with activated carbons. This is the topic of the SURFOLY project recently founded under the PRIMA EU funds and managed by the University of Perugia. 


\section{Technical and Economic analysis on the production of activated charcoal from lignin rich}

\section{biomass}

\subsection{Background}

In the work of [126] it is proposed a detailed analysis on the production of alternatives to petroleumbased polymers through technical lignins; where with the term "technical" the following types are indicated:

- lignosulfonates, which are obtained as byproducts of sulphite pulping;

- Kraft Lignin, which is produced from wood kraft pulping process;

- soda lignin, which is generated in the soda pulping process;

- hydrolysis lignin, obtained as a subproducts of second-generation ethanol production;

- organosolv lignin, which is produced from pulping processes that employ organic solvents to separate cellulose from lignin.

Dealing with the identification of best commercial products to be produced using lignin, a screening study [127] has selected the following promising products: phenol produced from Kraft lignin to be used in the synthesis of phenol-formaldehyde (PF) resins; polyols produced from lignosulfonate to be used in the synthesis of polyurethane (PU) foam; carbon fiber produced from organosolv lignin. In [127] it is presented also an interesting figure in which it is clearly identified the market price and the market size of different added value products which can be produced from lignin. The diameter of the bubbles in the graph is given by the product of the market value and the market price of the added value product. The percentage associated to each bubble represents the market share of the product respect to the total sum of the market shares of all the products. Three categories of final uses can be identified:

- high volume and low value (eg. bioenergy);

- low volume and high value (eg. carbon fibers);

- medium volume and medium value (eg. phenol). 
The dotted square in figure 19 represents the most interesting productions which can give the highest return. BTX, bitumen and phenols represent the markets with the highest volumes. Lignosulfonates can be successfully transformed in vanillin, additives and dispersants.

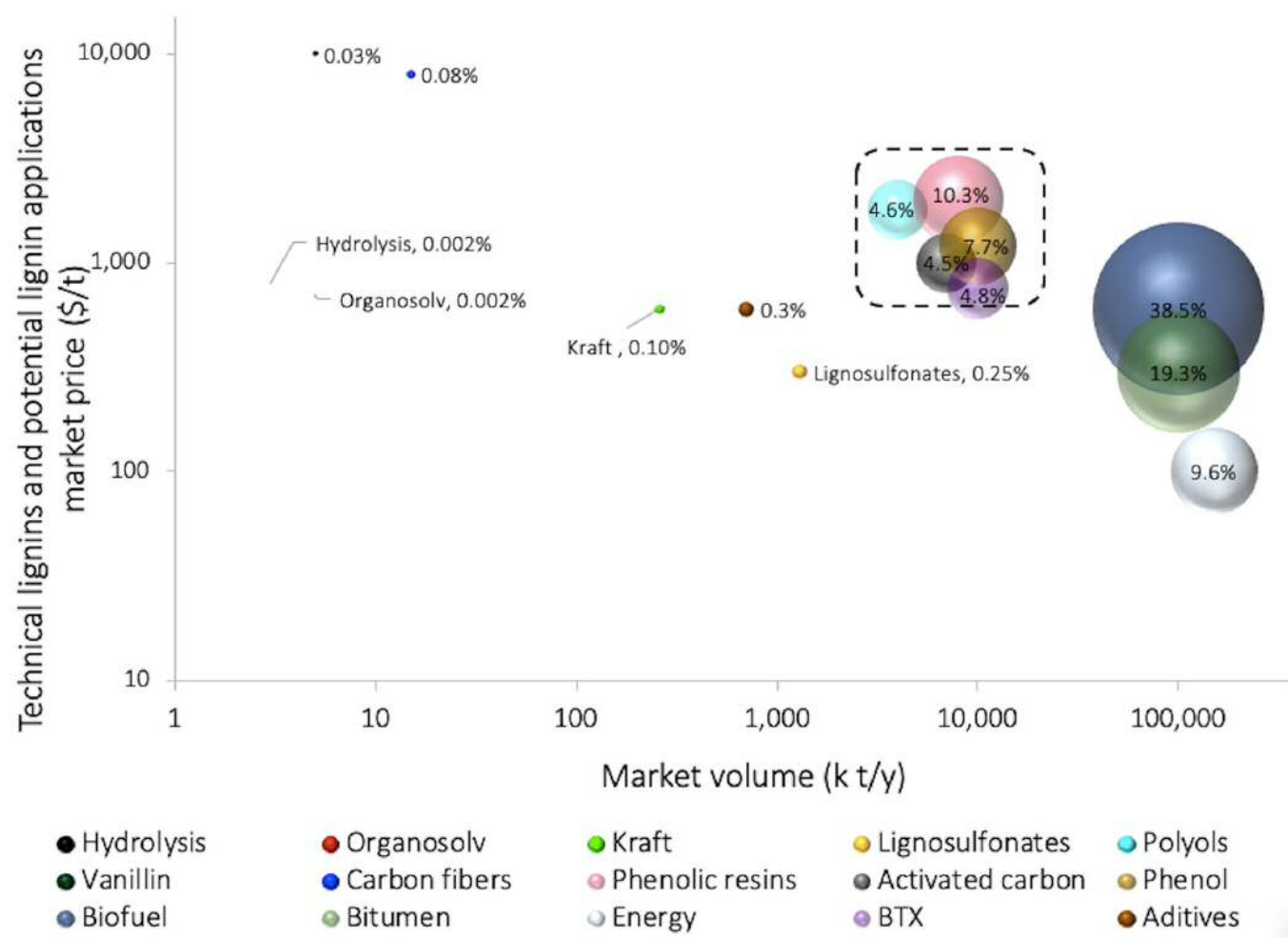

Figure 19: Potential market of added value products produced from lignin [127]

Other useful added value products are thermoplastics. The entire annual production of lignin could cover about $2 \%$ of the global consumption of plastics in the world [128]. The market of thermoplastics in fact is characterized by an annual demand of $280 \mathrm{Mt} / \mathrm{y}$ [129].

\subsection{Activated charcoal production costs}

An important work on the estimation of the production costs of activated carbons is reported in [33].The analysis starts with the identification of potential yields and also of product quality (based on surface area), see table 7 . 
Table 7: Activated carbon yields and surface areas

\begin{tabular}{|l|l|l|l|l|l|}
\hline Raw material & Type of & \multicolumn{3}{|c|}{ Activated carbon yield (wt\%) } & \multicolumn{1}{|c|}{$\begin{array}{l}\text { Surface } \\
\text { activation }\end{array}$} \\
\cline { 3 - 5 } & & Pyrolysis yield & $\begin{array}{l}\text { Activation } \\
\text { yield }\end{array}$ & $\begin{array}{l}\text { Total carbon } \\
\text { yield }\end{array}$ & Area $\left(\mathrm{m}^{2} / \mathrm{g}\right)$ \\
\hline Wood & $\begin{array}{l}\text { Activation with } \\
\text { steam }\end{array}$ & 25 & 50 & 12.5 & 800 \\
\hline Used tires & $\begin{array}{l}\text { Activation with } \\
\text { steam }\end{array}$ & 30 & 50 & 15 & 500 \\
\hline Pet coke & $\begin{array}{l}\text { Activation with } \\
\text { steam }\end{array}$ & 90 & 70 & 63 & 1000 \\
\hline Carbon Black & $\begin{array}{l}\text { Activation with } \\
\text { steam }\end{array}$ & 95 & 50 & 47.5 & 500 \\
\hline Charcoal & $\begin{array}{l}\text { Activation with } \\
\text { steam }\end{array}$ & 90 & 50 & 45 & 900 \\
\hline Lignite & $\begin{array}{l}\text { Activation with } \\
\text { steam }\end{array}$ & 52 & 30 & 15.6 & 800 \\
\hline Wood & $\begin{array}{l}\text { Activation with } \\
\text { KOH }\end{array}$ & N/A & N/A & 22 & 800 \\
\hline Used tires & $\begin{array}{l}\text { Activation with } \\
\text { KOH }\end{array}$ & N/A & N/A & 20 & 700 \\
\hline Pet coke & $\begin{array}{l}\text { Activation with } \\
\text { KOH }\end{array}$ & N/A & N/A & 45 & 3000 \\
\hline Carbon black & $\begin{array}{l}\text { Activation with } \\
\text { KOH }\end{array}$ & N/A & N/A & 60 & 500 \\
\hline Charcoal & $\begin{array}{l}\text { Activation with } \\
\text { KOH }\end{array}$ & N/A & N/A & 44 & 2000 \\
\hline Lignite & $\begin{array}{l}\text { Activation with } \\
\text { KOH }\end{array}$ & N/A & N/A & 25 & 2200 \\
\hline
\end{tabular}

The final costs of the produced activated carbon for a plant with production capacity of $4.5 \mathrm{t} /$ day are reported in figure 20. The two alternatives are compared (with the assumption that the raw material has zero cost of supply): chemical activation (with $\mathrm{KOH}$ ) and physical activation (with steam). We can see from figure 20 that in general chemical activation has better performance than physical activation, this is due to the higher yields. The payback period of the plants range from 3 to 12 years, depending on the feedstock. The best performances in physical activation are achieved by pet coke: 3.12 years. The best performance for chemical activation are achieved by carbon black: 3.94 years. 


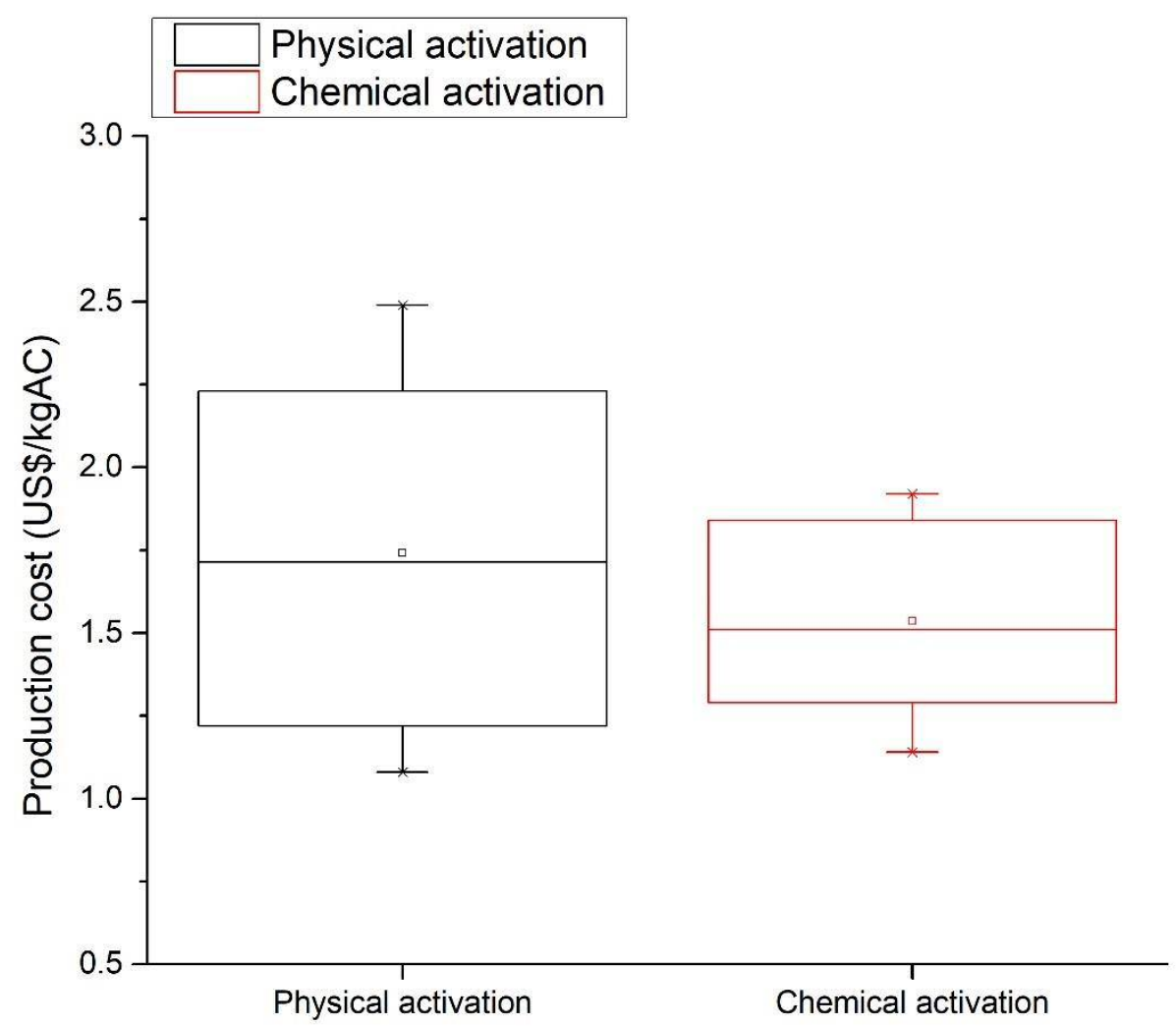

\section{Conclusions}

Lignin used as a precursor for the preparation of magnetic activated charcoal has been investigated and reviewed based on relevant articles published. Magnetic activated charcoal adsorbents are highly efficient for the removal of pollutants such as heavy metal ions, dyes, and organic and inorganic compounds. In past years a lot of low-cost biomass-based adsorbents has been synthesized and characterized, such as commercially activated carbon, but for large scale application they showed many complications, such as the separation process of activated carbon. On the other hand, magnetic activated materials showed great scope and application for wastewater treatment because of their physicochemical properties, large surface area and volume, great affinity toward pollutants and easy separation process. Based on detailed reviewed research articles it is concluded that the lignin based magnetic activated materials such as carbon nanotubes, nanoporous materials, are highly efficient for the wastewater treatment from small scale to large scale. 


\section{Acknowledgement}

This work is supported by the e-COST European Cooperation in Science and Technology, UK Biochar research center at Edinburgh University UK, the BioCarbUp project at SINTEF Energy Research and Biomass research center at Perugia University Italy.

\section{Reference}

1. Hu, J., Q. Zhang, and D.-J. Lee, Kraft lignin biorefinery: A perspective. Bioresource Technology, 2018. 247: p. 1181-1183.

2. Bajwa, D.S., et al., A concise review of current lignin production, applications, products and their environmental impact. Industrial Crops and Products, 2019. 139: p. 111526.

3. Ralph, J., C. Lapierre, and W. Boerjan, Lignin structure and its engineering. Current Opinion in Biotechnology, 2019. 56: p. 240-249.

4. Vanholme, R., et al., Lignin engineering. Current Opinion in Plant Biology, 2008. 11(3): p. 278285.

5. Noche, P.V.P.B., A review of the current digestate distribution models: storage and transport www.witpress.com, ISSN 1743-3541 (on-line) WIT Transactions on Ecology and The Environment, Vol 202, (C) 2016 WIT Press, doi:10.2495/WM160311, 2016.

6. Xue, S., et al., A systematic comparison of biogas development and related policies between China and Europe and corresponding insights. Renewable and Sustainable Energy Reviews, 2020. 117: p. 109474.

7. Rodríguez, G., et al., Olive stone an attractive source of bioactive and valuable compounds. Bioresource Technology, 2008. 99(13): p. 5261-5269.

8. Yahya, M.A., Z. Al-Qodah, and C.W.Z. Ngah, Agricultural bio-waste materials as potential sustainable precursors used for activated carbon production: A review. Renewable and Sustainable Energy Reviews, 2015. 46: p. 218-235. 
9. Hagemann, N., et al., Activated Carbon, Biochar and Charcoal: Linkages and Synergies across Pyrogenic Carbon's ABCs. Water, 2018. 10(2): p. 182.

10. Wang, S., et al., Lignocellulosic biomass pyrolysis mechanism: A state-of-the-art review. Progress in Energy and Combustion Science, 2017. 62: p. 33-86.

11. Funke, A. and F. Ziegler, Hydrothermal carbonization of biomass: $A$ summary and discussion of chemical mechanisms for process engineering. Biofuels, Bioproducts and Biorefining, 2010. 4(2): p. $160-177$.

12. McDougall, G.J., Physical nature and manufacture of activated carbon. Journal of The South African Institute of Mining and Metallurgy, 1991. 91(4): p. 109-120.

13. Al-Qodah, Z. and R. Shawabkah, Production and characterization of granular activated carbon from activated sludge. Brazilian Journal of Chemical Engineering, 2009. 26(1): p. 127-136.

14. Cruz, G., et al., Production of activated carbon from cocoa (Theobroma cacao) pod husk. J. Civ. Environ. Eng., 2012. 2(2): p. 1-6.

15. Asadullah, M., et al., Adsorption studies on activated carbon derived from steam activation of jute stick char. Journal of Surface Science and Technology, 2007. 23(1-2): p. 73-80.

16. Donald, J., Y. Ohtsuka, and C. Xu, Effects of activation agents and intrinsic minerals on pore development in activated carbons derived from a Canadian peat. Materials Letters, 2011. 65(4): p. 744-747.

17. Demiral, H., et al., Pore structure of activated carbon prepared from hazelnut bagasse by chemical activation. Surface and Interface Analysis, 2008. 40(3-4): p. 616-619.

18. Zhengrong, G. and W. Xiaomin, Carbon materials from high ash bio-char: a nanostructure similar to activated grapheme. Am Trans Eng Appl Sci, 2013. 2(1): p. 15-34.

19. Hayashi, J.i., et al., Preparing activated carbon from various nutshells by chemical activation with K2CO3. Carbon, 2002. 40(13): p. 2381-2386. 
20. Adinata, D., W.M.A. Wan Daud, and M.K. Aroua, Preparation and characterization of activated carbon from palm shell by chemical activation with K2CO3. Bioresource Technology, 2007. 98(1): p. 145-149.

21. Jassim, A.N., et al., Preparation and characterization of activated carbon from Iraqi apricot stones. Can J Cheml Eng Tech, 2012. 3: p. 60-65.

22. Chiang, H.-L., C.P. Huang, and P.C. Chiang, The surface characteristics of activated carbon as affected by ozone and alkaline treatment. Chemosphere, 2002. 47(3): p. 257-265.

23. Oh, W.-C., H.-J. Lee, and J.-S. Bae, REMOVAL EFFICIENCY OF THE POLLUTANTS BY MULTILAYERED METAL TREATED CARBON FILTER. Environmental Engineering Research, 2004. 9(5): p. 193-200.

24. Puziy, A.M., et al., XPS and NMR studies of phosphoric acid activated carbons. Carbon, 2008. 46(15): p. 2113-2123.

25. Gaur, V. and P.A. Shankar, Surface modification of activated carbon for the removal of water impurities. Water Cond Purif, 2008: p. 1-5.

26. Li, L., P.A. Quinlivan, and D.R.U. Knappe, Effects of activated carbon surface chemistry and pore structure on the adsorption of organic contaminants from aqueous solution. Carbon, 2002. 40(12): p. 2085-2100.

27. Oh, W.C. and C.S. Lim, Metal elimination effect by sulfuric acid for Ag and Cu pre-treated activated carbon. Journal of Ceramic Processing Research, 2006. 7(2): p. 95-105.

28. Boretti, A. and L. Rosa, Reassessing the projections of the World Water Development Report. npj Clean Water, 2019. 2(1): p. 15.

29. Mugagga, F. and B.B. Nabaasa, The centrality of water resources to the realization of Sustainable Development Goals (SDG). A review of potentials and constraints on the African continent. International Soil and Water Conservation Research, 2016. 4(3): p. 215-223.

30. Liu, J., et al., Nexus approaches to global sustainable development. Nature Sustainability, 2018. 1(9): p. 466-476. 
31. Marsh, H. and F.R. Reinoso, Activated carbon. 2006: Elsevier.

32. MarketsandMarkets, Activated Carbon Market by Type (Powdered, Granular, Others (Pelletized, Bead)), Application (Liquid Phase (Water Treatment, Foods \& Beverages, Pharmaceutical \& Medical), Gaseous Phase (Industrial, Automotive)), Region - Global Forecast to 2021. 2017.

33. Stavropoulos, G.G. and A.A. Zabaniotou, Minimizing activated carbons production cost. Fuel Processing Technology, 2009. 90(7): p. 952-957.

34. Mailler, R., et al., Study of a large scale powdered activated carbon pilot: Removals of a wide range of emerging and priority micropollutants from wastewater treatment plant effluents. Water Research, 2015. 72: p. 315-330.

35. Suhas, P.J.M. Carrott, and M.M.L. Ribeiro Carrott, Lignin - from natural adsorbent to activated carbon: A review. Bioresource Technology, 2007. 98(12): p. 2301-2312.

36. Xiang, W., et al., Biochar technology in wastewater treatment: A critical review. Chemosphere, 2020. 252: p. 126539.

37. Inyang, M.I., et al., A review of biochar as a low-cost adsorbent for aqueous heavy metal removal. Critical Reviews in Environmental Science and Technology, 2016. 46(4): p. 406-433.

38. Wang, X., et al., Recent advances in biochar application for water and wastewater treatment: a review. PeerJ, 2020. 8: p. e9164-e9164.

39. Shaheen, S.M., et al., Wood-based biochar for the removal of potentially toxic elements in water and wastewater: a critical review. International Materials Reviews, 2019. 64(4): p. 216247.

40. Tang, Y., et al., Influence of pyrolysis temperature on production of digested sludge biochar and its application for ammonium removal from municipal wastewater. Journal of Cleaner Production, 2019. 209: p. 927-936. 
41. Godwin, P.M., et al., Progress in Preparation and Application of Modified Biochar for Improving Heavy Metal Ion Removal From Wastewater. Journal of Bioresources and Bioproducts, 2019. 4(1): p. 31-42.

42. Kopecký, M., et al., Modified Biochar-A Tool for Wastewater Treatment. Energies, 2020. 13(20): p. 1-13.

43. Cooney, D.O., Adsorption design for wastewater treatment. 1998, United States: Lewis Publishers, Boca Raton, FL (United States).

44. Sciences, B.o.T.a.E.H.H.S.D.W.C.A.o.L., Drinking Water and Health,: Volume 2. 1980, Washington, DC: The National Academies Press. 408.

45. Worch, E., Adsorption Technology in Water Treatment: Fundamentals, Processes, and Modeling. 2012, Berlin, Boston: De Gruyter.

46. Ferhan Çeçen, Ö.A., Activated Carbon for Water and Wastewater Treatment, Wiley, Editor. 2011. p. 365-388.

47. Supanchaiyamat, N., et al., Lignin materials for adsorption: Current trend, perspectives and opportunities. Bioresource Technology, 2019. 272: p. 570-581.

48. Cotoruelo, L.M., et al., Activated Carbons from Lignin: Their Application in Liquid Phase Adsorption. Separation Science and Technology, 2007. 42(15): p. 3363-3389.

49. Rabinovich, M.L., et al., Carbon adsorbents from industrial hydrolysis lignin: The USSR/Eastern European experience and its importance for modern biorefineries. Renewable and Sustainable Energy Reviews, 2016. 57: p. 1008-1024.

50. Gordobil, O., et al., Assesment of technical lignins for uses in biofuels and biomaterials: Structure-related properties, proximate analysis and chemical modification. Industrial Crops and Products, 2016. 83: p. 155-165.

51. García, R., et al., Spanish biofuels heating value estimation. Part II: Proximate analysis data. Fuel, 2014. 117: p. 1139-1147. 
52. Cordero, T., et al., Predicting heating values of lignocellulosics and carbonaceous materials from proximate analysis. Fuel, 2001. 80(11): p. 1567-1571.

53. Nevárez, L.A.M., et al., Biopolymer-based nanocomposites: effect of lignin acetylation in cellulose triacetate films. Science and Technology of Advanced Materials, 2011. 12(4): p. 045006.

54. Baumberger, S., et al., Molar mass determination of lignins by size-exclusion chromatography: towards standardisation of the method. Holzforschung, 2007. 61(4): p. 459-468.

55. Bartocci, P., et al., Kinetic Analysis of Digestate Slow Pyrolysis with the Application of the Master-Plots Method and Independent Parallel Reactions Scheme. Molecules, 2019. 24(9).

56. Barbanera, M., F. Cotana, and U. Di Matteo, Co-combustion performance and kinetic study of solid digestate with gasification biochar. Renewable Energy, 2018. 121: p. 597-605.

57. Fernández-Bolaños, J., et al., Characterization of the lignin obtained by alkaline delignification and of the cellulose residue from steam-exploded olive stones. Bioresource Technology, 1999. 68(2): p. 121-132.

58. Bartocci, P., et al., Pyrolysis of Olive Stone for Energy Purposes. Energy Procedia, 2015. 82: p. $374-380$.

59. Chu, S., A.V. Subrahmanyam, and G.W. Huber, The pyrolysis chemistry of a B-O-4 type oligomeric lignin model compound. Green Chemistry, 2013. 15(1): p. 125-136.

60. Ben, H. and A.J. Ragauskas, NMR Characterization of Pyrolysis Oils from Kraft Lignin. Energy \& Fuels, 2011. 25(5): p. 2322-2332.

61. Liu, W.-J., H. Jiang, and H.-Q. Yu, Thermochemical conversion of lignin to functional materials: a review and future directions. Green Chemistry, 2015. 17(11): p. 4888-4907.

62. Rutherford, D.W., et al., Effect of formation conditions on biochars: Compositional and structural properties of cellulose, lignin, and pine biochars. Biomass and Bioenergy, 2012. 46: p. 693-701. 
63. Caballero, J.A., A. Marcilla, and J.A. Conesa, Thermogravimetric analysis of olive stones with sulphuric acid treatment. Journal of Analytical and Applied Pyrolysis, 1997. 44(1): p. 75-88.

64. Caballero, J.A., et al., Pyrolysis kinetics of almond shells and olive stones considering their organic fractions. Journal of Analytical and Applied Pyrolysis, 1997. 42(2): p. 159-175.

65. Carrott, P.J.M., et al., Reactivity and porosity development during pyrolysis and physical activation in $\mathrm{CO} 2$ or steam of kraft and hydrolytic lignins. Journal of Analytical and Applied Pyrolysis, 2008. 82(2): p. 264-271.

66. Balwant Singh, M.C.A., Johannes Lehmann, Biochar, A Guide to Analytical Methods. ISBN $9781498765534,2017$.

67. Goldfarb, J.L., et al., Novel Integrated Biorefinery for Olive Mill Waste Management: Utilization of Secondary Waste for Water Treatment. ACS Sustainable Chemistry \& Engineering, 2017. 5(1): p. $876-884$.

68. Boundzanga, H.M., et al., Contributions of hemicellulose, cellulose, and lignin to the mass and the porous characteristics of activated carbons produced from biomass residues by phosphoric acid activation. Biomass Conversion and Biorefinery, 2020.

69. Collard, F.-X. and J. Blin, A review on pyrolysis of biomass constituents: Mechanisms and composition of the products obtained from the conversion of cellulose, hemicelluloses and lignin. Renewable and Sustainable Energy Reviews, 2014. 38: p. 594-608.

70. Peterson, A.A., et al., Thermochemical biofuel production in hydrothermal media: A review of sub- and supercritical water technologies. Energy \& Environmental Science, 2008. 1(1): p. 3265.

71. Rodríguez Correa, C., et al., Influence of the Carbonization Process on Activated Carbon Properties from Lignin and Lignin-Rich Biomasses. ACS Sustainable Chemistry \& Engineering, 2017. 5(9): p. 8222-8233. 
72. Kang, S., et al., A direct synthesis of adsorbable hydrochar by hydrothermal conversion of lignin. Energy Sources, Part A: Recovery, Utilization, and Environmental Effects, 2016. 38(9): p. $1255-1261$.

73. Missaoui, A., et al., Hydrothermal carbonization of dried olive pomace: Energy potential and process performances. Journal of Analytical and Applied Pyrolysis, 2017. 128: p. 281-290.

74. Cao, Z., et al., Hydrothermal carbonization of biogas digestate: Effect of digestate origin and process conditions. Waste Management, 2019. 100: p. 138-150.

75. Kang, S., et al., Characterization of Hydrochars Produced by Hydrothermal Carbonization of Lignin, Cellulose, $d$-Xylose, and Wood Meal. Industrial \& Engineering Chemistry Research, 2012. 51(26): p. 9023-9031.

76. Dizhbite, T., et al., Lignin - a useful bioresource for the production of sorption-active materials. Bioresource Technology, 1999. 67(3): p. 221-228.

77. Demirbas, A., Adsorption of lead and cadmium ions in aqueous solutions onto modified lignin from alkali glycerol delignication. Journal of Hazardous Materials, 2004. 109(1-3): p. 221-226.

78. Lalvani, S.B., A. Hübner, and T.S. Wiltowski, Chromium adsorption by lignin. Energy Sources, 2000. 22(1): p. 45-56.

79. Mackay, D. and P. Roberts, The influence of pyrolysis conditions on the subsequent gasification of lignocellulosic chars. Carbon, 1982. 20(2): p. 105-111.

80. Mackay, D. and P. Roberts, The dependence of char and carbon yield on lignocellulosic precursor composition. Carbon, 1982. 20(2): p. 87-94.

81. Khezami, L., et al., Production and characterisation of activated carbon from wood components in powder: Cellulose, lignin, xylan. Powder Technology, 2005. 157(1): p. 48-56.

82. Rodríguez-Mirasol, J., T. Cordero, and J.J. Rodríguez, Activated Carbons from CO2 Partial Gasification of Eucalyptus Kraft Lignin. Energy and Fuels, 1993. 7(1): p. 133-138.

83. Hayashi, J., et al., Preparation of activated carbon from lignin by chemical activation. Carbon, 2000. 38(13): p. 1873-1878. 
84. Baklanova, O.N., et al., Preparation of microporous sorbents from cedar nutshells and hydrolytic lignin. Carbon, 2003. 41(9): p. 1793-1800.

85. Kuznetsov, B.N. and M.L. Shchipko, The conversion of wood lignin to char materials in a fluidized bed of AlCuCr oxide catalysts. Bioresource Technology, 1995. 52(1): p. 13-19.

86. Gergova, K., N. Petrov, and S. Eser, Adsorption properties and microstructure of activated carbons produced from agricultural by-products by steam pyrolysis. Carbon, 1994. 32(4): p. 693-702.

87. Gonzalez-Serrano, E., et al., Development of Porosity upon Chemical Activation of Kraft Lignin with $\mathrm{ZnCl}$. Industrial and Engineering Chemistry Research, 1997. 36(11): p. 4832-4838.

88. Gonzalez-Serrano, E., et al., Removal of water pollutants with activated carbons prepared from H3PO4 activation of lignin from kraft black liquors. Water Research, 2004. 38(13): p. 30433050.

89. Zou, Y. and B.X. Han, Preparation of activated carbons from Chinese coal and hydrolysis lignin. Adsorption Science and Technology, 2001. 19(1): p. 59-72.

90. Fierro, V., et al., Activated carbons prepared from kraft lignin by phosphoric acid impregnation. Proc. Carbon, 2003.

91. Zhao, X., et al., Fertilizer and activated carbon production by hydrothermal carbonization of digestate. Biomass Conversion and Biorefinery, 2018. 8(2): p. 423-436.

92. Bernardo, M., et al., Porous carbons derived from hydrothermally treated biogas digestate. Waste Management, 2020. 105: p. 170-179.

93. Chaturvedi, V., S. Usangonvkar, and M.V. Shelke, Synthesis of high surface area porous carbon from anaerobic digestate and it's electrochemical study as an electrode material for ultracapacitors. RSC Advances, 2019. 9(62): p. 36343-36350.

94. Yakout, S.M. and G. Sharaf El-Deen, Characterization of activated carbon prepared by phosphoric acid activation of olive stones. Arabian Journal of Chemistry, 2016. 9: p. S1155S1162. 
95. Martínez, M.L., et al., Preparation and characteristics of activated carbon from olive stones and walnut shells. Industrial Crops and Products, 2006. 23(1): p. 23-28.

96. Kula, I., et al., Adsorption of Cd(II) ions from aqueous solutions using activated carbon prepared from olive stone by ZnCl2 activation. Bioresource Technology, 2008. 99(3): p. 492-501.

97. Uğurlu, M., A. Gürses, and M. Açıkyıldız, Comparison of textile dyeing effluent adsorption on commercial activated carbon and activated carbon prepared from olive stone by $\mathrm{ZnCl} 2$ activation. Microporous and Mesoporous Materials, 2008. 111(1): p. 228-235.

98. Moreno-Castilla, C., et al., Chemical and physical activation of olive-mill waste water to produce activated carbons. Carbon, 2001. 39(9): p. 1415-1420.

99. Yavuz, R., et al., Influence of preparation conditions on porous structures of olive stone activated by H3PO4. Fuel Processing Technology, 2010. 91(1): p. 80-87.

100. Saleem, J., et al., Production and applications of activated carbons as adsorbents from olive stones. Biomass Conversion and Biorefinery, 2019. 9(4): p. 775-802.

101. Alcaraz, L., et al., Preparation and characterization of activated carbons from winemaking wastes and their adsorption of methylene blue. Adsorption Science \& Technology, 2018. 36(56): p. 1331-1351.

102. Zabaniotou, A., G. Stavropoulos, and V. Skoulou, Activated carbon from olive kernels in a twostage process: Industrial improvement. Bioresource Technology, 2008. 99(2): p. 320-326.

103. Anfruns, A., et al., New insights into the influence of activated carbon surface oxygen groups on $\mathrm{H} 2 \mathrm{O} 2$ decomposition and oxidation of pre-adsorbed volatile organic compounds. Carbon, 2014. 77: p. 89-98.

104. Wu, L., et al., Effect of liquid-phase $O 3$ oxidation of activated carbon on the adsorption of thiophene. Chemical Engineering Journal, 2014. 242: p. 211-219.

105. Sun, C., C.E. Snape, and H. Liu, Development of Low-Cost Functional Adsorbents for Control of Mercury (Hg) Emissions from Coal Combustion. Energy \& Fuels, 2013. 27(7): p. 3875-3882. 
106. Gokce, Y. and Z. Aktas, Nitric acid modification of activated carbon produced from waste tea and adsorption of methylene blue and phenol. Applied Surface Science, 2014. 313: p. 352-359.

107. Dehkhoda, A.M., A.H. West, and N. Ellis, Biochar based solid acid catalyst for biodiesel production. Applied Catalysis A: General, 2010. 382(2): p. 197-204.

108. Dehkhoda, A.M. and N. Ellis, Biochar-based catalyst for simultaneous reactions of esterification and transesterification. Catalysis Today, 2013. 207: p. 86-92.

109. Kastner, J.R., et al., Catalytic esterification of fatty acids using solid acid catalysts generated from biochar and activated carbon. Catalysis Today, 2012. 190(1): p. 122-132.

110. Ormsby, R., J.R. Kastner, and J. Miller, Hemicellulose hydrolysis using solid acid catalysts generated from biochar. Catalysis Today, 2012. 190(1): p. 89-97.

111. Li, S., et al., Biochar based solid acid catalyst hydrolyze biomass. Journal of Environmental Chemical Engineering, 2013. 1(4): p. 1174-1181.

112. Shafeeyan, M.S., et al., The application of response surface methodology to optimize the amination of activated carbon for the preparation of carbon dioxide adsorbents. Fuel, 2012. 94: p. $465-472$.

113. Jansen, R.J.J. and H. van Bekkum, Amination and ammoxidation of activated carbons. Carbon, 1994. 32(8): p. 1507-1516.

114. Stöhr, B., H.P. Boehm, and R. Schlögl, Enhancement of the catalytic activity of activated carbons in oxidation reactions by thermal treatment with ammonia or hydrogen cyanide and observation of a superoxide species as a possible intermediate. Carbon, 1991. 29(6): p. 707720.

115. Ma, Y.-z., et al., Magnetic lignin-based carbon nanoparticles and the adsorption for removal of methyl orange. Colloids and Surfaces A: Physicochemical and Engineering Aspects, 2018. 559: p. 226-234. 
116. Dai, L., et al., Green mussel-inspired lignin magnetic nanoparticles with high adsorptive capacity and environmental friendliness for chromium(III) removal. International Journal of Biological Macromolecules, 2019. 132: p. 478-486.

117. Huang, C., et al., Boosted selectivity and enhanced capacity of As (V) removal from polluted water by triethylenetetramine activated lignin-based adsorbents. International journal of biological macromolecules, 2019. 140: p. 1167-1174.

118. Cho, D.-W., et al., Fabrication and environmental applications of multifunctional mixed metalbiochar composites (MMBC) from red mud and lignin wastes. Journal of Hazardous Materials, 2019. 374: p. 412-419.

119. Jiang, C., et al., Construction of magnetic lignin-based adsorbent and its adsorption properties for dyes. Journal of hazardous materials, 2019. 369: p. 50-61.

120. Geng, J., F. Gu, and J. Chang, Fabrication of magnetic lignosulfonate using ultrasonic-assisted in situ synthesis for efficient removal of $\mathrm{Cr}(\quad$ ) and Rhodamine B from wastewater. Journal of hazardous materials, 2019. 375: p. 174-181.

121. Zhang, Y., et al., Ultrafast adsorption of heavy metal ions onto functionalized lignin-based hybrid magnetic nanoparticles. Chemical Engineering Journal, 2019. 372: p. 82-91.

122. Wu, Q., et al., Lignin-based magnetic activated carbon for p-arsanilic acid removal: Applications and absorption mechanisms. Chemosphere, 2020. 258: p. 127276.

123. Li, Y., et al., Synthesis of magnetic lignin-based hollow microspheres: a highly adsorptive and reusable adsorbent derived from renewable resources. ACS Sustainable Chemistry \& Engineering, 2016. 4(10): p. 5523-5532.

124. Naseer, A., et al., Lignin and Lignin Based Materials for the Removal of Heavy Metals from Waste Water-An Overview. Zeitschrift für Physikalische Chemie, 2019. 233(3): p. 315-345.

125. Ge, Y. and Z. Li, Application of lignin and its derivatives in adsorption of heavy metal ions in water: a review. ACS Sustainable Chemistry \& Engineering, 2018. 6(5): p. 7181-7192. 
126. Dessbesell, L., et al., Global lignin supply overview and kraft lignin potential as an alternative for petroleum-based polymers. Renewable and Sustainable Energy Reviews, 2020. 123: p. 109768.

127. Ahvazi, B., et al., Lignin profiling: a guide for selecting appropriate lignins as precursors in biomaterials development. ACS Sustainable Chemistry \& Engineering, 2016. 4(10): p. 50905105.

128. Berlin, A. and M. Balakshin, Industrial lignins: analysis, properties, and applications. Bioenergy Research: Advances and Applications, 2014: p. 315-336.

129. Manufacturers., P.E.A.o.P., Plastics - the facts 2017. 2018. 


\section{Declaration of interests}

The authors declare that they have no known competing financial interests or personal relationships that could have appeared to influence the work reported in this paper.

$\square$ The authors declare the following financial interests/personal relationships which may be considered as potential competing interests:

Pietro Bartocci 
This work was developed by Eid Gul at the university of Perugia, within the LIGNOCOST action funded by the EU and during an STSM performed at UK Biochar and the University of Edinburgh, when the PhD was coordinated by Dr. Ondrej Masek, Dr. Pietro Bartocci and prof. Francesco Fantozzi. Hewen Zhou, Dr. Khalideh Al Bkoor Alrawashdeh and prof. Qing Yang, helped with economic analysis: Øyvind Skreiberg, Andrea Corona, Mauro Zampilli and Liang Wang, helped with thermal treatments analysis. Petros Samaras helped with wastewater treatment analysis. 
Click here to access/download e-Component supplementary material.docx

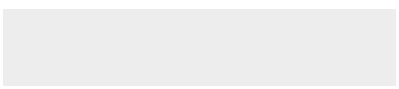

